FUNDCHRONIK

AUSGRABUNGEN UND

FUNDE IM JAHR 2020

Martin Allemann

Marco Bernasconi

Sven Billo

Ingmar M. Braun

Simon Graber

Corinne Hodel

David Roth

Pascale Roth

Johann Savary

Roman Schmidig

Susan Steiner 
$\uparrow$

$\mathrm{N}$

Frankreich
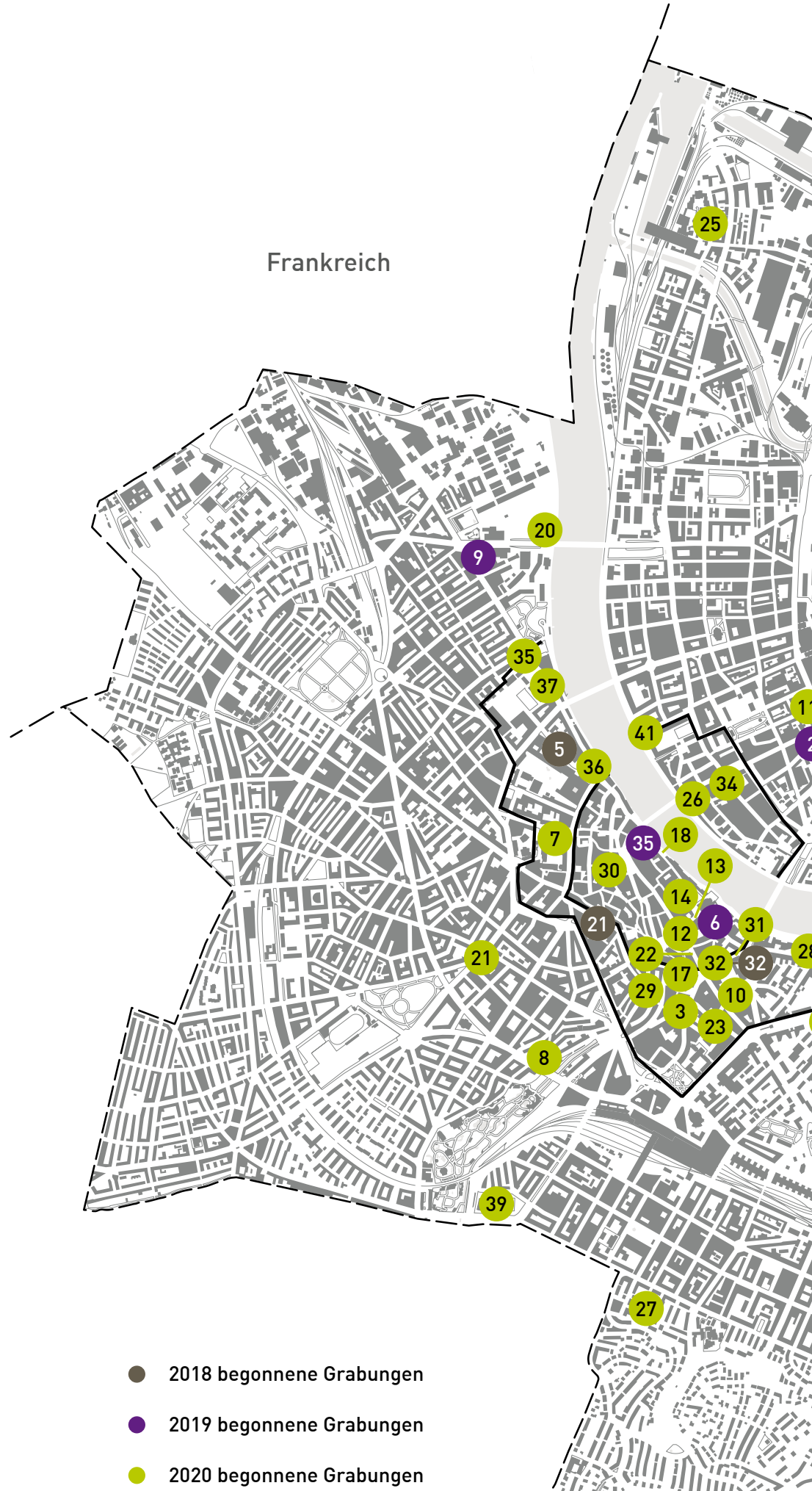

(26.

Deutschland

站?

35

5

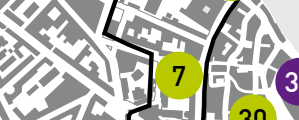

ivi

121

(21) $11,0.31$

- i. ${ }^{2}$ II ItIthillit

5 . 5 E

$\&_{\text {Rhein }}$

24

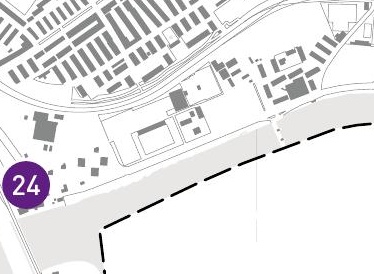
(1)

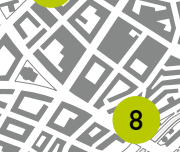

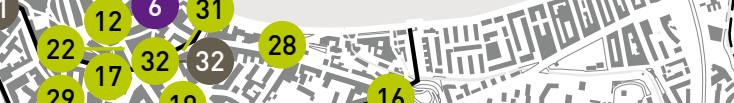
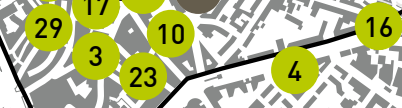
$=\frac{19}{17}$
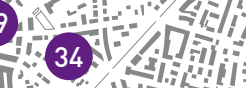

III

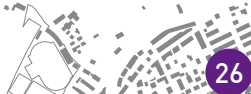

115 40

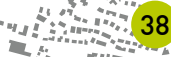

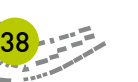

37

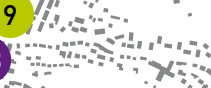
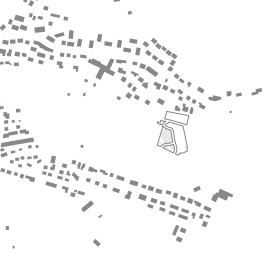

(1)

Riehen

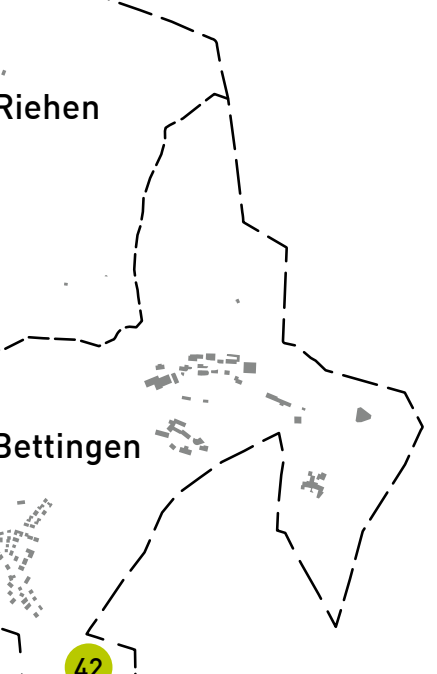

24

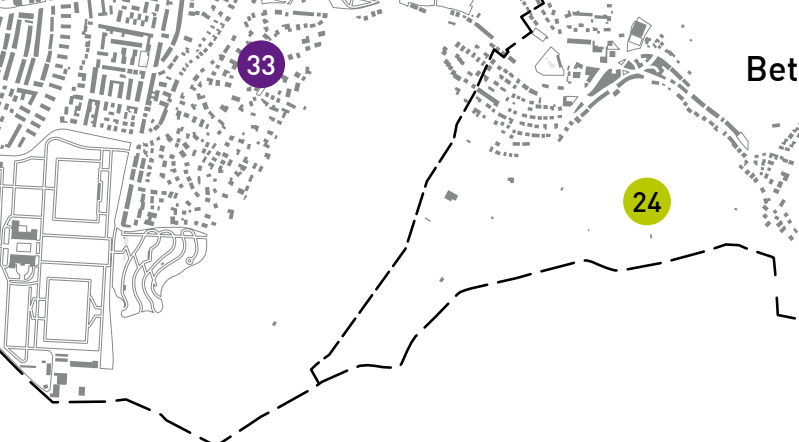

\section{AUSGRABUNGEN UND FUNDE \\ IM JAHR 2020}

Übersichtsplan des Kantons Basel-Stadt mit den Einsatzstellen der ABBS im Jahr 2020.

Zu den einzelnen Einsatzstellen vgl. die Tabellen auf den folgenden Doppelseiten «Übersicht nach Laufnummern» und «Übersicht nach Bereichen».

Plangrundlage: Grundbuch- und Vermessungsamt des Kantons Basel-Stadt. Ergänzungen und Kartierung: Peter von Holzen.

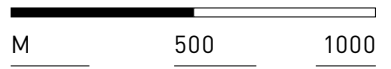




\section{ÜBERSICHT}

\section{NACH LAUFNUMMERN}

Im Berichtsjahr 2020 laufende Untersuchungen der Archäologischen Bodenforschung Basel-Stadt

im Kantonsgebiet nach Laufnummern. Zusammenstellung: Andreas Niederhäuser.

\section{LEGENDE}

PAL Paläolithikum

NL Neolithikum

BZ Bronzezeit

HZ Hallstattzeit

LZ Latènezeit

RZ Römische Zeit

FMA Frühmittelalter

MA Mittelalter

NZ Neuzeit

ZU Zeit unbestimmt

ㅁ Befund ohne Funde

- Befund mit Funden

- Streu- und Einzelfunde/

Funde bei Prospektionsgängen

- Geologischer Befund

- Ohne Befund/Funde

> Untersuchung noch nicht abgeschlossen

\section{BEGONNENE UNTERSUCHUNGEN}

\begin{tabular}{llll}
$\mathbf{N r}$. & Lauf-Nr. & Adresse (A = Allmend) & Ergebnis \\
\hline $\mathbf{5}$ & $2018 / 5$ & Spitalstrasse (A) Süd & $\mathbf{a N Z}$ \\
\hline $\mathbf{2 1}$ & $2018 / 21$ & Leonhardsgraben 46 & $\mathbf{\square N Z}$ \\
\hline $\mathbf{3 2}$ & $2018 / 32$ & St. Alban-Graben (A) 5/Luftgässlein (A) & $\mathbf{\square Z} / \mathbf{\square} \mathrm{MA} /$ \\
& & $\mathbf{\square} \mathrm{NZ}$ \\
\hline
\end{tabular}

\section{BEGONNENE UNTERSUCHUNGEN}

\begin{tabular}{|c|c|c|c|}
\hline Nr. & Lauf-Nr. & Adresse ( $\mathrm{A}=$ Allmend $)$ & Ergebnis \\
\hline 2 & $2019 / 2$ & Clarastrasse 52,54 & $\square N Z$ \\
\hline 6 & $2019 / 6$ & Rittergasse 4 & $\boldsymbol{\square} \mathrm{RZ}$ \\
\hline 9 & $2019 / 9$ & Voltastrasse 43, 41, 39 / Elsässerstrasse 54, 56 & 0 \\
\hline 11 & $2019 / 11$ & Grenzstrasse 15 / Neuhausstrasse 85 & $\bullet$ \\
\hline 14 & $2019 / 14$ & $\begin{array}{l}\text { Riehen - Inzlingerstrasse } 51 \text { / Haselrain / } \\
\text { Kettenackerweg } 5\end{array}$ & $\diamond \mathrm{BZ}$ \\
\hline 19 & $2019 / 19$ & Riehen - Äussere Baselstrasse 220 & 0 \\
\hline 24 & $2019 / 24$ & Eisenbahnweg 6, 22, 24 & - $\mathrm{BZ} / \bullet \mathrm{FMA}$ \\
\hline 26 & $2019 / 26$ & Riehen - Burgstrasse 46 / Rebenstrasse 39 & - BZ \\
\hline 29 & $2019 / 29$ & Gundeldingerstrasse / Reinacherstrasse (A) & 0 \\
\hline 33 & $2019 / 33$ & Riehen - Rütiring 84 & - \\
\hline 34 & $2019 / 34$ & Riehen - Sonnenbühlstrasse 19 & 0 \\
\hline 35 & $2019 / 35$ & Martinskirchplatz 1 & $\begin{array}{l}\bullet \mathrm{BZ} / \bullet \mathrm{RZ} / \\
\mathrm{MA} / \boldsymbol{\mathrm { NZ }}\end{array}$ \\
\hline 37 & $2019 / 37$ & Riehen - Hellring 41 (Wenkenpark) & $\sim N Z$ \\
\hline 38 & $2019 / 38$ & Riehen - Oberdorfstrasse 43 & $\bullet / \bullet N Z$ \\
\hline
\end{tabular}

\section{BEGONNENE UNTERSUCHUNGEN}

\begin{tabular}{|c|c|c|c|}
\hline $\mathrm{Nr}$. & Lauf-Nr. & Adresse ( $\mathrm{A}=\mathrm{Allmend})$ & Ergebnis \\
\hline 1 & $2020 / 1$ & Riehen - Artelweg & $\begin{array}{l}\boldsymbol{R Z} / \diamond \mathrm{MA} \\
\mathrm{NZ}\end{array}$ \\
\hline 2 & $2020 / 2$ & Riehen - Hirtenweg 14, 22, 24, 28 & 0 \\
\hline 3 & $2020 / 3$ & Elisabethenstrasse 27 (Haus zum Kirschgarten) & $\square N Z$ \\
\hline 4 & $2020 / 4$ & St. Alban-Anlage 26-38 & $\square N Z$ \\
\hline 5 & $2020 / 5$ & Burgweg - Schaffhauserrheinweg (A) & - \\
\hline 6 & $2020 / 6$ & $\begin{array}{l}\text { Riehen - Inzlingerstrasse } 51 \text { / Haselrain / } \\
\text { Kettenackerweg } 5\end{array}$ & 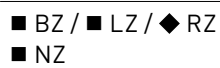 \\
\hline
\end{tabular}




\section{LEGENDE}

PAL Paläolithikum

NL Neolithikum

BZ Bronzezeit

$\mathrm{HZ}$ Hallstattzeit

LZ Latènezeit

RZ Römische Zeit

FMA Frühmittelalter

MA Mittelalter

NZ Neuzeit

ZU Zeit unbestimmt

ㅁ Befund ohne Funde

- Befund mit Funden

- Streu- und Einzelfunde/ Funde bei Prospektionsgängen

- Geologischer Befund

- Ohne Befund/Funde

> Untersuchung noch nicht abgeschlossen

\section{BEGONNENE UNTERSUCHUNGEN}

\begin{tabular}{|c|c|c|c|}
\hline Nr. & Lauf-Nr. & Adresse ( $\mathrm{A}=\mathrm{Allmend})$ & Ergebnis \\
\hline 7 & $2020 / 7$ & Petersplatz (A) (Kälteverbund) & $\square \mathrm{MA} / \mathbf{\square Z}$ \\
\hline 8 & $2020 / 8$ & Birsigstrasse $(A) 50$ & $\square \mathrm{MA} / \mathbf{\square Z}$ \\
\hline 9 & $2020 / 9$ & $\begin{array}{l}\text { Riehen - Inzlingerstrasse / Bäumliweg } \\
\text { (Hinter Gärten) }\end{array}$ & $>$ \\
\hline 10 & $2020 / 10$ & Brunngässlein $(A) 6,8,12$ & $\square N Z$ \\
\hline 11 & $2020 / 11$ & Riehenring $(A)$ 63-75 & $\square \mathrm{MA}$ \\
\hline 12 & $2020 / 12$ & Barfüsserplatz 7 & - MA / $\mathbf{n Z Z}$ \\
\hline 13 & $2020 / 13$ & Münsterplatz 12 (Domhof) & $\square \mathrm{RZ} / \boldsymbol{M A} / \boldsymbol{\mathrm { NZ }}$ \\
\hline 14 & $2020 / 14$ & Schlüsselberg (Innenhof Schulhaus zur Mücke) & - $\mathrm{RZ}$ \\
\hline 15 & $2020 / 15$ & Riehen - Baselstrasse $34 / 30$ & 口NZ \\
\hline 16 & $2020 / 16$ & St. Alban-Anlage (A) & $\square \mathrm{NZ}$ \\
\hline 17 & $2020 / 17$ & Theater-Passage (A) & 口MA \\
\hline 18 & $2020 / 18$ & Rheinsprung gegenüber 16 und 18 (Unigarten) & $\square M A / \square N Z$ \\
\hline 19 & $2020 / 19$ & Riehen - Bettingerstrasse $(A) /$ Hellring $(A) 5$ & - NZ \\
\hline 20 & $2020 / 20$ & $\begin{array}{l}\text { St. Johanns-Hafen-Weg 5, Novartis Exhibition } \\
\text { Center WSJ-189 }\end{array}$ & 0 \\
\hline 21 & $2020 / 21$ & Schützenmattstrasse (A) 61 & 口MA \\
\hline 22 & $2020 / 22$ & Freie Strasse (A), Etappe 1 & $\square \mathrm{RZ} / \boldsymbol{\square} \mathrm{MA} / \boldsymbol{\square} \mathrm{NZ}$ \\
\hline 23 & $2020 / 23$ & Henric-Petri-Strasse (A) / Sternengasse (A) & $>$ \\
\hline 24 & $2020 / 24$ & Bettingen - Auf dem Buechholz & $\diamond \mathrm{PAL} / \mathrm{NL}$ \\
\hline 25 & $2020 / 25$ & $\begin{array}{l}\text { Kleinhüningeranlage / Hochbergerplatz / } \\
\text { Dorfstrasse / Weilerweg (A) }\end{array}$ & $>$ \\
\hline 26 & $2020 / 26$ & Rheingasse $(A) 7$ & $\square M A / \square N Z$ \\
\hline 27 & $2020 / 27$ & Gundeldingerstrasse 172 & 口NZ \\
\hline 28 & $2020 / 28$ & Mühlenberg (A) 2-10 & 口NZ \\
\hline 29 & $2020 / 29$ & Steinenvorstadt $(\mathrm{A}) 4$ & MA/NZ \\
\hline 30 & $2020 / 30$ & Schneidergasse $24-26$ & $>$ \\
\hline 31 & $2020 / 31$ & St. Alban-Graben (A), Parking Kunstmuseum & $\square \mathrm{RZ} / \boldsymbol{M A} / \boldsymbol{\nabla} \mathrm{NZ}$ \\
\hline 32 & $2020 / 32$ & Freie Strasse (A) 90 (Poller) & 0 \\
\hline 33 & $2020 / 33$ & Riehenstrasse 154 & $\square \mathrm{NZ}$ \\
\hline 34 & $2020 / 34$ & Rebgasse (A) 10-12 & MA/NZ/ロNZ \\
\hline 35 & $2020 / 35$ & St. Johanns-Platz (A) & $>$ \\
\hline 36 & $2020 / 36$ & Totentanz (A) & $>$ \\
\hline 37 & $2020 / 37$ & St. Johanns-Vorstadt (A) 51 & $>$ \\
\hline 38 & $2020 / 38$ & Riehen - Auf der Bischoffhöhe 42 & 0 \\
\hline 39 & $2020 / 39$ & Höhenweg 85 (Sportplatz Pruntrutermatte) & $\diamond \mathrm{ZU}$ \\
\hline 40 & $2020 / 40$ & Riehen - Immenbachstrasse 17-19 & $>$ \\
\hline 41 & $2020 / 41$ & Klingentalgraben $(A) 2$ & 0 \\
\hline 42 & $2020 / 42$ & Bettingen - Im Junkholz & $\diamond \mathrm{NL}$ \\
\hline
\end{tabular}




\section{ÜBERSICHT}

\section{NACH BEREICHEN}

Im Berichtsjahr 2020 laufende Untersuchungen der Archäologischen Bodenforschung Basel-Stadt im Kantonsgebiet nach Bereichen. Zusammenstellung: Andreas Niederhäuser.

\section{LEGENDE}

PAL Paläolithikum

NL Neolithikum

BZ Bronzezeit

HZ Hallstattzeit

LZ Latènezeit

RZ Römische Zeit

FMA Frühmittelalter

MA Mittelalter

NZ Neuzeit

ZU Zeit unbestimmt

ㅁ Befund ohne Funde

- Befund mit Funden

- Streu- und Einzelfunde/

Funde bei Prospektionsgängen

- Geologischer Befund

- Ohne Befund/Funde

> Untersuchung noch nicht abgeschlossen
MÜNSTERHÜGEL

\begin{tabular}{|c|c|c|c|c|}
\hline Adresse $(\mathrm{A}=\mathrm{Allmend})$ & $\mathrm{Nr}$. & Lauf-Nr. & Ergebnis & Seitenzahl \\
\hline Rittergasse 4 & 6 & $2019 / 6$ & - $\mathrm{RZ}$ & 42 \\
\hline Martinskirchplatz 1 & 35 & $2019 / 35$ & $\begin{array}{l}\diamond \mathrm{BZ} / \bullet \mathrm{RZ} / \\
\square \mathrm{MA} / \boldsymbol{\mathrm { NZ }}\end{array}$ & $43-44$ \\
\hline Münsterplatz 12 (Domhof) & 13 & $2020 / 13$ & 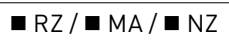 & $45-46$ \\
\hline Schlüsselberg (Innenhof Schulhaus zur Mücke) & 14 & $2020 / 14$ & - $\mathrm{RZ}$ & 46 \\
\hline Rheinsprung gegenüber 16 und 18 (Unigarten) & 18 & $2020 / 18$ & $\square M A / \square N Z$ & 47 \\
\hline
\end{tabular}

INNERSTADT

\begin{tabular}{|c|c|c|c|c|}
\hline Adresse ( $\mathrm{A}=\mathrm{Allmend}$ ) & Nr. & Lauf-Nr. & Ergebnis & Seitenzahl \\
\hline Leonhardsgraben 46 & 21 & $2018 / 21$ & $\mathbf{\square N Z}$ & 48 \\
\hline St. Alban-Graben (A) 5 / Luftgässlein (A) & 32 & $2018 / 32$ & $\begin{array}{l}\square \mathrm{RZ} / \boldsymbol{M A} / \\
-\mathrm{NZ} \\
\end{array}$ & 48 \\
\hline Elisabethenstrasse 27 (Haus zum Kirschgarten) & 3 & $2020 / 3$ & $\mathbf{a N Z}$ & 49 \\
\hline Petersplatz (A) (Kälteverbund) & 7 & $2020 / 7$ & $\square \mathrm{MA} / \mathbf{\mathrm { NZ }}$ & $49-51$ \\
\hline Brunngässlein $(A) 6,8,12$ & 10 & $2020 / 10$ & $\square N Z$ & 51 \\
\hline Barfüsserplatz 7 & 12 & $2020 / 12$ & $\boldsymbol{M A} / \boldsymbol{v} \mathrm{NZ}$ & $52-53$ \\
\hline Theater-Passage (A) & 17 & $2020 / 17$ & 口MA & - \\
\hline Freie Strasse (A), Etappe 1 & 22 & $2020 / 22$ & $\square \mathrm{RZ} / \boldsymbol{m A} / \boldsymbol{\nabla} \mathrm{NZ}$ & $53-54$ \\
\hline Henric-Petri-Strasse (A) / Sternengasse (A) & 23 & $2020 / 23$ & $>$ & - \\
\hline Rheingasse (A) 7 & 26 & $2020 / 26$ & $\square M A / \square N Z$ & 55 \\
\hline Mühlenberg (A) 2-10 & 28 & $2020 / 28$ & $\square N Z$ & 55 \\
\hline Steinenvorstadt (A) 4 & 29 & $2020 / 29$ & - MA/NZ & 56 \\
\hline Schneidergasse $24-26$ & 30 & $2020 / 30$ & $>$ & - \\
\hline St. Alban-Graben (A), Parking Kunstmuseum & 31 & $2020 / 31$ & $\square \mathrm{RZ} / \boldsymbol{M A} / \boldsymbol{N Z}$ & $56-57$ \\
\hline Freie Strasse (A) 90 (Poller) & 32 & $2020 / 32$ & 0 & - \\
\hline Rebgasse (A) 10-12 & 34 & $2020 / 34$ & $\diamond \mathrm{MA} / \mathrm{NZ} / \mathbf{\mathrm { N } Z}$ & 57 \\
\hline St. Johanns-Platz (A) & 35 & $2020 / 35$ & $>$ & - \\
\hline Totentanz (A) & 36 & $2020 / 36$ & $>$ & - \\
\hline St. Johanns-Vorstadt (A) 51 & 37 & $2020 / 37$ & $>$ & - \\
\hline Klingentalgraben (A) 2 & 41 & $2020 / 41$ & 0 & - \\
\hline
\end{tabular}




\section{LEGENDE}

PAL Paläolithikum

NL Neolithikum

BZ Bronzezeit

$\mathrm{HZ}$ Hallstattzeit

LZ Latènezeit

RZ Römische Zeit

FMA Frühmittelalter

MA Mittelalter

NZ Neuzeit

ZU Zeit unbestimmt

ㅁ Befund ohne Funde

- Befund mit Funden

- Streu- und Einzelfunde/ Funde bei Prospektionsgängen

- Geologischer Befund

- Ohne Befund/Funde

> Untersuchung noch nicht abgeschlossen

\section{AUSSENBEZIRKE/BETTINGEN/RIEHEN}

\begin{tabular}{|c|c|c|c|c|}
\hline Adresse $(\mathrm{A}=\mathrm{Allmend})$ & Nr. & Lauf-Nr. & Ergebnis & Seitenzah \\
\hline Spitalstrasse (A) Süd & 5 & $2018 / 5$ & $\square N Z$ & 58 \\
\hline Clarastrasse 52,54 & 2 & $2019 / 2$ & $\square N Z$ & - \\
\hline Voltastrasse 43, 41, 39 / Elsässerstrasse 54, 56 & 9 & $2019 / 9$ & 0 & - \\
\hline Grenzstrasse 15 / Neuhausstrasse 85 & 11 & $2019 / 11$ & $\bullet$ & - \\
\hline $\begin{array}{l}\text { Riehen - Inzlingerstrasse } 51 \text { / Haselrain / } \\
\text { Kettenackerweg } 5\end{array}$ & 14 & $2019 / 14$ & $\diamond \mathrm{BZ}$ & $58-59$ \\
\hline Riehen - Äussere Baselstrasse 220 & 19 & $2019 / 19$ & 0 & - \\
\hline Eisenbahnweg 6, 22, 24 & 24 & $2019 / 24$ & $\boldsymbol{B Z Z} / \diamond \mathrm{FMA}$ & $59-60$ \\
\hline Riehen - Burgstrasse 46 / Rebenstrasse 39 & 26 & $2019 / 26$ & - BZ & $60-61$ \\
\hline Gundeldingerstrasse / Reinacherstrasse (A) & 29 & $2019 / 29$ & 0 & - \\
\hline Riehen - Rütiring 84 & 33 & $2019 / 33$ & $\bullet$ & - \\
\hline Riehen - Sonnenbühlstrasse 19 & 34 & $2019 / 34$ & 0 & - \\
\hline Riehen - Hellring 41 (Wenkenpark) & 37 & $2019 / 37$ & $\diamond \mathrm{NZ}$ & 61 \\
\hline Riehen - Oberdorfstrasse 43 & 38 & $2019 / 38$ & $\bullet / \diamond N Z$ & 62 \\
\hline Riehen - Artelweg & 1 & $2020 / 1$ & $\begin{array}{l}\diamond \mathrm{RZ} / \diamond \mathrm{MA} / \\
\diamond \mathrm{NZ} \\
\end{array}$ & 63 \\
\hline Riehen - Hirtenweg 14, 22, 24, 28 & 2 & $2020 / 2$ & 0 & 63 \\
\hline St. Alban-Anlage 26-38 & 4 & $2020 / 4$ & $\square N Z$ & 64 \\
\hline Burgweg - Schaffhauserrheinweg (A) & 5 & $2020 / 5$ & $\bullet$ & 64 \\
\hline $\begin{array}{l}\text { Riehen - Inzlingerstrasse } 51 \text { / Haselrain / } \\
\text { Kettenackerweg } 5\end{array}$ & 6 & $2020 / 6$ & $\begin{array}{l}\square \mathrm{BZ} / \boldsymbol{\square} \mathrm{LZ} / \bullet \mathrm{RZ} \\
\mathbf{\mathrm { NZ }}\end{array}$ & $65-67$ \\
\hline Birsigstrasse (A) 50 & 8 & $2020 / 8$ & $\square M A / \square N Z$ & 67 \\
\hline $\begin{array}{l}\text { Riehen - Inzlingerstrasse / Bäumliweg } \\
\text { (Hinter Gärten) }\end{array}$ & 9 & $2020 / 9$ & $>$ & - \\
\hline Riehenring (A) 63-75 & 11 & $2020 / 11$ & $\square \mathrm{MA}$ & 68 \\
\hline Riehen - Baselstrasse 34/30 & 15 & $2020 / 15$ & $\square N Z$ & 68 \\
\hline St. Alban-Anlage (A) & 16 & $2020 / 16$ & $\square N Z$ & 69 \\
\hline Riehen - Bettingerstrasse (A) / Hellring (A) 5 & 19 & $2020 / 19$ & $\mathbf{n} \mathrm{NZ}$ & $69-70$ \\
\hline $\begin{array}{l}\text { St. Johanns-Hafen-Weg 5, Novartis Exhibition } \\
\text { Center WSJ-189 }\end{array}$ & 20 & $2020 / 20$ & 0 & - \\
\hline Schützenmattstrasse (A) 61 & 21 & $2020 / 21$ & $\square \mathrm{MA}$ & 70 \\
\hline Bettingen - Auf dem Buechholz & 24 & $2020 / 24$ & $\diamond \mathrm{PAL} / \mathrm{NL}$ & 70 \\
\hline $\begin{array}{l}\text { Kleinhüningeranlage / Hochbergerplatz / } \\
\text { Dorfstrasse / Weilerweg (A) }\end{array}$ & 25 & $2020 / 25$ & $>$ & - \\
\hline Gundeldingerstrasse 172 & 27 & $2020 / 27$ & $\square N Z$ & 71 \\
\hline Riehenstrasse 154 & 33 & $2020 / 33$ & $\square N Z$ & 71 \\
\hline Riehen - Auf der Bischoffhöhe 42 & 38 & $2020 / 38$ & 0 & - \\
\hline Höhenweg 85 (Sportplatz Pruntrutermatte) & 39 & $2020 / 39$ & $\bullet \mathrm{ZU}$ & - \\
\hline Riehen - Immenbachstrasse 17-19 & 40 & $2020 / 40$ & $>$ & - \\
\hline Bettingen - Im Junkholz & 42 & $2020 / 42$ & $\diamond \mathrm{NL}$ & 72 \\
\hline
\end{tabular}




\section{MÜNSTERHÜGEL}

\section{$2019 / 6$}

\section{RITTERGASSE 4}

Anlass: Umbau Verwaltungsbau zu Schulhaus

\section{Zeitstellung: Römische Zeit}

Untersuchungsdauer: Februar 2019 bis Mai 2020

Verantwortlich: Simon Graber, Martin Allemann, Benedikt Wyss

Text: Martin Allemann

Im Jahr 2019 hatte die Begleitung der Umbauarbeiten am Rittergasse-Schulhaus schon zahlreiche interessante Einblicke in die Geschichte des Basler Münsterhügels ergeben: Hier konnten u. a. frührömische, spätantike und frühmittelalterliche Befunde dokumentiert und zahlreiche Funde geborgen werden. ${ }^{1}$ Im Berichtsjahr waren die wichtigsten Bauarbeiten schon weitgehend abgeschlossen. Auch ein Aushub für Akustikelemente entlang der Fassade des Baudepartements hatte nur wenige Aufschlüsse erbracht, als einige kleinflächige Eingriffe für den Bau von Schächten zur Dachund Oberflächenentwässerung angekündigt wurden (ABB. 11. ${ }^{2}$ Rasch zeigte sich, dass zwei vermeintlich alt unterkellerte Schachtstandorte eine sehr mächtige Schichterhaltung aufwiesen. Zwar waren beide Schachtgruben teilweise von älteren Kanalisationen beeinträchtigt, erbrachten aber Befunde und Funde von der frührömischen Zeit bis in die Spätantike.

Der direkt neben dem Schulhauseingang an der Rittergasse gelegene Schacht wies eine gut erhaltene Schichtenfolge von über zwei Metern Mächtigkeit auf, ohne dass seine Sohle sicher den Anstehenden erreicht hätte. Eine erste grobe Durchsicht des Fundmaterials lässt vermuten, dass die Schichten zwischen dem 1. und 2. Jahrhundert $\mathrm{n}$. Chr. entstanden sind. Spätere Befunde waren hier offenbar gekappt, wie auch Spuren der mittelalterlichen Vorgängerbebauung völlig fehlten. Dass in der Antike in etwas mehr als 100 Jahren über zwei Meter Material abgelagert wurde, mag auf den ersten Blick überraschen. Eine Übersicht der Befunde zeigt aber, dass wir hier hauptsächlich Lehmböden, Brandschutt und Fachwerkabbruch von Gebäuden fassen (Авв. 2). Offenbar hatte man hier nach jedem der Brände die Ruinen ausplaniert und das neue Fachwerkgebäude über dem einplanierten Schutt errichtet, ohne viel Material zu entfernen. Diese Brandereignisse haben eine Folge von gut erhaltenem und gut stratifiziertem Fundmaterial und viel Brandschutt hinterlassen. Das ermöglicht einen seltenen Einblick in die Bauweise von Fachwerkbauten, da von diesen nur die bei einem Schadenfeuer verziegelten Wandlehmteile erhalten bleiben. Wenn hingegen ein Fachwerkbau nach und nach zerfällt, löst er sich quasi in Erde auf und Aussagen zur Gestaltung des Aufgehenden werden sehr viel schwieriger.
Weniger eindeutig, aber nicht minder eindrücklich waren die spätantiken Befunde in der Schachtgrube an der Nordwestfassade. Hier konnten viele Funde in sehr guter Erhaltung geborgen werden, u. a. Terra Sigillata, darunter ein Gefäss mit eingeritzter Inschrift (ABB. 3).
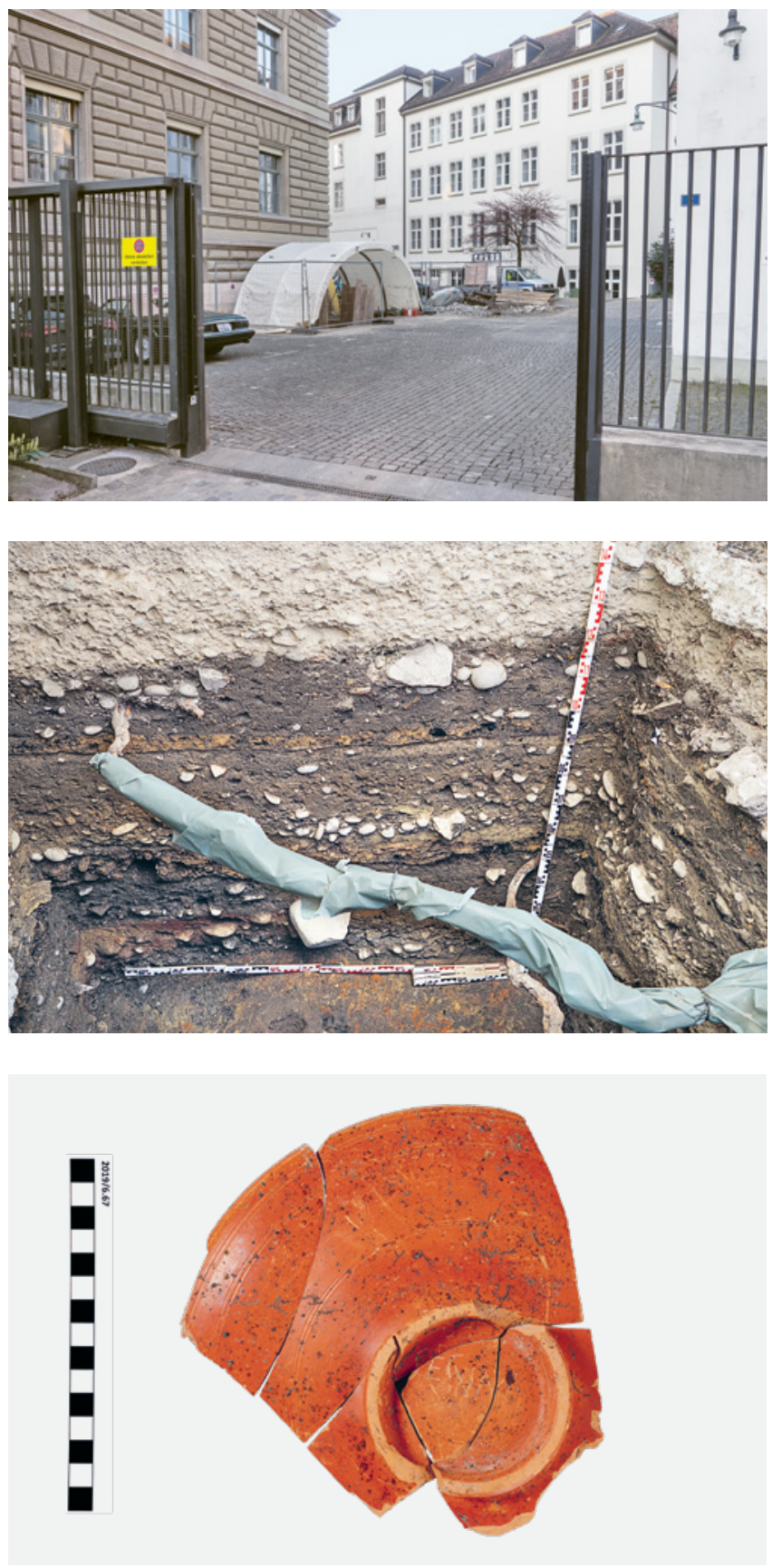

ABB. 1 Im Innenhof der Rittergasse 4 kam in einem Schachtaushub gut erhaltene spätantike Keramik zum Vorschein. Foto: Simon Graber.

ABB. 2 Im Profil des Schachtes vor dem Rittergasse-Schulhaus sind sich abwechselnde Lehmböden. Planien und Brandschuttschichten aus der römischen Zeit erkennbar. Foto: Marc Schuurmans.

ABB. 3 Auf dem Boden dieses Sigillata-Tellers ist im Standring eine Inschrift eingeritzt, vielleicht SECVN - eine Besitzerinschrift eines Secun(dus)? Foto: Philippe Saurbeck. 


\section{9/35}

\section{MARTINSKIRCHPLATZ 1}

Anlass: Einbau Lift, Sanierung Kellerboden und Leitungen

Zeitstellung: Bronzezeit, Römische Zeit, Mittelalter, Neuzeit

Untersuchungsdauer: November 2019 bis Mai 2020

Verantwortlich: Simon Graber, Martin Allemann, Benedikt Wyss

Text: Simon Graber

Der Umbau der Liegenschaft Martinskirchplatz 1 zu einem Beherbergungsbetrieb führte Anfang November 2019 zu einer Sondierung und ab Februar 2020 zu einer Flächengrabung im $30 \mathrm{~m}^{2}$ grossen Keller der Liegenschaft (ABB. 4). ${ }^{3}$ In dieser historisch und archäologisch sensiblen Zone auf dem Martinskirchsporn waren Befunde von der späten Bronzezeit bis in die Neuzeit zu erwarten. Aus der Bronzezeit sind aus unmittelbarer Nähe Siedlungsbefunde mit Gruben und einem Graben bekannt sowie aus römischer Zeit ein Gebäude mit Hypokaust. ${ }^{4}$ Im Mittelalter war der Platz neben der Martinskirche als Friedhof genutzt worden. Die Liegenschaft - das Haus zum Bramen - wird in den Quellen erstmals um 1290 erwähnt. ${ }^{5}$ Die Denkmalpflege konnte in früheren Untersuchungen vereinzelte Bauelemente in dieser Anfangszeit verorten. Im Jahr 1542 erfolgte ein grösserer Umbau der Liegenschaft. Damals wurde das Haus auf die heutigen Dimensionen verkleinert, als es vom östlich anschliessenden Gebäude (heute Rheinsprung 14) getrennt wurde. In das 16. Jahrhundert fallen auch die Malereien und eine Fachwerkmauer im ersten Stockwerk des Gebäudes.

Nach dem Entfernen des modernen Betonbodens kam feiner Bauschutt mit Steinkohlen der letzten Nutzung und darunter der frühneuzeitliche Mörtelgussboden zum Vorschein. Der Boden zieht an die Trennmauer zur Liegenschaft Rheinsprung 14, was eine Datierung nach 1542 plausibel erscheinen lässt. Am Mörtelgussboden liessen sich diverse Veränderungen ablesen: Ein Eingriff in der Mitte des Raumes nahm ein Sandsteinbecken auf (ABB. 5). Solche Becken sind in vielen neuzeitlichen Kellern anzutreffen und dienten der Kontrolle des Wasserhaushaltes, entweder um störendes Wasser abschöpfen zu können oder umgekehrt als Wasserbehälter, um eine höhere Luftfeuchtigkeit zu erreichen. Das Becken wurde zu einem unbestimmten Zeitpunkt obsolet und mit beigem Versatzmörtel ausgegossen. Von Bautätigkeiten und Instandsetzungen erzählt auch eine Kalksumpfgrube, in deren sekundärer Verfüllung ein beidseitig glasierter Randscherben lag, der frühestens in die Mitte des 17. Jahrhunderts datiert.

In der südwestlichen Mauerecke hatte man den Boden durchschlagen und einen Schacht von 1,20 × 1,70 m gemauert. Das Baumaterial war rezykliert und die Schachtwände unterfangen die Hausecke. Der Schacht wurde im 19. Jahrhundert aufgegeben und mit Bauschutt verfüllt. Im Schutt fanden sich grob fragmentierte Keramikgefässe und ein dicht verschlossenes Glasfläschchen, das noch Quecksilber enthielt. Ein ehemaliges Balkenlager einer Binnenmauer war, wie eine Flickstelle im Boden anzeigte, mit plattigen Sandsteinen verfüllt. Anschliessend hatte man die Oberfläche mit Mörtel versiegelt.

Das Mauerwerk des Kellers wurde nur im Fundamentbereich dokumentiert. Das Aufgehende war Gegenstand der nachfolgenden Untersuchung der Denkmalpflege. Auffällig ist die heterogene Ausführung der Fundamente, die stellenweise lediglich eine (niedrige) Steinlage unter das Boden- $\rightarrow$

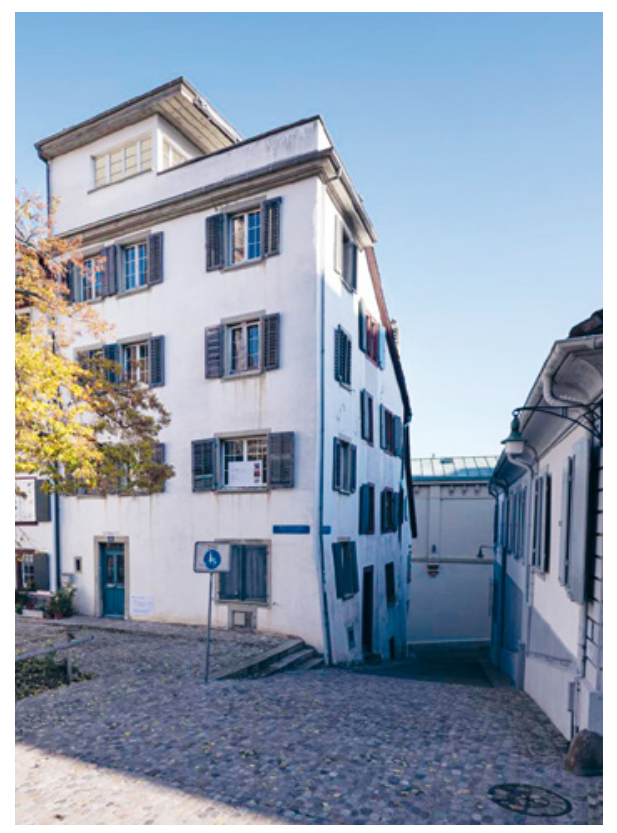

ABB. 4 Die Liegenschaft Martinskirchplatz 1. Linkerhand die Martinskirche, in der Bildmitte rechts das Archivgässlein, das zum Rheinsprung hinunterführt. Foto: Philippe Saurbeck. 
niveau reichen. Hier stellt sich die Frage, ob der Keller nachträglich abgetieft wurde, so dass die ehemaligen Fundamente fortan die Kellerwände bildeten. Diese ruhen auf dem anstehenden Kies. Wo die älteren Grubenverfüllungen anstanden, reichen die Fundamente tiefer und sind aus sorgfältig gelegten grösseren Geröllen mit kompaktem Mörtel gebaut. Unzählige Staketen- und Pfostenlöcher durchschlagen den Mörtelgussboden. Aus einem stammt ein Bronzeobjekt, bei dem es sich um einen Rechenpfennig handeln dürfte.

Der mittelalterliche Friedhof und das römische Grossgebäude konnten nicht gefasst werden, da der Keller tiefer als das bekannte Niveau dieser Befunde reichte. Unter dem Mörtelgussboden kamen jedoch zwei grosse, sich randlich überschneidende Gruben mit Durchmessern von zwei bzw. drei Metern zum Vorschein (ABB. 6). Nach ungefähr einem Meter brachen wir den Abbau der Verfüllungen ab, da die Solltiefe des Baus längst erreicht und noch kein Ende der Verfüllschichten in Sicht war. Das Fundmaterial aus den Gruben entsprach weitgehend dem, was im Vorfeld der Ausgrabung unterhalb der neuzeitlichen Niveaus erwartet worden war: Lose Menschenknochen, die vermutlich vom mittelalterlichen Friedhof stammen, römische Baukeramik und eine Bronzemünze (ABB. 7), die zum römischen Grossgebäude passen, sowie spätbronzezeitliche Keramikscherben. Innerhalb der Grubenverfüllungen streuten die Funde allerdings ohne nachvollziehbares Muster. Somit lässt sich einzig feststellen, dass das Verfüllungsmaterial aus unmittelbarer Nähe stammen muss und es sich wohl um eingefüllten Aushub handelt. Der Zweck der Gruben erschliesst sich nicht ohne Weiteres. Denkbar wäre, dass sie als Materialentnahmegruben gedient hatten.

Es wurden keine Siedlungsbefunde aus der späten Bronzezeit gefunden. Lediglich die in den jüngeren Gruben gefundenen Keramikscherben stammen aus dieser Zeit.
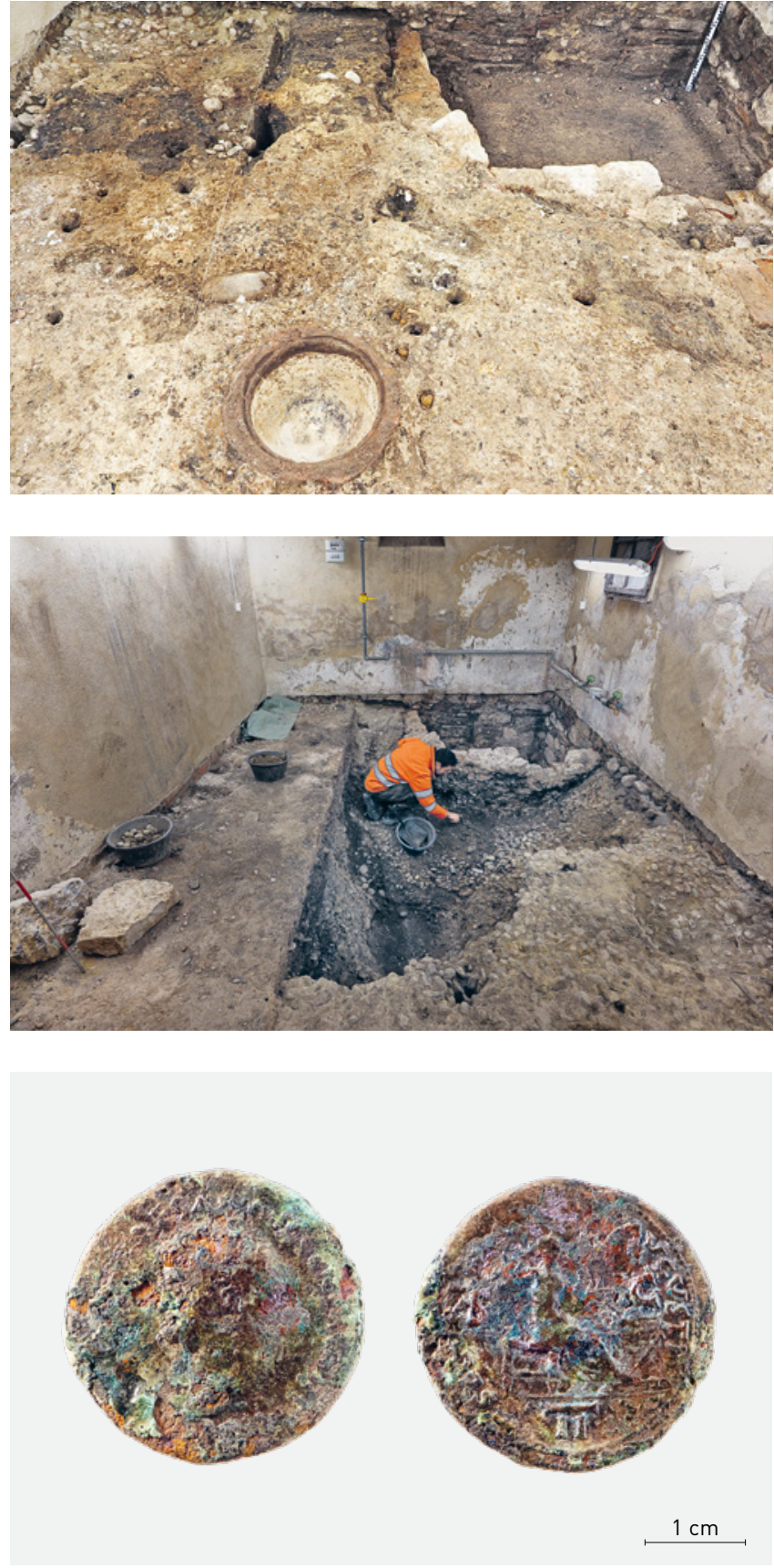

ABB. 5 Der frühneuzeitliche Mörtelgussboden mit dem sekundär eingelassenen Sandsteinbecken und dem gemauerten Schacht in der Hausecke. Foto: Simon Graber.

ABB. 6 Übersicht mit den teilweise ausgenommenen Gruben. In der Hausecke der jüngere Schacht. Im Vordergrund ist bereits der natürliche Boden erreicht. Foto: Philippe Saurbeck.

ABB. 7 Die römische Münze, eine Prägung Kaiser Neros aus dem Jahr 65 n. Chr., stammt aus einer der Verfüllungen der grossen Gruben. Bestimmung: Markus Peter. Foto: Philippe Saurbeck. 


\section{0/13}

\section{MÜNSTERPLATZ 12 (DOMHOF)}

Anlass: Abdichtung der Fundamente

\begin{tabular}{l} 
Zeitstellung: Römische Zeit, Mittelalter, Neuzeit \\
\hline Untersuchungsdauer: März bis Juni 2020 \\
\hline Verantwortlich: Martin Allemann, Pascale Roth \\
\hline Text: Pascale Roth, Martin Allemann
\end{tabular}

Die Fundamente des Domhofs am Münsterplatz 12 mussten von aussen gegen eindringende Feuchtigkeit abgedichtet werden. Zwar war der benötigte Bodeneingriff kleinflächig, aber unsere Baubegleitung zeigte, dass an Schlüsselstellen des Münsterhügels jeder noch so kleine Aushub wichtige Einblicke ermöglicht. An der Ecke zwischen Münsterplatz und Münsterberg gelegen, kann der Domhof auf eine abwechslungsreiche Geschichte zurückblicken: Im Spätmittelalter Sitz des bischöflichen Domkapitels, war er später ein Privathaus und beherbergt heute das Bauinspektorat.

Der tiefe Aushub für die Fassadenabdichtung brachte schon im März so viele intakte Schichten zu Tage, dass eine Handgrabung bis auf den anstehenden Boden nötig wurde. Diese verzögerte sich allerdings wegen der Corona-Pandemie, so dass erst im Mai und Juni eine kleine Flächengrabung zustande kam, die wertvolle Einblicke von der frührömischen Zeit bis ins 19. Jahrhundert ermöglichte. ${ }^{6}$ Das grosse Potential der Fundstelle war schon zuvor klar gewesen, hatte doch zuletzt der Umbau des benachbarten Baudepartements (Münsterplatz 11) im Jahr 2017 Befunde von der Latènezeit bis in die Neuzeit in sehr guter Erhaltung erbracht. ${ }^{7}$

Unterhalb der nordwestlichen Eingangstreppe des Domhofs wurden von Mai bis Mitte Juni insgesamt zwei Flächen ergraben. In beiden Flächen kam in 1,70 $\mathrm{m}$ Tiefe der rote Verwitterungshorizont des anstehenden Schotters zum Vorschein. Darin eingetieft fanden sich drei parallele, von Nordwesten nach Südosten leicht abfallend verlaufende Balkengräben sowie ein weiterer, nahezu rechtwinklig dazu liegender Balkengraben (ABB. 8). Vergleichbare Strukturen mit rechtwinklig angelegten Balkengräben konnten bereits in diversen Gebäuden um den Münsterplatz herum nachgewiesen werden. ${ }^{8}$
Nordwestlich des Schnittpunktes zweier solcher Gräben wurde ein ca. $30 \mathrm{~cm}$ tiefes Pfostenloch gefasst, das auf ca. 1,90 m Tiefe den grauen anstehenden Schotter erreichte.

Direkt über dem Verwitterungshorizont lagen einige graue Schichten mit unterschiedlichen Komponenten, wie etwa Mörtelflocken oder Abschlägen von Muschelkalk-Bausteinen, deren genauere Identifikation noch aussteht. Vermutlich handelt es sich dabei aber um Bau- und Abbruchhorizonte. Darauf folgte eine mächtige rot-orangefarbene Planie aus tonigem Lehm, welche in sämtlichen Profilen gut erkennbar ist (АВв. 9. Innerhalb dieser Struktur fand sich Keramik des späten 3. oder frühen 4. Jahrhunderts. ${ }^{9}$ Auf der Oberkante dieser Lehmplanie konnte ein grauschwarzer Übergangshorizont mit mehreren Eintiefungen festgestellt werden, die als Pfostenlöcher und kleine Gruben zu deuten sind. Sie liegen ungefähr in der Flucht des im anstehenden Schotter gefassten Pfostenloches. Der Übergangshorizont enthielt nebst einer Glasperle und Feinkeramik auch zahlreiche Münzen aus dem späten 4. Jahrhundert, darunter $\rightarrow$
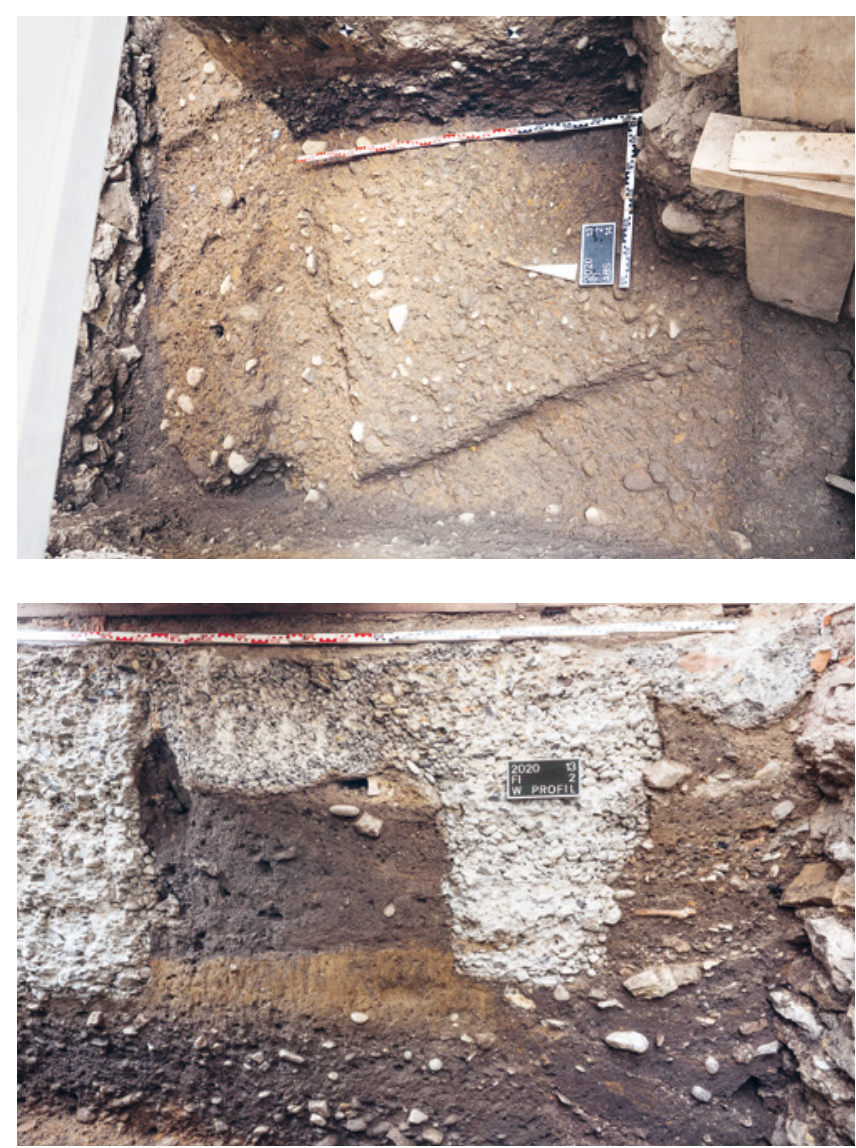

ABB. 8 Nach dem Ausnehmen der Balkengräben kommt überall der rotbraune Verwitterungshorizont des anstehenden Schotters zum Vorschein. Foto: Marc Schuurmans.

ABB. 9 Im Profil ist auf halber Höhe die rot-orange Lehmplanie des 3./4. Jahrhunderts zu erkennen, die rechts vom Fundamentgraben des Domhofs durchschlagen wird. Foto: Pascale Roth. 
eine gut erhaltene Münze Kaiser Julians aus seiner Zeit als Caesar 358-361 n. Chr. ${ }^{10}$ Eine weitere, sehr kleine Münze stammt aus der Zeit von 388-403 n. Chr. Während die rotorangefarbene Lehmplanie somit in die Übergangszeit zur Spätantike datiert, legen die oberhalb davon zu Tage geförderten Funde nahe, dass der dunkle, aus drei bis sechs Schichten bestehende Horizont eher vom Ende der Spätantike oder aus dem Frühmittelalter stammt.

Über diesen Schichten liess sich entlang der Fassade des Domhofs ein Fundamentgraben fassen, dessen Fundmaterial grösstenteils aus Holzkohlefragmenten und Tierknochen bestand; darunter vor allem solche von Jungtieren, Schweinen und Vögeln. Hier wurden offenbar Küchen- und Speiseabfälle einer gehobenen Küche entsorgt. An Keramik enthielt die Verfüllung mit Ausnahme von wenigen spätrömischen Altstücken vor allem viel grautonige Irdenware, während glasierte Keramik gänzlich fehlte. Die Interpretation des Fundamentgrabens als Baugrube des Domhofs passt zwar recht gut zur schriftlichen Erstüberlieferung des Gebäudes um 1382, ${ }^{11}$ dagegen spricht allerdings, dass damit die Tierknochen nicht als Verpflegung des Domkapitels, sondern was doch eher unwahrscheinlich ist - der Bauequipe anzusprechen wären. Die sehr dünn gebänderte Verfüllung des Grabens wird vom Fundament der Vortreppe des Riggenbachbaus von 1841 sowie von einer seichten Grube für dessen Quaderung durchschlagen.

Die Untersuchung ermöglichte trotz ihrer kleinen Fläche einen spannenden Einblick in die Geschichte des Hofareals von frührömischer Zeit bis zu den mittelalterlichen Bauten: Sie zeigt, dass die Besiedlung des Areals an der Hangkante des Münsterhügels spätestens in frührömischer Zeit begann. Gleichzeitig liessen sich aber auch Siedlungsbefunde aus den über tausend Jahren zwischen der Antike und den ersten schriftlich fassbaren mittelalterlichen Bauten fassen. Unerfreulich war hingegen die Erkenntnis, dass die heutige Hofgestaltung - mit Terrassen entlang der Fassaden - bei einem Umbau 1913 nicht durch deren Aufschüttung zustande kam. Vielmehr hatte man die Oberfläche des Hofs dazwischen auf das Niveau des Münsterplatzes abgesenkt. Damit wurden spätestens damals auf rund $250 \mathrm{~m}^{2}$ wohl alle archäologischen Schichten im Hofinnern bis auf den anstehenden Boden entfernt. Umso wertvoller ist damit die archäologische Substanz, die noch unter den seitlichen Terrassen schlummert.

\section{0/14}

\section{SCHLÜSSELBERG (INNENHOF SCHULHAUS ZUR MÜCKE)}

Anlass: Kanalisationsanschluss im Rahmen des Schulhausumbaus

Zeitstellung: Römische Zeit

Untersuchungsdauer: Mai 2020

Verantwortlich: Martin Allemann

Text: Martin Allemann

Auf dem Münsterhügel kann jeder Bodeneingriff Befunde zu Tage bringen und zerstören. Deshalb begleiteten wir am Schlüsselberg einen kurzfristig angekündigten Kanalisationseingriff. ${ }^{12}$ Hier im Hof des Schulhauses zur Mücke (ABB. 10) stand einst ein mehrphasiger spätantiker Grossbau des 4. Jahrhunderts, unter dessen beiden Mörtelböden sich auch latènezeitliche und frührömische Gruben erhalten haben. ${ }^{13}$ Der Aushub erbrachte aber erst tief unten im Schacht möglicherweise antike Mauerbefunde. Er erreichte den Verwitterungshorizont des anstehenden Schotters, ohne dass Spuren der beiden spätantiken Mörtelböden gefasst werden konnten: Der gesamte Eingriff lag in einem Bereich, der zunächst wohl mittelalterlich, vor allem aber neuzeitlich bereits stark gestört und durchwühlt war. Aufgrund der gestörten Schichten ist die genaue Datierung und Interpretation der zuunterst in der Grube liegenden mehrphasigen Mauerreste kaum möglich. Immerhin konnten wir aus dem umgelagerten schwarzen Lehm drei wohl spätantike Gürtelbeschlagteile aus Buntmetall bergen.

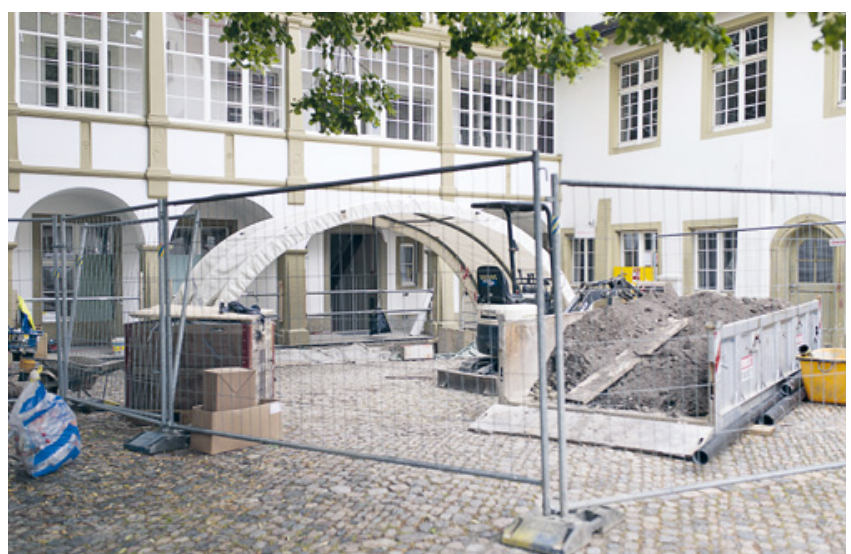

ABB. 10 Der Innenhof des Schulhauses zur Mücke mit dem Aushub für den Kanalisationsanschluss rechts unter dem Zelt. Foto: Philippe Saurbeck. 


\section{0/18 \\ RHEINSPRUNG GEGENÜBER 16 UND 18 (UNIGARTEN)}

Anlass: Sanierung bzw. Ersatz der Rheinufermauer

\begin{tabular}{l} 
Zeitstellung: Mittelalter, Neuzeit \\
\hline Untersuchungsdauer: Juni bis Juli 2020 \\
\hline Verantwortlich: David Roth, Martin Allemann \\
\hline Text: David Roth, Martin Allemann
\end{tabular}

Seit 2017 ist der ehemalige Universitätsgarten am Rheinsprung wieder öffentlich zugänglich. ${ }^{14}$ Im Sommer 2020 wurde auf der untersten Etage des terrassierten Gartens die rheinseitige Stützmauer teilweise abgebrochen und erneuert. ${ }^{15} \mathrm{Um}$ die neue Stützmauer am Münsterhügel zu verankern, mussten auf der Terrasse bis zu 3,70 m Erdmaterial abgetragen werden.

Vor 1433 lag hier der sogenannte «Schalerhof», der Sitz der Familie Schaler, der später an die Familie Zibol verkauft wurde. ${ }^{16}$ Mit der Gründung der Universität Basel 1460 und dem Verkauf der Liegenschaft kam auch das Gebiet am Rheinbord in den Besitz des Basler Rats. ${ }^{17} 1589$ richtet die Universität auf dem Gelände mit dem «hortus medicus» den ersten botanischen Garten der Schweiz ein. ${ }^{18}$ Auf dem Stadtplan von Matthäus Merian von 1615 sind neben dem unteren Kollegium drei Terrassenniveaus erkennbar. Ansonsten ist abgesehen von den rheinparallel verlaufenden Terrassenmauern in diesen Gärten keine feste Bebauung sichtbar. 1695 wurde das Areal von Hans Franz Sarasin (1649-1719) gekauft und in einen barocken Lustgarten umgewandelt. ${ }^{19}$ Von diesem Gartenareal gibt es mehrere Darstellungen und den Plan einer nicht realisierten Umstrukturierung. Ende des 18. Jahrhunderts kam das Gelände wieder in den Besitz der Universität. Aufgrund der knappen Mittel wurde der Garten nur geringfügig unterhalten und war in schlechtem Zustand. Grössere Umbauten sind daher in dieser Zeit wohl nicht zu erwarten. Erst beim Umbau des Universitätsgebäudes um 1859/60 kam es zu einer Neugestaltung. ${ }^{20}$ Auf dem Falknerplan (um 1860) sind auf der mittleren Terrasse Fischbecken und auf der untersten Terrasse Ställe, Gehege und Volieren des Zoologischen Instituts abgebildet, eine Aufteilung, die bis ins Jahr 2000 bestand. ${ }^{21}$

Die Rheinmauer wurde auf der gesamten Länge untersucht. Sie war teilweise in schlechtem Zustand und ihr morscher Mörtel war von zahlreichen Wurzeln durchbrochen. Neben den modernen Fundamenten der Volieren zeigten sich in der Rheinmauer mehrere mit Backsteinen zugemauerte Durchgänge, die grösstenteils unter dem modernen Verputz versteckt waren. Dabei dürfte es sich um ehemalige Zugänge vom Garten zum Rhein handeln. Überraschend war eine rund 1,60 m breite Mauer, die ungefähr rechtwinklig auf den Rhein zuläuft (ABB. 11). Ihre Lage, ihre Ausrichtung und ihre Massivität legen eine Deutung als Stützmauer für die Terrassierung oder für ein Gebäude nahe. Eine genaue Datierung ist jedoch schwierig, da das Erdreich beidseitig gestört war und kaum Funde vorliegen. So könnte sie im Zusammenhang mit dem Schalerhof, dem botanischen Garten, der Umstrukturierung zum Lustgarten oder mit dem unteren Kollegium stehen (ABB. 12).
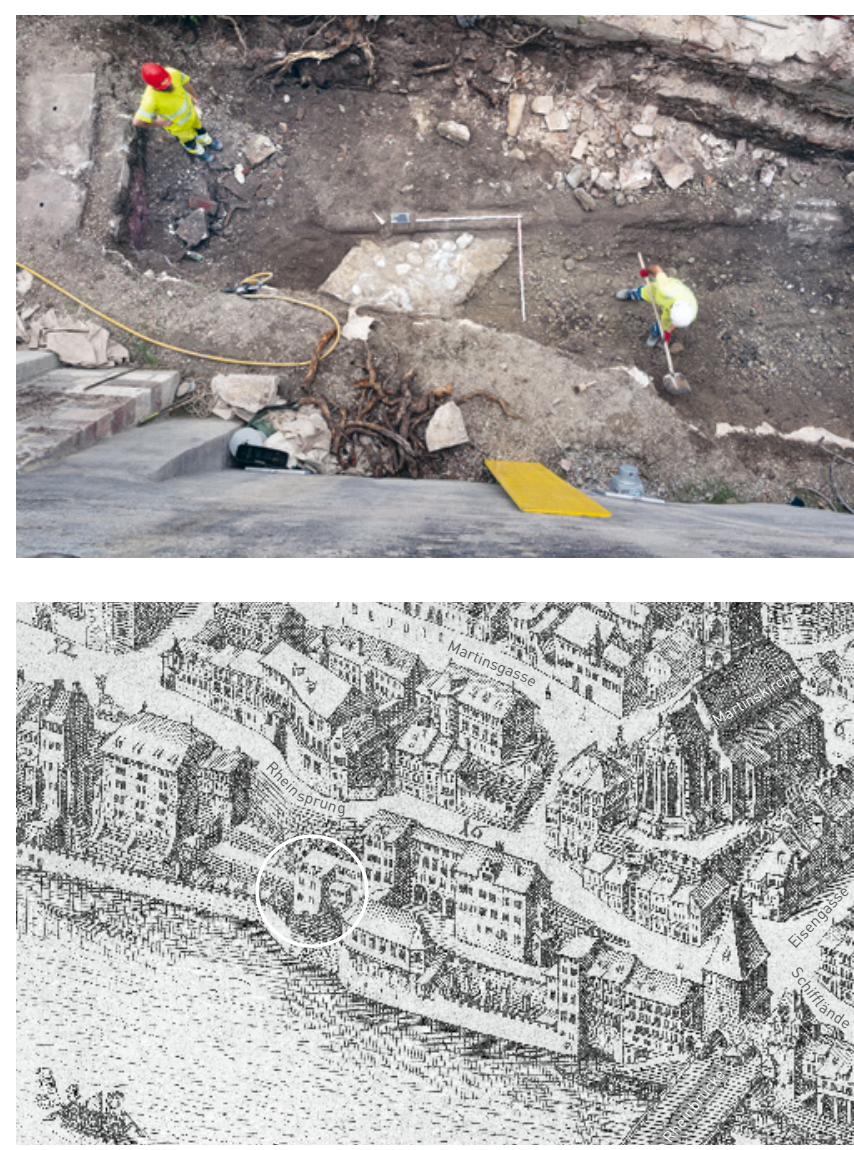

ABB. 11 Blick von der mittleren auf die unterste Terrasse während der Arbeiten. In der Bildmitte die ungefähr rechtwinklig auf den Rhein zulaufende Mauer, deren Funktion unklar ist. Foto: David Roth.

ABB. 12 Auf dem Merianplan von 1615 ist im Bereich des Gartens ein Gebäude zu sehen (weisser Kreis), das in Zusammenhang mit der aufgefundenen Mauer stehen könnte. Bildbearbeitung: Peter von Holzen. 


\section{INNERSTADT}

\section{$2018 / 21$}

\section{LEONHARDSGRABEN 46}

Anlass: Umbau zu Hotel

\section{Zeitstellung: Neuzeit}

Untersuchungsdauer: Juli 2018 bis April 2019

Verantwortlich: Norbert Spichtig, Martin Allemann

Text: Martin Allemann

Das Haus Leonhardsgraben 46 wurde 2018 bis 2019 zur Dependance des Hotels Teufelhof umgebaut. Weil die grossen Bodeneingriffe der Kontermauer zur Inneren Stadtmauer in mittelalterlich bebautem Gebiet nahe kamen, begleiteten wir sie. ${ }^{22}$ Dabei kamen im Gebäudeinnern und unter dem Trottoir vor dem Haus zwei ungefähr parallel laufende Mauern zum Vorschein. Während die Mauer im Gebäude zur Parzelle hin gegen die Erde gemauert und zur Strasse hin verputzt war, war umgekehrt die Mauer im Trottoirbereich zum Haus hin verputzt und strassenseitig an die Erde gemauert. Daher gehören die beiden Mauern offensichtlich zum Keller eines Vorgängerbaus. Dazu passt auch der Befund eines Lichtschachts oder Kohlenabwurfs in der strassenseitigen Mauer, neben dem Reste der Auflagesteine erhalten waren, die einst Balken der Kellerdecke trugen. Das dazugehörige Haus ist auf dem Falknerplan (um 1860) noch abgebildet. Recherchen zur Baugeschichte sind aufgrund der dichten, aber verworrenen Quellenlage zu diesem Stadtteil aufwendig, da hier oft Liegenschaften zusammengelegt und abgetrennt wurden. Das zum Keller gehörende Haus ragte weiter in die heutige Strasse hinein als sein Nachfolger - und in den 1950er Jahren wollte man auch diesen nochmals zurücksetzen, um mehr Platz für den Verkehr zu schaffen.

\section{8/32}

\section{ST. ALBAN-GRABEN (A) 5 / LUFTGÄSSLEIN (A)}

Anlass: Bau eines unterirdischen Parkhauses

Zeitstellung: Römische Zeit, Mittelalter, Neuzeit

Untersuchungsdauer: Oktober 2018 bis Februar 2021

Verantwortlich: Martin Allemann

Text: Martin Allemann

Die Arbeiten am unterirdischen Parkhaus im ehemaligen Stadtgraben ${ }^{23}$ erforderten auch in diesem Jahr eine enge archäologische Begleitung. Bis Ende 2020 wurden die obertägigen Arbeiten weitgehend beendet. Der unterirdische Aushub unter der bereits betonierten Parkhausdecke wurde aus organisatorischen Gründen unter der Laufnummer 2020/31 dokumentiert (S. 56-57). Zusätzlich zum Parkhausaushub sorgte der Bau einer grossen Kanalisation für einigen Aufwand, weil sie auf gut $100 \mathrm{~m}$ Länge in die Mauerschale der Inneren Stadtmauer verlegt wurde, die dafür erheblich zurückgespitzt und zuvor dokumentiert werden musste (ABB. 13).

Die bewährte Zusammenarbeit mit der Tiefbauequipe ${ }^{24}$ ermöglichte es, zahlreiche Befunde zu dokumentieren, u. a. Aufschlüsse zur Baugeschichte der Stadt- und Kontermauer, zur Grabenverfüllung, eine mittelalterliche Wasserleitung sowie einen spätmittelalterlichen Latrinenturm. Zu den Highlights unter den Funden gehören spolierte jüdische Grabsteine und das vollständige Skelett vermutlich eines Berberaffen aus dem Spätmittelalter. Ausführliche Informationen dazu finden sich in der Coverstory des vorliegenden Jahresberichtes (S. 77-117).

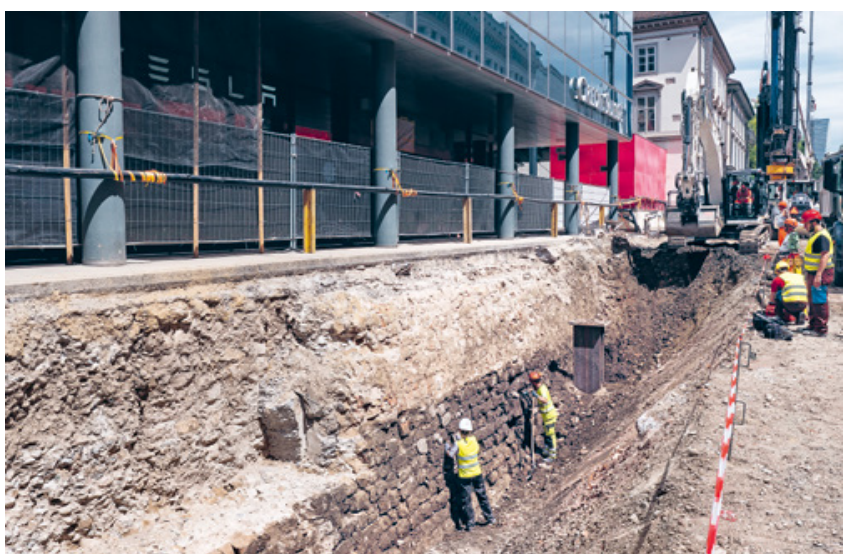

ABB. 13 Unter den Gebäuden nördlich am St. Alban-Graben war die Innere Stadtmauer meist grossflächig erhalten. Sie musste aber streckenweise dem Parkhaus weichen. Foto: Philippe Saurbeck. 


\section{0/3}

\section{ELISABETHENSTRASSE 27 (HAUS ZUM KIRSCHGARTEN)}

Anlass: Leitungsarbeiten im Garten

\begin{tabular}{l} 
Zeitstellung: Neuzeit \\
\hline Untersuchungsdauer: Februar 2020 \\
\hline Verantwortlich: Martin Allemann \\
\hline Text: Martin Allemann
\end{tabular}

Das Haus zum Kirschgarten ist das monumentale Stadtpalais eines Bandfabrikanten aus dem späten 18. Jahrhundert. Hier ist auch der Basler Orientalist Johann Ludwig Burckhardt (1784-1817) alias «Scheich Ibrahim» aufgewachsen, der Entdecker der antiken Felsenstadt Petra in Jordanien. Heute gehört das für Basler Verhältnisse sehr repräsentative Palais als Museum für Wohnkultur zum Historischen Museum Basel. Im Garten hinter dem Palais kam bei Leitungsarbeiten an einem Laufbrunnen von 1880 ein gemauerter Kanal aus Vollbacksteinen zum Vorschein, der uns gemeldet wurde (ABB. 14). ${ }^{25}$ Vor Ort war rasch klar, dass es sich um eine alte Dachwasserleitung handelt, die von einer Regenrinne in der Gartenecke auf das Fundament und die Entwässerung des Brunnens zielt. Wahrscheinlich stammt sie aus der Bauzeit des inschriftlich datierten Brunnens, jedenfalls ist sie sicher nicht älter als das zwischen 1775 und 1780 errichtete Haus.

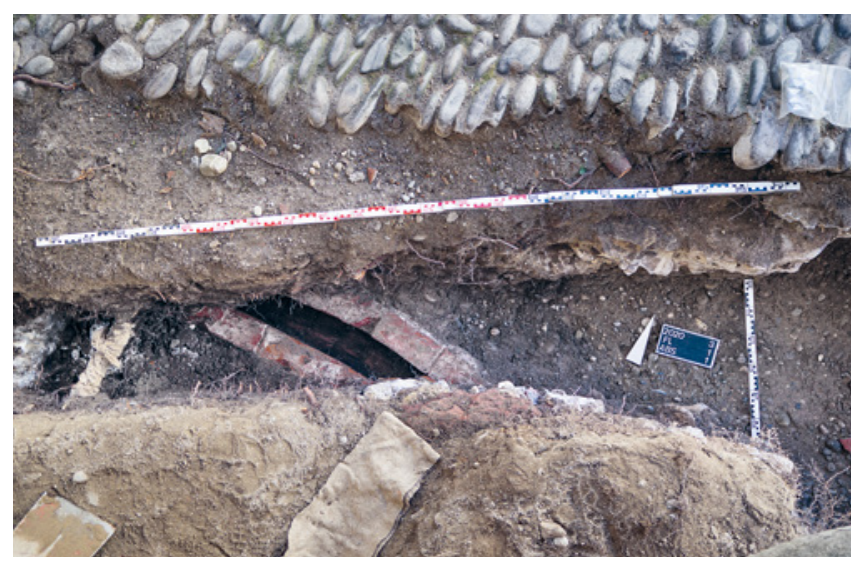

ABB. 14 Unter der Kieselpflästerung und modernen Aufschüttungen ist der aus Backsteinen gemauerte Kanal zu erkennen, links und rechts begleitet von einer schmalen Baugrube. Foto: Michael Weber.

\section{0/7}

\section{PETERSPLATZ (A) (KÄLTEVERBUND)}

Anlass: Leitungsbau Kälteverbund

Zeitstellung: Mittelalter, Neuzeit

Untersuchungsdauer: März bis August 2020

Verantwortlich: Johann Savary, Fabian Bubendorf

Text: Johann Savary

Zwischen März und August begleitete die Bodenforschung den Aushub für die Installation eines Kälteverbunds der Universität Basel und einer neuen Stromleitung. Der Kanal erstreckte sich ungefähr über eine Länge von $550 \mathrm{~m}$ mit einer Breite von 1,10 bis 1,50 m und einer Tiefe von 1,20 bis 3,20 m vom Bernoullianum bis zum Petersgraben (ABB. 15). Die Bauarbeiten tangierten damit einen archäologisch sensiblen Bereich. Zu erwarten waren nicht nur Mauern der mittelalterlichen und neuzeitlichen Stadtbefestigung und Gräber des Spalenfriedhofs, der ersten ausserhalb der Stadt angelegten Friedhofsanlage, sondern möglicherweise auch Reste des jüdischen Friedhofs. ${ }^{26}$ Dank einer Verlegung des Leitungstrassees konnte jedoch verhindert werden, dass allfällig erhalten gebliebene Bestattungen aus der Zeit der ersten jüdischen Gemeinde gestört worden wären.

Aufgedeckt wurden hingegen Überreste der Ende des 14. Jahrhunderts errichteten Äusseren Stadtmauer und der Kontermauer vor und am östlichen Ende der Universitätsbibliothek sowie am westlichen Ende des Stachelschützenhauses, in dem heute das Institut für medizinische Mikrobiologie untergebracht ist (АВB. 16). An der Ecke östlich der Universitätsbibliothek am Eingang zum Petersplatz war die Kontermauer offensichtlich zwischen dem 17. und 19. Jahrhundert zerstört und der Graben trapezförmig erweitert worden. ${ }^{27}$ Dort und am westlichen Ende des Stachelschützenhauses $\rightarrow$

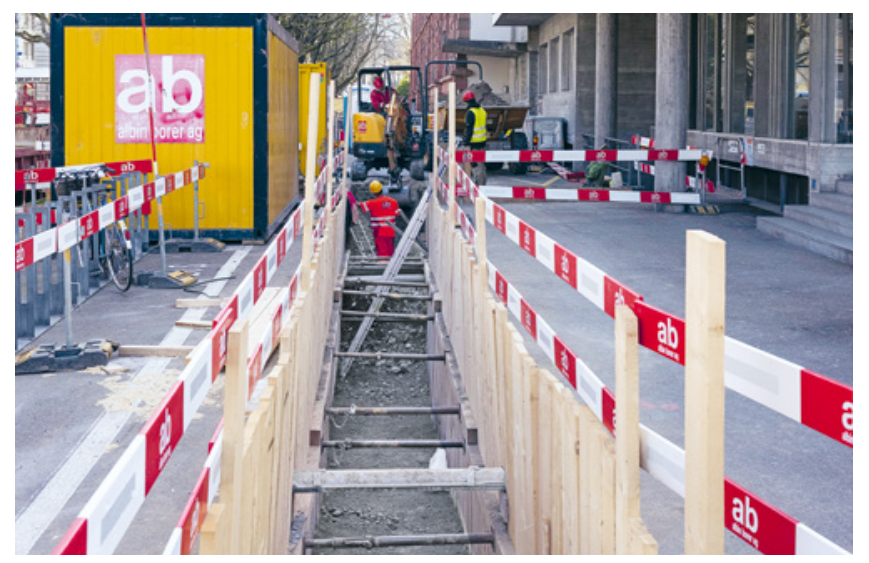

ABB. 15 Der Kanal für die Installation eines Kälteverbundes und einer neuen Stromleitung erstreckte sich ca. $550 \mathrm{~m}$ lang vom Bernoullianum bis zum Petersgraben. Foto: Philippe Saurbeck. 


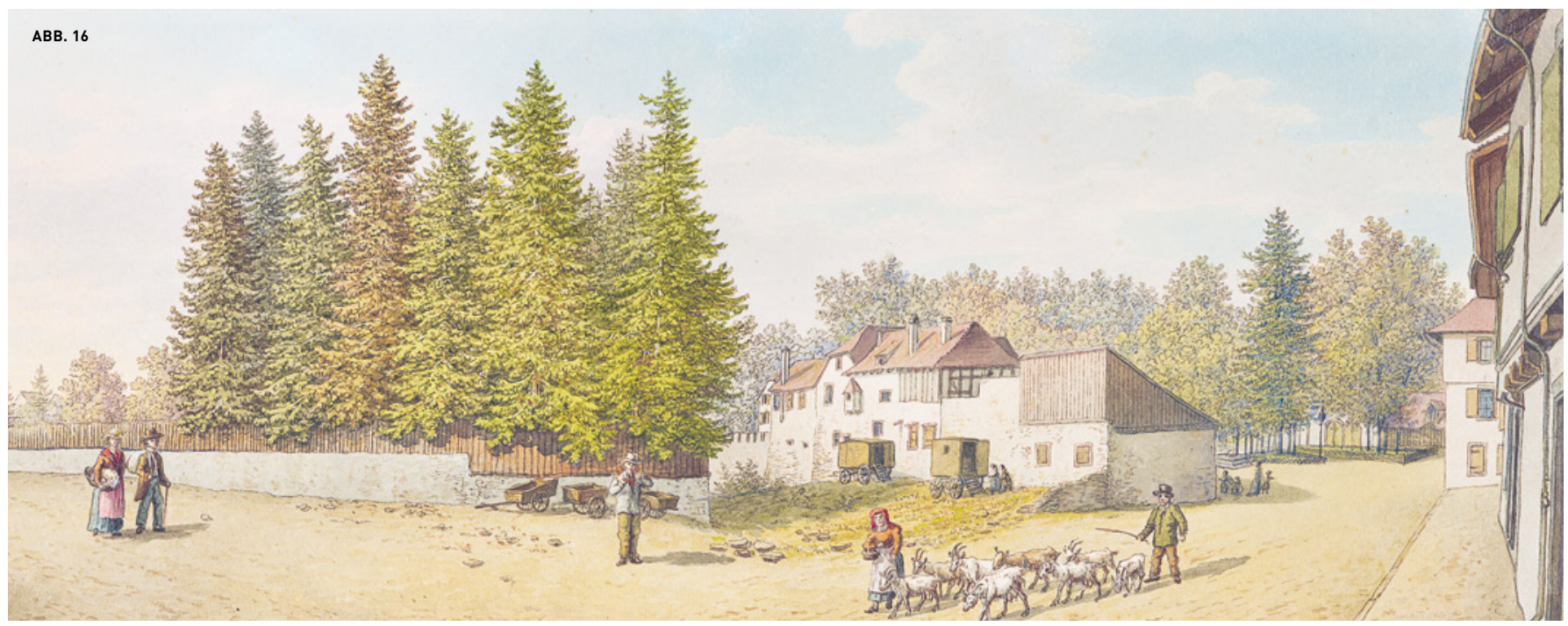

wurden zusätzlich noch zwei schmale Mauern aus KalksteinHandquadern und Geröllen dokumentiert, welche möglicherweise eine erste Phase der Äusseren Stadtmauer im 13. Jahrhundert darstellen. ${ }^{28} \mathrm{Im}$ Bereich des Bernoullianums wäre eigentlich das zu Beginn des 16. Jahrhunderts errichtete Wasenbollwerk zu erwarten gewesen, allerdings konnten dort nur fundlose Kiesaufschüttungen erfasst werden.

Besonders interessant sind markante, dicke schwarze Brandschichten mit viel Schlacke und magnetischen Metallpartikeln, die im Bereich des Stachelschützenhauses zum Vorschein kamen. Bereits 1999 war hier den Ausgräbern eine Ansammlung von Metallschlacken aufgefallen, die sie wegen der begrenzten Menge als Abfallgrube von Metallverarbeitern interpretiert hatten. ${ }^{29}$ Möglicherweise handelt es sich bei den Brandschichten jedoch um Überreste einer frühneuzeitlichen Metallwerkstatt (ABв. 17). Die Spalenvorstadt ist zwar für die Ansiedlung von Schlossern und Metallverarbeitern bekannt, allerdings gibt es noch wenige Recherchen zum neuzeitlichen Handwerk im Areal und dem näheren Umfeld des Stachelschützenhauses. Die Entnahme mikromorphologischer Proben wird es erlauben, die Schichtbildung der vermuteten Werkstatt genauer zu untersuchen und Fragen zum Arbeitsprozess zu klären.

Im Graben entlang der Universitätsbibliothek kamen 38 Skelette - fast ausschliesslich Säuglinge, Kinder und Jugendliche - aus dem Spalenfriedhof zu Tage. ${ }^{30}$ Der Spalenfriedhof wurde 1825 als erster Friedhof ausserhalb der Stadtmauer eingeweiht, 1835 und 1845 nach Norden vergrössert und schliesslich 1868 geschlossen. Die Skelette lagen mehrheitlich mit dem Kopf nach Südwesten, was auf eine Ausrichtung auf den nördlichen, äusseren Weg des Friedhofs hinweist (ABB. 18). Besonders auffällig ist eine Doppelbestattung, bei der ein Säugling auf der Brust eines Kindes liegt, ansonsten waren die Gräber Einzelbestattungen ohne Überlappung. Meistens war keine Grabgrube erkennbar, bei vielen Bestattungen sind jedoch Reste des Sargholzes erhalten geblieben. Teilweise fand sich allerdings nur noch Holz - möglicherweise ein Hinweis darauf, dass die Skelette im Zuge der Aufhebung des Friedhofes an einem neuen Ort, etwa auf dem 1868 eingerichteten Kannenfeldfriedhof, wiederbestattet worden sind. Die häufigsten Funde waren Kleiderhäkchen aus Buntmetall oder Glasknöpfe, die möglicherweise zu einem Totenhemd gehören. Bei einer Bestattung lag ein Bronzering im Kopf-/Brustbereich. Ein Verschlusshaken könnte Zeugnis für ein Sargfenster sein. Aufgrund eines Leitungsbruches an der Schönbeinstrasse konnten auch einige aus Backsteinen gemauerte Gruften dokumentiert werden.

Im Bereich des heutigen Kollegiengebäudes der Universität kam eine Aussenmauer mit einem Innenboden aus Baukeramikplatten zum Vorschein. Möglicherweise handelt es sich dabei um Reste des Klosters Gnadental, das einst an dieser Stelle gestanden hat und nach der Reformation teilweise ins Zeughaus integriert wurde. Der Abbruchschutt ist aber leider weitgehend modern und ist wohl beim Bau der Kollegiengebäude in den 1930 erJahren entstanden.

Zuletzt konnten frühe Bauphasen des 1884/1885 gebauten Vesalianums aufgedeckt werden. Die Befunde lassen ein ganz anderes Erscheinungsbild der Umgebung des Universitätsgebäudes als heute erahnen. Die nördliche Gebäudeseite war mit grossen Geröllen gepflastert, während die östliche Seite mehrlagige Schichten von sehr hartem, sandig-mörtelhaltigem, rotem oder grünem Buntsandsteinpulver aufwies, worin teilweise Grobkies eingelassen war. Dies dürfte eine Art Terrazzo-Boden (Mörtelboden) oder sogar ein frühes Beispiel eines Steinholzbodens darstellen, eine Technik, die 1867 vom französischen Physiker Stanislas Sorel erfunden wurde. ${ }^{31} \mathrm{Da}$ - 
bei erstarrt das Erdmaterial durch Beimischung von Chemikalien (Magnesiumoxid und Magnesiumchlorid) zu einer zementartigen Masse, die für einen Boden im Aussenbereich besonders geeignet ist. An der nordöstlichen Ecke des Gebäudes verlief die Hofmauer einst weiter nach Norden. An deren innerer Eingrenzung wurde ein Boden aus Baukeramikplatten aufgedeckt, die auf mehreren Lagen von Blöcken aus Buntsandstein ruhten und von Stahleisen zusammengehalten wurden. Wegen des massiven Baus lässt sich vermuten, dass es sich hierbei um eine Art Lieferweg oder Lagerplatz für schwere Objekte handelte, als das Vesalianum zwischen 1885 und 1921 für die Physiologie und Anatomie der Universität benutzt wurde.
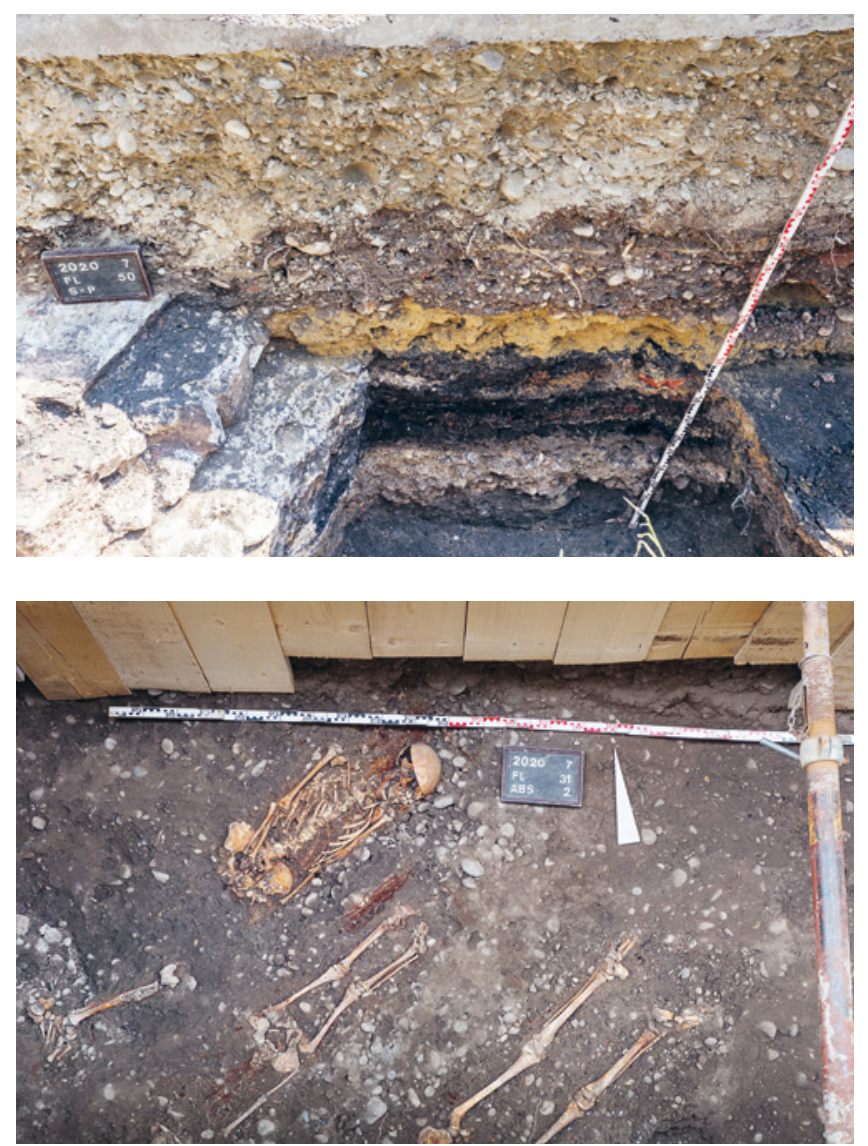

ABB. 16 Blick vom Spalengraben her auf das Stachelschützenhaus mit seinen Nebengebäuden und links anschliessend einem kleinen Rest der Stadtmauer. Auf der linken Bildhälfte befindet sich der Spalenfriedhof, im Hintergrund ist der Petersplatz zu erkennen. Bild: StaBS Bild Schn. 168.

ABB. 17 Die markanten schwarzen Brandschichten, in denen sich viel Metallschlacke und magnetische Partikel befanden, deuten auf eine frühneuzeitliche Metallwerkstatt hin. Foto: Fabian Bubendorf.

ABB. 18 Die Gräber wurden ordentlich angelegt. Der Kopf wurde entweder nach Nordosten oder nach Südwesten orientiert. Foto: Fabian Bubendorf.

\section{0/10}

\section{BRUNNGÄSSLEIN (A) 6, 8, 12}

Anlass: Versetzen von Schächten für Trottoirverbreiterung (Restaurant-Boulevard)

Zeitstellung: Neuzeit
Untersuchungsdauer: März 2020
Verantwortlich: Martin Allemann
Text: Martin Allemann

Der bescheidene Name Brunngässlein überrascht, da es sich heute um eine zweispurige Strasse mit Trottoir handelt. Alte Pläne hingegen zeigen, dass der Weg bis ins 20. Jahrhundert hinein ein nicht einmal drei Meter breiter Durchschlupf von der Aeschenvorstadt zur damaligen Malzgasse war, der vor allem Hinterhäuser und Gärten erschloss.

Das Trottoir wurde nun im Bereich eines Restaurants in die Strasse hinaus verbreitert, um Platz für eine Aussenbestuhlung zu schaffen. Es war zu vermuten, dass die Versetzung von zwei Schächten im Zuge dieser Umgestaltung Reste von alten Bauten tangieren würde, die hier einst für die Verbreiterung der Strasse abgebrochen worden waren. ${ }^{32}$ Tatsächlich wurden zwei quer zur Strassenachse laufende Mauern angeschnitten. Dabei dürfte es sich einerseits um die Mauer zwischen den abgebrochenen Häusern Brunngässlein 6 und 8 (heute Nummer 8 und 12) handeln, andererseits um eine Binnenmauer im Keller des Hauses Brunngässlein 6. Das historische Grundbuch zeigt, dass hier schon lange kleine Hinter- und Gartenhäuser standen. ${ }^{33}$ 


\section{0/12}

\section{BARFÜSSERPLATZ 7}

Anlass: Abdichtung von Räumlichkeiten des HMB

Zeitstellung: Mittelalter, Neuzeit

Untersuchungsdauer: April bis September 2020

Verantwortlich: Johann Savary

Text: Johann Savary

Im Zuge der Abdichtung von Räumlichkeiten des Historischen Museums wurden der unterirdische Kulturgüterschutzraum und die Bereiche beim Chor der Barfüsserkirche freigelegt, um das Mauerwerk neu zu verputzen. Dies erlaubte uns eine ausführliche Dokumentation der Mauerfundamente und der daran anschliessenden Befunde (АВB. 19). ${ }^{34}$

Die erste Barfüsserkirche mit dazugehörigem Kloster wurde zwischen 1250 und 1256 durch den Bettelorden der Franziskaner im Bereich des unteren Steinenbergs errichtet. Das mit dem Bau der Inneren Stadtmauer neu umfriedete Areal erhielten sie vom Basler Bischof geschenkt. Schon zwischen 1275 und 1309 wurde die erste Klosterkirche wieder abgebrochen und die heutige Barfüsserkirche wenige Meter weiter nördlich errichtet. Sie war mit $80 \mathrm{~m}$ Länge deutlich grösser und stand auf einer $2 \mathrm{~m}$ hohen Kiesaufschüttung, weshalb die Überreste der ersten Kirche im Untergeschoss des heutigen Baus liegen. ${ }^{35}$

Bei den Untersuchungen wurden die Chorfundamente der heutigen Barfüsserkirche bis auf eine Tiefe von 5,50 m geöffnet. Besonders auffällig war hier, wie regelmässig man das Mauerwerk in Abwechslung von grossen Kalksteinblöcken und Ausgleichslagen von Kalksteinplatten ausgeführt hatte. Die Tatsache, dass die Kirchenpfeiler mit dem Chorfundament weitgehend im Verband stehen, ist ein klarer Hinweis darauf, dass das Bauwerk in einem Zuge errichtet wurde, wenn auch - worauf markante Baufugen hinweisen - in verschiedenen Etappen. Das Mauerwerk der Sakristei hingegen besteht aus vielen verschiedenen Baumaterialien, $u$. a. Buntsandstein- und Kalksteinblöcken, Baukeramikplatten und Geröllen (ABB. 20). Auch wenn der Anschluss an die Kirche nicht freigelegt wurde - dieser Bereich ist bereits durch den Bau des Kulturgüterschutzraums in den 1970 Jahren gestört worden, ohne dass eine archäologische Dokumentation der Aussenseite stattgefunden hätte -, ist die grundsätzlich andere Bauweise ein Argument dafür, dass die Sakristei später an den Chor angebaut wurde. Die grosse Anzahl an Architekturspolien lässt zudem vermuten, dass sie aus den Resten der ersten Barfüsserkirche errichtet wurde. ${ }^{36}$ Eine Spolie mit Resten von blauer und roter Farbe stach dabei besonders hervor: Untersuchungen von Farbproben lassen den Schluss zu, dass es sich um das Fragment einer Statue handelt. ${ }^{37}$
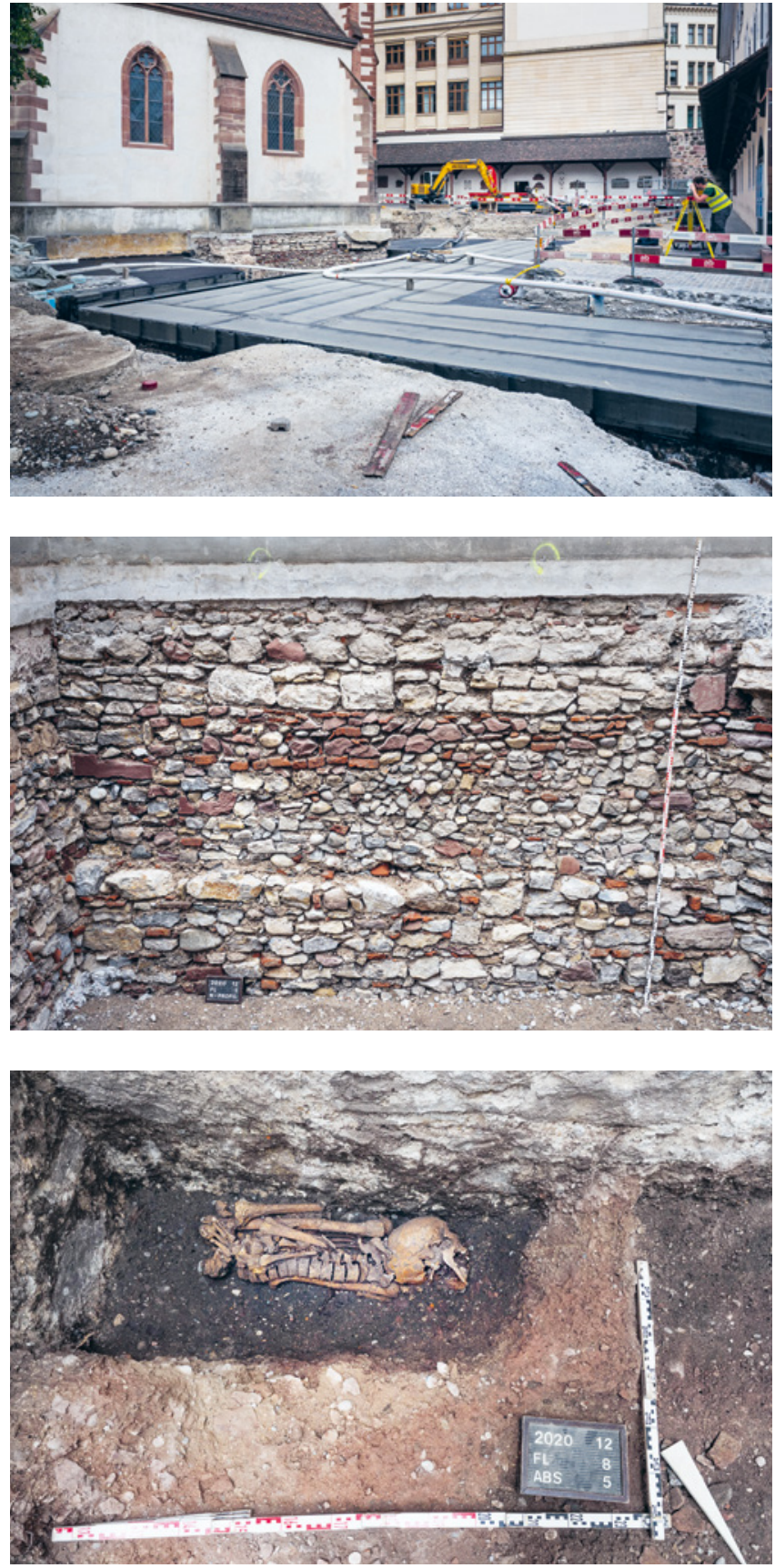

ABB. 19 Die Freilegung des Kulturgüterschutzraums des Historischen Museums erlaubte es, die Aussenseiten der Sakristeifundamente zu dokumentieren. Foto: Fabian Bubendorf.

ABB. 20 Das Fundament der rechten Südwand der Sakristei der zweiten Barfüsserkirche wurde aus unterschiedlichsten Materialien und vermutlich Spolien vom ersten Kirchenbau errichtet. Foto: Fabian Bubendorf.

ABB. 21 In der Nähe des Altarbereichs konnte das Skelett eines erwachsenen Mannes aufgedeckt werden, der vermutlich in halb verwestem Zustand in einer Holzkiste (wieder-)bestattet worden war. Foto: Johann Savary. 
Die Baugrube des Kirchenfundaments ist teilweise erhalten geblieben. Meistens wurde das Fundament freistehend aufgebaut und Material progressiv aufgeschüttet. An einer Stelle konnte im unteren Grubenteil zusätzlich ein enger, ca. 2,20 m tiefer Graben im anstehenden Boden dokumentiert werden.

Ungefähr auf der Höhe des Kirchenaltars wurden in einer rotfarbigen, vermutlich von der Bearbeitung des beim Kirchenbau verwendeten Buntsandsteins stammenden Sandsteinmehlschicht Skelettteile eines erwachsenen Mannes aufgedeckt. Diese waren nicht mehr in situ, sondern «zusammengepackt», wobei der Schädel im Bereich des Beckens lag. Insbesondere das Becken selbst und das rechte Bein fehlen (ABB. 21). Die Wirbelsäule war jedoch noch im Verband, weshalb der Leichnam wahrscheinlich in halb verwestem Zustand entweder eng in ein Tuch verschnürt oder in einer kleinen Holzkiste - es fanden sich direkt neben dem Schädel zwei Eisennägel - (wieder-)bestattet wurde. Der Ort der Bestattung, möglichst nahe beim Altar, weist darauf hin, dass es sich um das nach dem Bau der zweiten Kirche 1298 und vor der Reformation von 1528 angelegte Grab einer gesellschaftlich höherstehenden Person handelt. ${ }^{38}$ C14-Datierungen im Rahmen einer noch laufenden Bachelor-Arbeit an der Universität Zürich kommen zum Schluss, dass der Mann entweder im späten 13. oder im späten 14. Jahrhundert gestorben ist. Das Grab wurde nach der Bestattung von einer Pflasterung überdeckt, welche in diesem Bereich jedoch stark beschädigt war.

Sicher ist, dass der Bereich in der Neuzeit erneut gepflastert wurde und man die Kirchenpfeiler mit einer gemauerten Unterlage verband, auf der möglicherweise ein Holzschuppen stand. Auf Fotografien des 19. Jahrhunderts sind im Südwesten solche zwischen die Pfeiler gestellte Holzschuppen erkennbar. Im 20. Jahrhundert überdeckte man den Hof im Bereich der heutigen Fasnachtsgasse dann mit einer Mergellage.

In jedem zweiten Pfeilerbereich wurden vermutlich im 19. Jahrhundert gemauerte Schächte ca. 3,60 m eingetieft. Diese waren am Boden mit einer Pflasterung versehen, auf deren Höhe Fenster in die Kirchenwand eingelassen wurden. Schächte und Fenster dienten, als man die Kirche zwischen 1799 und 1815 als Salzlager verwendete, wohl dazu, das Salz ins Untergeschoss der Kirche zu befördern. Die dadurch entstandene starke Kontaminierung der Umgebung dürfte der Grund dafür sein, dass trotz der Totalsanierung zwischen 1975 und 1981 erneut eine Abdichtung u. a. des unterirdischen Kulturgüterschutzraums notwendig wurde.

\section{0/22}

\section{FREIE STRASSE (A), ETAPPE 1}

Anlass: Werkleitungsbauten

Zeitstellung: Römische Zeit, Mittelalter, Neuzeit

Untersuchungsdauer: August bis November 2020

Verantwortlich: Roman Schmidig, David Roth

Text: Roman Schmidig

Bis im Jahr 2023 werden in der Freien Strasse und ihren Seitengassen der Belag und sämtliche Werkleitungen erneuert sowie eine neue Fernwärmeleitung verlegt. ${ }^{39}$ Insbesondere der Aushub des Grabens für die Erweiterung des Fernwärmenetzes in bisher ungestörten Bereichen veranlasste die Archäologische Bodenforschung zu einer engen Begleitung dieser Grossbaustelle. Der Perimeter dieser ersten Etappe lag zwischen der Einmündung in den St. Alban-Graben und der Ecke Freie Strasse / Bäumleingasse, zusätzlich wurde ein Abschnitt des Fernwärmegrabens vor der Freien Strasse 68 für die archäologischen Untersuchungen vorgezogen. Weitere kleine Flächen wurden in der Barfüssergasse sowie vor der Freien Strasse 62 und 53 geöffnet.

Vom Mittelalter bis zur letzten Strassenkorrektur in den Jahren um 1900 war die hauptsächlich von Handwerksbetrieben gesäumte Freie Strasse deutlich enger als heute. Deshalb liegen diverse zu erneuernde Leitungen innerhalb der mittelalterlichen und frühneuzeitlichen Häuser. Es zeigte sich während der Ausgrabung, dass die alten Mauerwerke $\rightarrow$

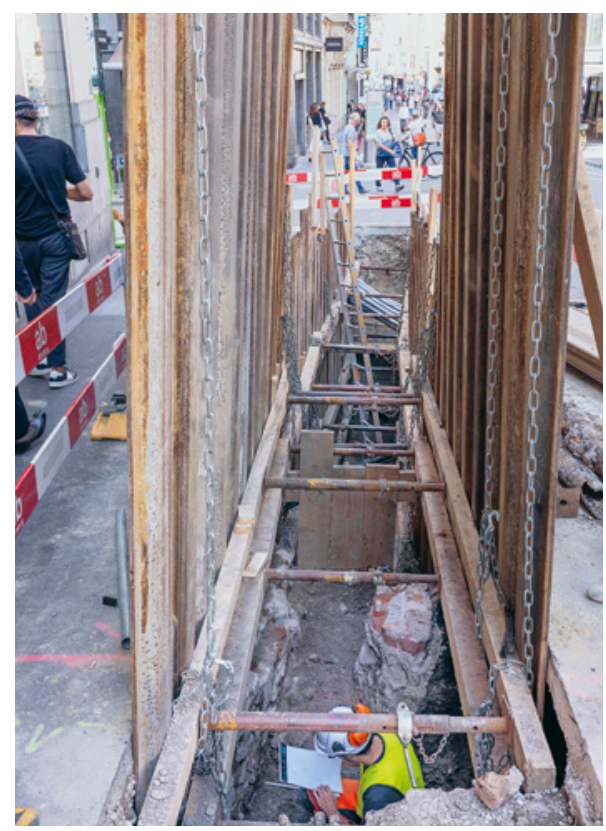

ABB. 22 Dokumentation der Mauern des Spitals «An den Schwellen» im Graben der neuen Fernwärmeleitung im Bereich der Freien Strasse 68. Foto: Philippe Saurbeck. 


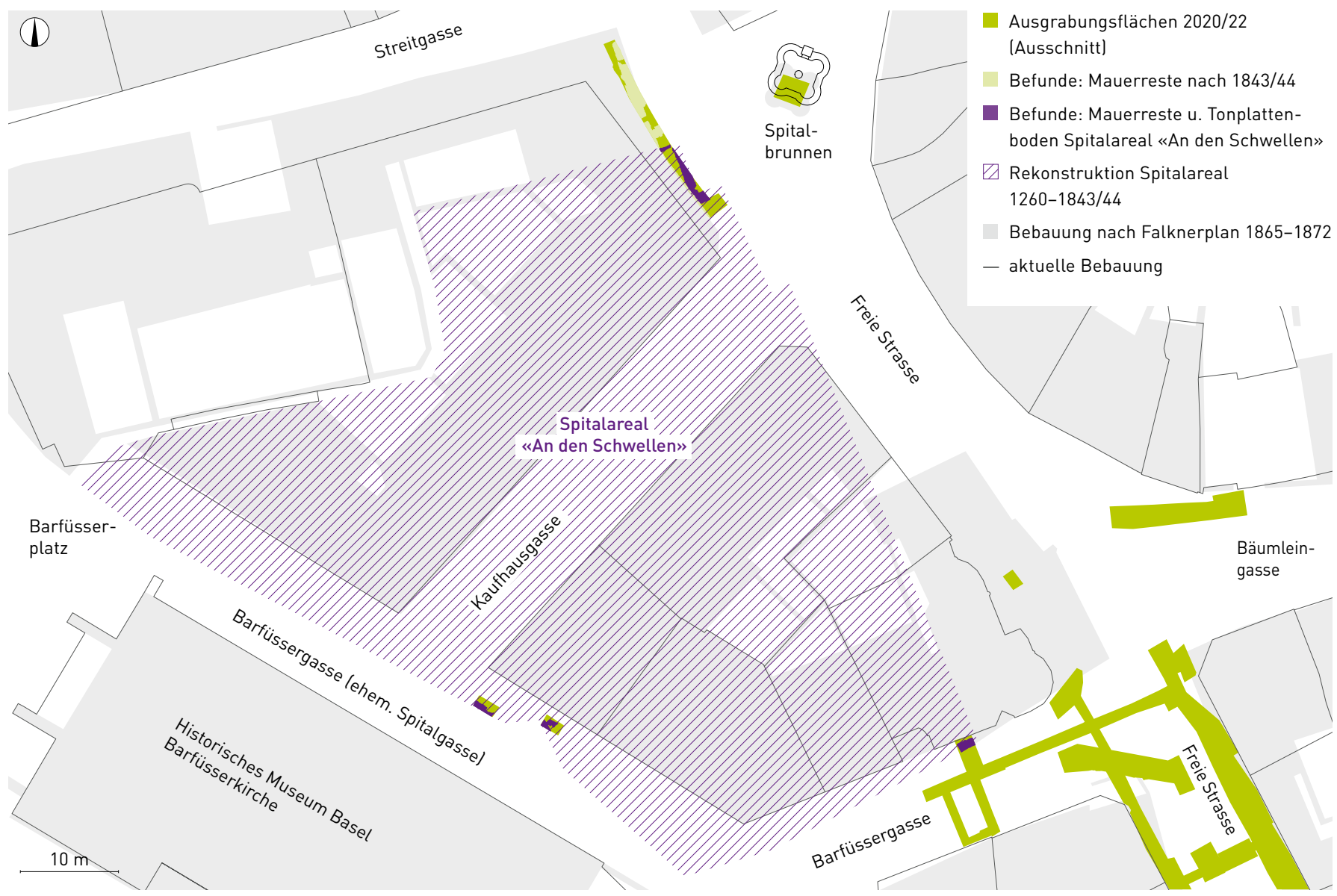

ABB. 23 Übersichtsplan zum Areal des Spitals «An

den Schwellen» und den aktuellen Ausgrabungen an

der Freien Strasse. Plan: Roman Schmidig, Peter

von Holzen.

beim Bau dieser Leitungen nicht komplett zerstört worden waren, sondern stellenweise bis heute als Unterbau der Rohre dienen. Somit konnte besonders auf der Ostseite der Freien Strasse eine grosse Zahl an Mauern freigelegt werden, die grösstenteils auch auf dem Falknerplan (um 1860) eingezeichnet sind. Bei der Einmündung in den St. Alban-Graben kamen zudem Reste der Inneren Stadtmauer und möglicherweise des Aeschenschwibbogens zum Vorschein.

Die Flächen nördlich der Einmündung von Barfüsserund Bäumleingasse lagen im Bereich des im 13. Jahrhundert erbauten und 1843/44 abgerissenen Spitals «An den Schwellen». Zu diesem gehörten seit der Reformation auch die Gebäude des Barfüsserklosters. ${ }^{40}$ Die Umrisse des Gebäudekomplexes sind uns durch einen Plan von Matthäus Merian ${ }^{41}$ bekannt und lassen sich mit einigen archäologischen Befunden gut in Deckung bringen: Ein grösserer Mauerabschnitt wurde im Graben der neuen Fernheizung vor der Freien Strasse 68 gefunden (Авв. 22, Авв. 23). Weitere Reste, darunter erfreulicherweise auch ein Stück Tonplattenboden, fanden sich in der Barfüssergasse. Eher überraschend kamen an der Ecke Freie
Strasse / Barfüssergasse zwei Skelette zum Vorschein, bei denen es sich um verstorbene Patienten des Spitals handeln könnte.

An mehreren Stellen wurden Teile des Dolensystems gefunden, das die Abwässer der Stadt in den Birsig leitete. Bei zwei kurzen Abschnitten handelt es sich um Hausanschlüsse des Spitals, weitere Teile fanden sich an den Ecken Freie Strasse / Barfüssergasse und Freie Strasse / Streitgasse. Unklar ist im Moment noch, ob die Dolen ins Mittelalter datieren oder jüngeren Datums sind.

Bei der Einmündung der Bäumleingasse in die Freie Strasse und vor der Freien Strasse 74 kamen Schichten mit römischer Keramik zum Vorschein. Bereits bei früheren Grabungen in der unmittelbaren Umgebung sowie in der Freien Strasse selbst hatte man römerzeitliche Befunde aufgedeckt, die einer antiken Strasse zugeordnet wurden. ${ }^{42}$ Es könnte sich deshalb bei den aktuell dokumentierten Schichten ebenfalls um einen Abschnitt der römischen Strasse handeln.

Die zweite Etappe des Projekts beginnt im Januar 2021 und wird das ganze Jahr dauern. 


\section{$2020 / 26$}

\section{RHEINGASSE (A) 7}

Anlass: Hausanschluss Wasser und Gas

\begin{tabular}{l} 
Zeitstellung: Mittelalter, Neuzeit \\
\hline Untersuchungsdauer: August 2020 \\
\hline Verantwortlich: Martin Allemann, Birgit Lißner \\
\hline Text: Marco Bernasconi, Martin Allemann
\end{tabular}

Nicht gemeldete Bauarbeiten für einen Hausanschluss in der Rheingasse führten zu einer kurzen Intervention seitens der Archäologischen Bodenforschung. Neben einer Dole, die auf dem Falknerplan (um 1860) verzeichnet ist, konnten im Profil auch intakte ältere Schichten festgestellt werden. Die unruhigen Straten zeigen u. a. eine stark mit Holzkohle und Ziegelbruch versetzte Schicht, darüber - ebenfalls mit Brandspuren - eine lehmige Struktur (ABB. 24). Sowohl die Datierung des Befunds wie auch die Frage, ob dieser Befund mit einem Brandereignis zusammenhängt, müssen vorderhand offen bleiben.

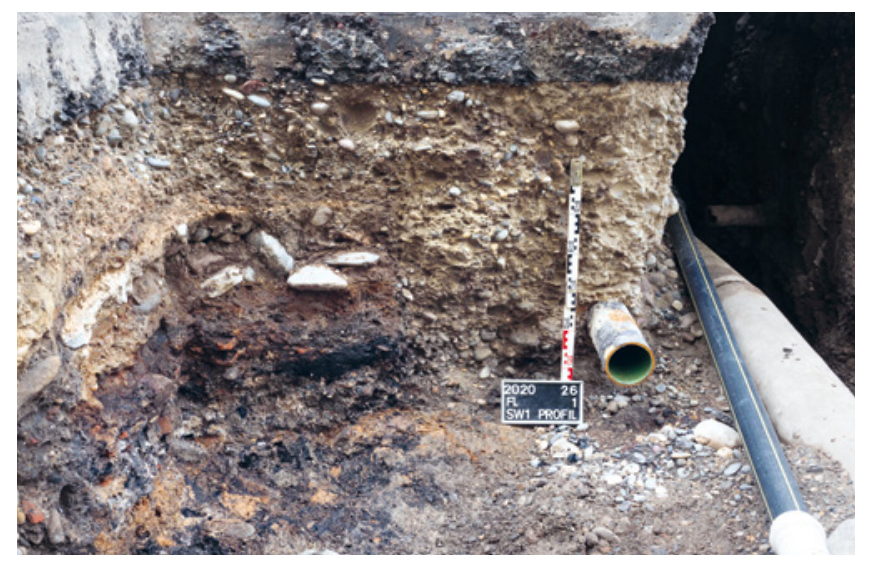

ABB. 24 Blick in Richtung Rhein: Nur wenige Zentimeter unter der modernen Asphaltoberfläche sind bereits Befunde erhalten, am auffälligsten die unten links freigelegte, stark kohlehaltige Schicht. Foto: Johann Savary.

\section{0/28}

\section{MÜHLENBERG (A) 2-10}

Anlass: Neubau eines Kanalisations-Absturzschachtes

\section{Zeitstellung: Neuzeit}

Untersuchungsdauer: August bis September 2020

Verantwortlich: Martin Allemann

Text: Martin Allemann

Am Mühlenberg kam 2020 ein fast hausgrosser neuer Absturzschacht für die Kanalisation mitten unter die Strasse zu liegen. Hier waren u. a. ältere Strassenverbindungen etwa zum Kloster St. Alban zu erwarten, aber auch Aufschlüsse zur Topografie und Dynamik des Hanges. Daher begleiteten wir die Baustelle und wurden früh in die Planung miteinbezogen. ${ }^{43}$

Bereits am ersten Aushubtag kamen Reste einer Kanalisation des 18./19. Jahrhunderts zum Vorschein. Die Dole war gegen den anstehenden Kies gemauert und hatte sich zwischen Trottoir und Leitungen erhalten. Sie war nicht vom tiefliegenden, begehbaren, überwölbten Typ, sondern relativ flach aus mörtelreichem Wackenmauerwerk auf monolithischen, aber sehr unterschiedlichen Bodenplatten aus Sandstein errichtet worden und mit ebensolchen Platten überdeckt (ABB. 25). Während beim Bau der Kanalisation im 19. Jahrhundert am nahegelegenen St. Alban-Graben Sandsteinspolien, u. a. mittelalterliche jüdische Grabsteine ${ }^{44}$, verwendet wurden, fanden sich hier unter den heterogenen Sandsteinquadern keine bestimmbaren Spolien.

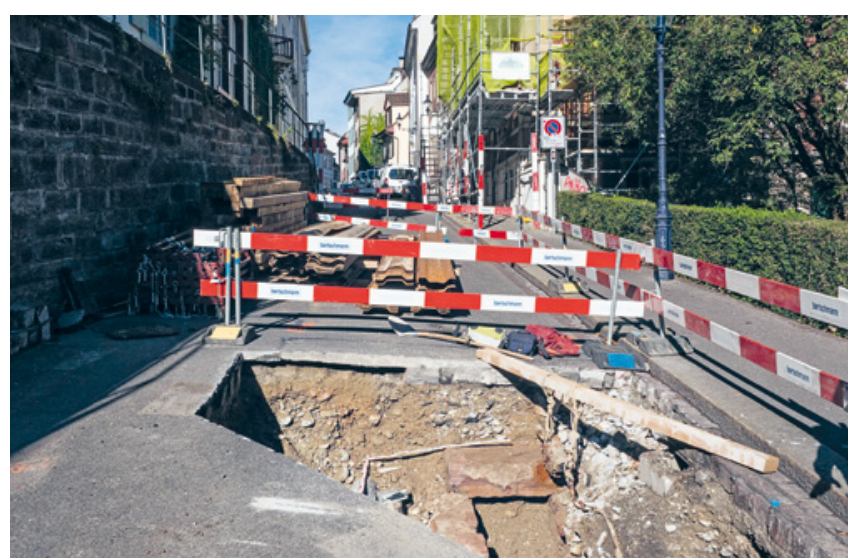

ABB. 25 Blick stadteinwärts, den Mühlenberg hinauf. Unten rechts, neben dem Trottoirrand, ist der aufgedeckte Dolenkanal sichtbar. Foto: Martin Allemann. 


\section{0/29}

\section{STEINENVORSTADT (A) 4}

Anlass: Fernwärme-Hausanschluss

Zeitstellung: Mittelalter, Neuzeit

Untersuchungsdauer: September 2020

Verantwortlich: Martin Allemann

Text: Martin Allemann

Unter dem Strassenbelag und teils auch noch in den Liegenschaften der Steinenvorstadt steckt trotz des modernen Aussehens der Strasse oft noch Substanz aus mehreren Jahrhunderten Siedlungsgeschichte. Diese ist geprägt von der Nachbarschaft zum Birsig und der Nähe zum Steinentor, das die Stadt mit dem landwirtschaftlich wichtigen Leimental verband. So war klar, dass wir den tiefen Graben für einen Fernwärme-Hausanschluss eng begleiten würden. ${ }^{45}$

Tatsächlich kamen unter zahlreichen modernen Leitungen in grosser Tiefe intakte Schichtreste zum Vorschein. Direkt an der Fassade des Hauses «Zum Schwarzen Widder» hatte sich eine Schichtfolge bis unter die heutige Vortreppe erhalten. Die Dokumentation des Profils gestaltete sich allerdings schwierig, weil die vielen bestehenden Leitungen den schmalen, tiefen Graben verdunkelten. Zudem reichen die spärlichen Funde, darunter etwa eine Wandscherbe von grautoniger Irdenware, für eine verlässliche absolute Datierung nicht aus. Die Besitzergeschichte des Hauses, in dem ab 1399 Weber und ab 1509 vor allem Bäcker ansässig waren, ist dagegen recht gut überliefert. ${ }^{46}$

\section{0/31}

\section{ST. ALBAN-GRABEN (A), PARKING KUNSTMUSEUM}

Anlass: Neubau eines Parkhauses

Zeitstellung: Römische Zeit, Mittelalter, Neuzeit

Untersuchungsdauer: September bis Dezember 2020

Verantwortlich: Martin Allemann, Birgit Lißner

Text: Martin Allemann

Schon seit 2018 beschäftigt uns der Aushub für ein unterirdisches Parking beim Kunstmuseum am St. Alban-Graben. ${ }^{47}$ Der oberirdische Aushub und die begleitenden Leitungsarbeiten konnten 2020 weitgehend abgeschlossen werden, seit Mitte 2020 läuft nun der Aushub im Gebäudeinnern unter den bereits betonierten Decken des Parkings. Die Arbeiten finden dementsprechend unter schwierigen Bedingungen statt: grosse Lärmbelastung, Hitze, hohe Luftfeuchtigkeit und Dokumentation bei Kunstlicht (ABB. 26).
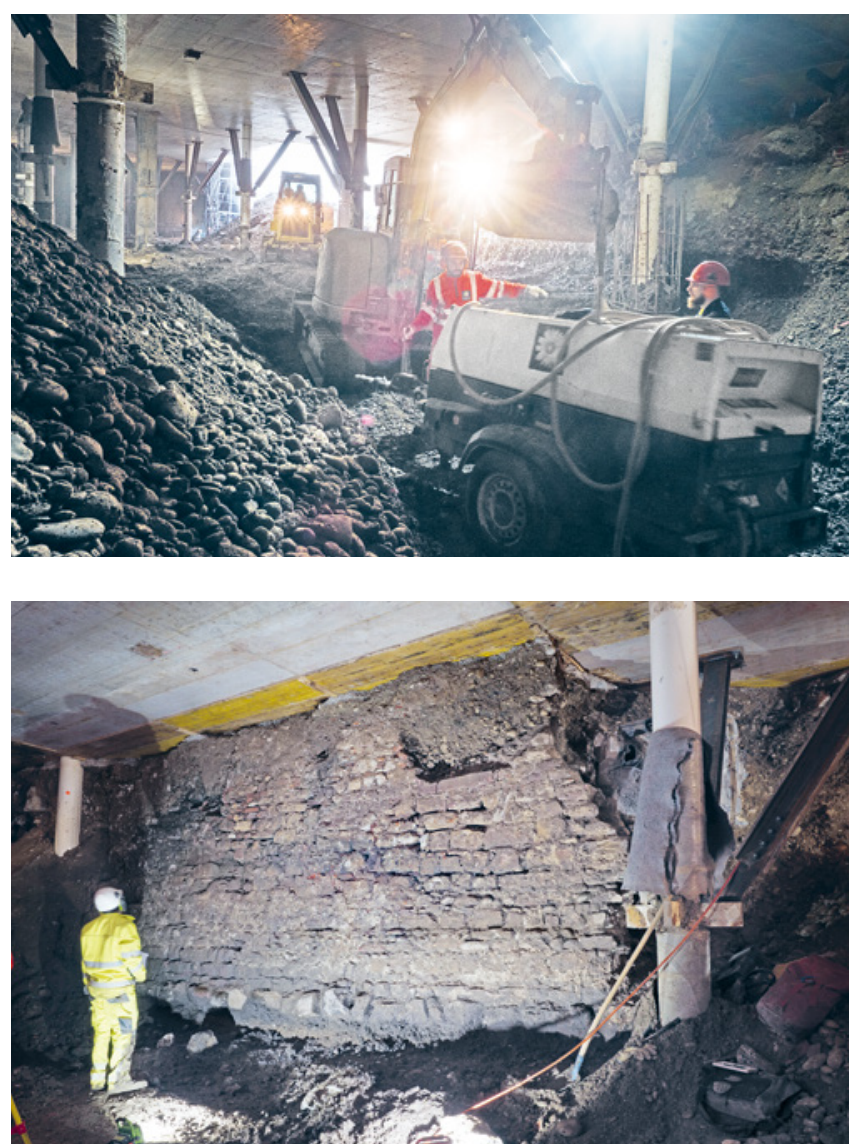

ABB. 26 Nur dank des Einsatzes von Kompressor und Druckluftlanze gelang es, die grossen Mauerflächen speditiv freizulegen. Foto: Birgit Lißner

ABB. 27 Oft waren grosse Flächen der Kontermauer erhalten, die zahlreiche Flickstellen aus unterschiedlichem Material aufwiesen. Die gesamte Dokumentation musste bei Kunstlicht erfolgen. Foto: Marco Worni. 
Zum Vorschein kamen wie erwartet die Innere Stadtmauer und ihre Kontermauer sowie diverse Einbauten im ehemaligen Stadtgraben, wobei grosse Mauerflächen nicht von Hand, sondern mit einer Druckluftlanze geputzt wurden. Während die Stadtmauer an diversen Stellen durch Kanalisationsbauten und vorgängig von oben erstellte Bohrungen gestört war, konnte die oft geflickte und sehr heterogene Kontermauer auf grosser Länge gefasst werden (ABB. 27). Verschiedene Befunde im Bereich des Stadtgrabens liessen sich aus Sicherheitsgründen dagegen nur einmessen und fotografisch dokumentieren, etwa eine quer zum Graben laufende Stützmauer des 18. Jahrhunderts, die errichtet wurde, als man den Graben in Etappen verfüllte. Ebenfalls aufgedeckt wurden zwei Pfeiler eines spätmittelalterlichen oder frühneuzeitlichen Aquädukts, ${ }^{48}$ der über den Stadtgraben führte, sowie zwei inschriftlich datierte Kanalisationsschächte von 1815. Während für die Abdeckung der höher liegenden Schächte mittelalterliche jüdische Grabsteine verwendet worden waren, ${ }^{49}$ kamen hier keine Spolien zum Vorschein: Offenbar hatte man damals nur für die anspruchsvolleren Überwölbungen auf diese masshaltigen Platten aus qualitativ hervorragendem Sandstein zurückgegriffen, für die tieferliegenden Bauteile aber deutlich heterogeneres Material bescheidenerer Qualität verbaut und kaum Mörtel verwendet.

Hinter der Kontermauer stiessen wir zudem auf die typischen Sedimente eines Gewässers, das schon in anderen Baubegleitungen in der Umgebung erfasst wurde und aus dem Spätglazial stammt. ${ }^{50}$

Die Auffüllung des Stadtgrabens war durchgängig in einen unteren, lehmigen und dunklen Teil sowie einen oberen, hellen, groben, locker-schuttigen Teil mit viel Baukeramik unterteilt. Die untere Verfüllung rührt von der Nutzung des Grabens als Garten ab dem 15. Jahrhundert ${ }^{51}$ und von dessen langsamer und stetiger organischer Auffüllung her, während die obere Einfüllung ein eindeutiges Zeugnis der planmässigen, von der Stadt geförderten Auffüllung des Inneren Stadtgrabens ab dem späten 18. Jahrhundert ist. Oftmals verwendete man dazu Abbruchschutt, was das Vorkommen einiger Steinspolien und Ofenkacheln zwischen den dominierenden Dachziegeln erklärt. Vereinzelt fanden sich auch Reste von Tafel- und braun glasiertem Kochgeschirr sowie hervorragend erhaltene, gelb glänzende Tierknochen.

Weitere im Frühjahr 2021 aufgedeckte Befunde, u. a. zwei tiefe spätrömische Schächte mit menschlichen und tierischen Knochen, werden im nächsten Jahresbericht ausführlich dargestellt.

\section{0/34}

\section{REBGASSE (A) 10-12}

Anlass: Fernwärme-Leitungsbau

Zeitstellung: Mittelalter, Neuzeit

Untersuchungsdauer: Oktober 2020

Verantwortlich: Martin Allemann

Text: Martin Allemann

Der Bau einer Fernwärmeleitung bedingte einen tiefen Leitungsgraben zwischen dem Vorplatz der Clarakirche und dem unterkellerten Gartenrestaurant im Gewerkschaftshaus. ${ }^{52}$ Diese Baustelle begleiteten wir in der Hoffnung, Reste der einst dichten mittelalterlichen Bebauung Kleinbasels und dazwischen auch Spuren vormittelalterlicher Besiedlung feststellen zu können.

Der Aushub erbrachte tatsächlich eine überraschend ungestört aussehende Schichtfolge von natürlichem, verlehmtem Hochflutsand im Nordosten des Grabens, eindeutige Siedlungsbefunde oder enger datierbare Funde liessen sich allerdings nicht fassen. Nach Südwesten, zum Claraplatz und der Rebgasse hin, war der Befund erwartungsgemäss von der grossen modernen Unterkellerung des Gewerkschaftshauses gekappt. Einzig die Nordwestecke des Kellers eines Vorgängerbaus war, mit mächtigen Bruchsteinmauern gegen die Erde gemauert, stehen geblieben. Wir konnten zwei Mauerstummel und den Mörtelboden des Kellers dokumentieren, wobei eine senkrechte vierkantige Aussparung im Mauerwerk vielleicht darauf hindeutet, dass der Keller nachträglich unter einem bestehenden, mit Holzbalken provisorisch abgestützten Gebäude errichtet wurde (АВв. 28).

Das Gebäude muss schon vor der Mitte des 19. Jahrhunderts abgebrochen worden sein, da es im Falknerplan (um 1860) nicht mehr verzeichnet ist.

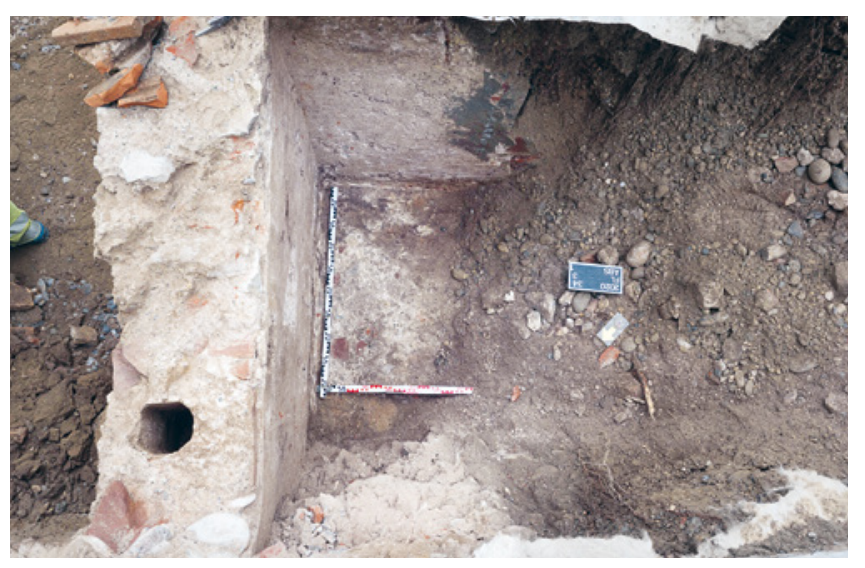

ABB. 28 Blick in die erhalten gebliebene verputzte Kellerecke. Links unten ist in der Mauer eine vierkantige Aussparung sichtbar, in der vermutlich einst ein Holzbalken als provisorische Stütze eine Unterfangung ermöglichte. Foto: Martin Allemann. 


\section{AUSSENBEZIRKE/ BETTINGEN/RIEHEN}

\section{8/5 \\ SPITALSTRASSE (A) SÜD}

Anlass: Koordinierter Werkleitungsbau

\section{Zeitstellung: Neuzeit}

Untersuchungsdauer: April 2018 bis Dezember 2020

Verantwortlich: Martin Allemann, Johann Savary

Text: Martin Allemann

Ab 2018 begleiteten wir mit sporadischen Kontrollgängen die Erneuerung der Werkleitungen und der Oberflächen in der Spitalstrasse. Es war damit zu rechnen, dass die Arbeiten Gräber des Laienfriedhofs der Predigerkirche tangieren oder Mauern von Gebäuden zum Vorschein bringen könnten, die im 19. Jahrhundert für den Bau der Spitalstrasse abgebrochen wurden. Um die Dokumentationen möglichst einheitlich zu halten, wurden zwei verschiedene Laufnummern vergeben, nämlich 2018/6 für diejenigen Eingriffe, die den eigentlichen Friedhof am Totentanz betrafen, und 2018/5 für die restlichen Bauarbeiten entlang der Strasse. Während die Eingriffe am Totentanz tatsächlich zahlreiche Gräber und Mauern von Bauten entlang der Predigerkirche zu Tage brachten, ${ }^{53}$ verlief die Begleitung der restlichen Bauarbeiten bis ins Jahr 2020 hinein weitgehend ergebnislos: Nur eine neuzeitliche Kanalisation im Predigergässlein und Hausfundamente des 19. Jahrhunderts in der Spitalstrasse wurden aufgedeckt, verblieben aber mehrheitlich im Boden.

\section{9/14}

\section{RIEHEN - INZLINGERSTRASSE 51 / HASELRAIN / KETTENACKERWEG 5}

Anlass: Sondagen zum Abbruch Schulgebäude und Neubau MFH

Zeitstellung: Bronzezeit

Untersuchungsdauer: Mai 2019

Verantwortlich: Susan Steiner, Marco Bernasconi

Text: Susan Steiner

Im August 2018 wurde bei einer Baggerbegleitung am Haselrain 20-24 ein Ausschnitt einer bronzezeitlichen Siedlung ausgegraben. ${ }^{54}$ Bereits während dieser Untersuchung kamen die Verantwortlichen eines auf der anderen Strassenseite geplanten Neubauprojektes an der Inzlingerstrasse 51 auf uns zu und erkundigten sich, ob auch hier mit archäologischen Resten zu rechnen sei. ${ }^{55}$

In dem rund $10000 \mathrm{~m}^{2}$ grossen Areal der ehemaligen Gehörlosen- und Sprachheilschule Riehen (GSR), das vom Heinrich Heusser-Weg, der Inzlingerstrasse, dem Haselrain und dem Kettenackerweg begrenzt wird, realisiert die Raiffeisenbank eine Überbauung mit 101 neuen Wohneinheiten. Da aufgrund der Ergebnisse der Ausgrabung am Haselrain eine grosse Wahrscheinlichkeit bestand, dass sich die Siedlung in westlicher Richtung und auch zur Inzlingerstrasse weiterzog, wurden vorgängig Baggersondagen durchgeführt. Zum Zeitpunkt, als wir das Gelände punktuell archäologisch untersuchten, hatte die Sprachheilschule ihre neuen Räumlichkeiten in Aesch (BL) bereits bezogen und eine Riehener Schule nutzte das Areal vorübergehend. Wir legten daher vier Bereiche fest, die für einen Bagger zugänglich waren, sich weit voneinander entfernt befanden und den laufenden Schulbetrieb möglichst wenig störten (ABB. 29).

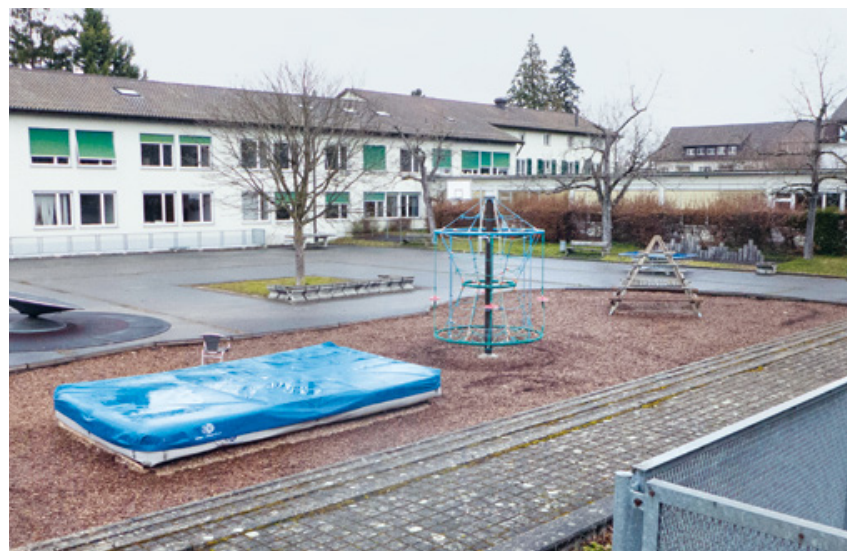

ABB. 29 Auch unter dem grossen Pausenplatz der Gehörlosen- und Sprachheilschule in Riehen lagen Reste einer über 3000 Jahre alten Siedlung verborgen. Foto: Susan Steiner. 
Zunächst wurde im Norden ein kleines Rasenstück freigebaggert. ${ }^{56}$ Unter dem Gras kam eine Humusschicht und darunter gelber Lösslehm zu Tage. Ab rund 1,30 m Tiefe konnten erste Keramikscherben geborgen werden, die bezüglich Tonqualität und Brennfarbe vergleichbar mit denjenigen der Ausgrabung Haselrain auf der gegenüberliegenden Strassenseite waren. Die beiden Sondagen im grossen Pausenhof enthielten bereits $70 \mathrm{~cm}$ unterhalb des Teerbelags weitere bronzezeitliche Keramikfragmente und Holzkohlespuren.

Die vierte Sondage wurde im Süden des Areals auf dem ehemaligen Parkplatz nahe der Inzlingerstrasse erstellt. Hier war die alte Oberfläche - möglicherweise im Zusammenhang mit dem Bau der Turnhalle der GSR - gekappt und mit Kies aufgefüllt worden. Da man beim Bau der Turnhalle 1988 einen Feuerstein und zwei Keramikscherben in der Baugrube entdeckt hatte, ${ }^{57}$ kann davon ausgegangen werden, dass auch hier einst ein bronzezeitlicher Horizont vorhanden war.

Die Sondagen ergaben eindeutige Siedlungsspuren, so dass eine dem Bauprojekt vorgängige, grossflächige Untersuchung des Areals zwingend war. Die reichhaltigen Funde und Befunde dieser Untersuchung werden in der aktuellen Fundchronik unter der Laufnummer 2020/6 (S. 65-67) sowie mit Fokus auf die Bronzezeit zusammen mit den Ergebnissen der Ausgrabung Haselrain 20-24 ausführlicher im wissenschaftlichen Bericht des vorliegenden Jahresberichtes (S. 119-151) vorgestellt.

\section{9/24}

\section{EISENBAHNWEG 6, 22, 24}

Anlass: Aushub unterirdische Autoeinstellhalle zur Wohnüberbauung

Zeitstellung: Bronzezeit, Frühmittelalter

Untersuchungsdauer: September 2019 bis März 2020

Verantwortlich: Martin Allemann, Benedikt Wyss, Michael Ketzler

Text: Martin Allemann

Den Aushub für eine unterirdische Autoeinstellhalle auf einer grossen, unüberbauten Parzelle zwischen dem Eisenbahnweg und der Grenzacherstrasse begleiteten wir eng. ${ }^{58}$ Zum einen liegt hier eine der letzten freien grossen Parzellen des rechten Rheinufers oberhalb der Kleinbasler Altstadt, zum andern sind seit rund 100 Jahren Grabfunde aus der näheren Umgebung bekannt, teils aus der Eisenzeit, ${ }^{59}$ vor allem aber das frühmittelalterliche Gräberfeld Gotterbarmweg. ${ }^{60}$ Dessen Schwerpunkt liegt zwar in einigem Abstand jenseits des Brückenkopfs der Schwarzwaldbrücke, doch war nicht auszuschliessen, dennoch auf vereinzelte, randlich gelegene Gräber zu stossen. Zudem hofften wir, auf dem flachen, hochwasserfreien Areal möglicherweise noch Reste der zum Friedhof gehörigen Siedlung fassen zu können. Die Lage der Parzelle versprach eine gute Befunderhaltung, da nur in ihrem Ostteil bis in die 1960er Jahre eine unterkellerte Fabrik gestanden hatte. Die moderne Überbauung der restlichen Fläche - Familiengärten und zuletzt Tennisplätze - hatte voraussichtlich nur seicht in den Boden eingegriffen.

Bei den im Herbst 2019 durchgeführten Sondagen kamen einzelne prähistorisch anmutende Scherben zum $\rightarrow$

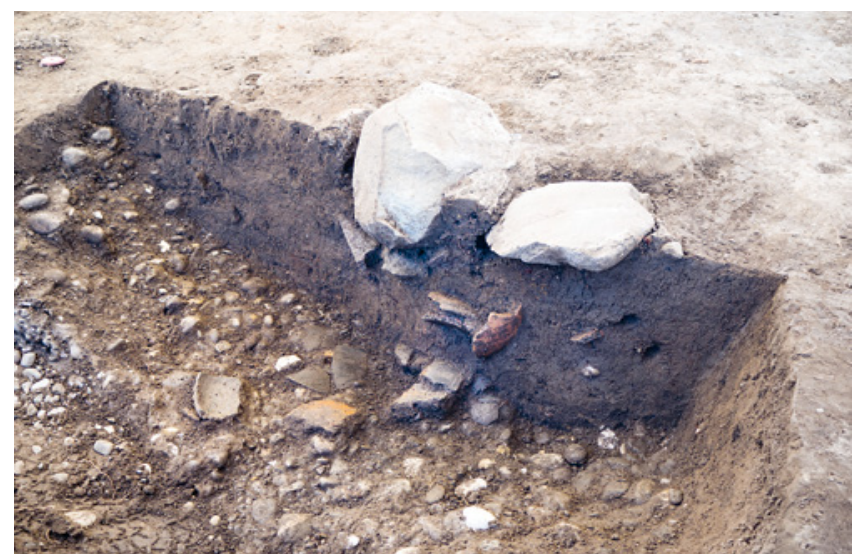

ABB. 30 Blick auf die mittig geschnittene und ausgenommene Grube; einige grössere Keramikscherben liegen noch auf dem Grund. Foto: Martin Allemann. 
Vorschein, weshalb wir auch den Aushub begleiteten. Das sorgfältige Abbaggern der modernen Planien in der Südwestecke deckte erste Befunde auf: Im ansonsten völlig steinfreien Auenlehm zeigten sich grosse, teils in steilen Winkeln liegende Gerölle, die von anderswo eingebracht worden sein müssen. Beim Freilegen von Hand fielen zudem hochkant stehende, handgeformte Keramikscherben auf. Ihre starke Magerung und stark variierenden Brandfarben legten allerdings eher eine prähistorische als eine frühmittelalterliche Datierung nahe. Ihre Lage mit steilem, konzentrischem Gefälle um die Gerölle herum sowie ihre grossteilige Erhaltung zeigten, dass es sich um eine Grubenverfüllung handeln musste. Die mit dem rundherum anstehenden Auenlehm verfüllte Grube war jedoch farblich nur schwer zu erkennen. Erst beim Handabtrag gelang es, die Grube, die neben der Keramik nur wenige Knochen enthielt, genauer zu fassen und mehrfach zu schneiden (ABB. 30). Leider waren alle zugehörigen Gehniveaus durch die modernen Kappungen beseitigt. Erfreulicher war hingegen, dass die Keramik so grossteilig erhalten geblieben ist (ABB. 31), dass sich teils ganze Profile bergen liessen. Typische Verzierungen datieren die Gefässe in die Spätbronzezeit (Hallstatt B, ca. 1060-800 v. Chr.). ${ }^{61}$ Aus dieser Epoche sind Siedlungsspuren am Rheinknie bislang eher selten, so dass der Neufund trotz seiner bescheidenen Ausmasse ein wichtiger Punkt auf der Fundstellenkarte ist.

Hinweise auf das frühmittelalterliche Gräberfeld oder eine dazugehörige Siedlung konnten keine gefasst werden. Aus dem Frühmittelalter stammt lediglich die Randscherbe eines Knickwandtopfs aus sogenannter Terra Nigra mit Rollstempeldekor.

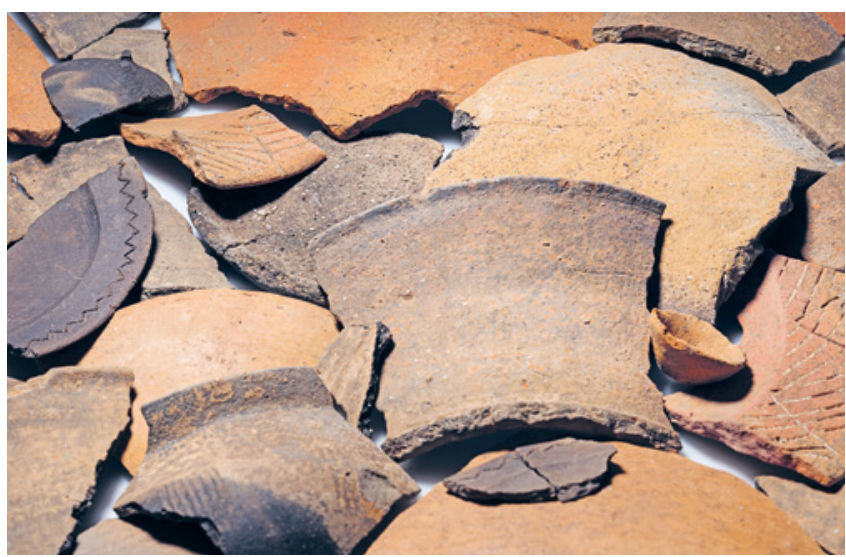

ABB. 31 Übersicht der grösseren spätbronzezeitlichen Keramikscherben. Foto: Philippe Saurbeck.

\section{9/26}

\section{RIEHEN - BURGSTRASSE 46 / REBENSTRASSE 39}

Anlass: Abbruch und Neubau Mehrfamilienhaus mit Autotiefgarage

Zeitstellung: Bronzezeit

Untersuchungsdauer: August 2019 bis März 2020

Verantwortlich: Susan Steiner, Birgit Lißner

Text: Susan Steiner

Im Jahre 1907 kamen bei Kanalisationsarbeiten unter der Burgstrasse in Riehen zwei besondere Bronzefunde zum Vorschein: ein Schwert und eine Lanzenspitze. Die ursprünglich $67 \mathrm{~cm}$ lange Schwertklinge war ungefähr in der Mitte so stark zusammengebogen worden, dass sie dabei in drei Teile zerbrach. Sie wird anhand ihrer Form in die Stufe Bz D datiert und ist damit zwischen 3300 und 3200 Jahre alt. Auch die Lanzenspitze war leicht verbogen, es fehlte die Spitze und sie war an einer Stelle angebrochen. Die genauen Fundumstände, etwa ob diese Waffen in einer Eintiefung lagen, sind nicht überliefert..$^{62}$

In der archäologischen Forschung wurde kontrovers diskutiert, ob es sich bei den beiden Funden um Beigaben eines Grabes handelt oder ob hier unbrauchbar gemachte Waffen deponiert worden waren. Die starke Deformation des Schwertes spricht für eine rituelle Niederlegung, wie sie in der Spätbronzezeit vielfach belegt sind. ${ }^{63}$ Möglicherweise handelt es sich um eine Niederlegung in einem Gewässer, denn die Waffen wurden im Schwemmkegel des Bettingerbaches geborgen.

2019 wurde 150 m südwestlich der Fundstelle der Aushub für ein Mehrfamilienhaus ausgebaggert. Die Baugrube war bereits ausgehoben, als wir vor Ort eintrafen. Hingegen konnten wir die Baggerarbeiten zur Rückversetzung der östlichen und nördlichen Baugrubenwand begleiten (ABB. 32). ${ }^{64}$ Nahe der Burgstrasse fiel eine bis zu $20 \mathrm{~cm}$ mächtige, sandige Lehmschicht auf, die einige auch kantige Kiesel und einzelne prähistorische Scherben enthielt (ABB. 33). Diese Fundschicht war ein Horizont mit Bebauungsresten, denn unterhalb dieser Kieselschicht wurden rund ein Dutzend Eintiefungen dokumentiert, die von Gruben, Pfosten oder schmalen Gräben stammen. Diese Befunde enthielten keine Funde, aber mög- 
lichweise handelt es sich um Gebäudereste oder Teile einer Installation, die zur Abgrenzung oder Umleitung des nahen Bettingerbaches oder zum Schutz einer Siedlungsstelle diente.

Leider befand sich unter den Funden aus der Kieselschicht weder ein Randstück noch ein verziertes Fragment. Die Scherben sind jedoch mit den bronzezeitlichen Keramikfragmenten der Fundstelle Riehen-Haselrain durchaus vergleichbar. ${ }^{65}$ Für eine genauere zeitliche Einordnung müssten jedoch in kommenden Bodeneingriffen rund um die Burgstrasse datierbare Scherben oder Bronzefunde aufgedeckt werden. Zukünftige Funde und Befunde werden möglicherweise auch Hinweise darauf geben können, warum die rituell zerstörten Waffen am nordwestlichen Ende der Burgstrasse deponiert wurden.
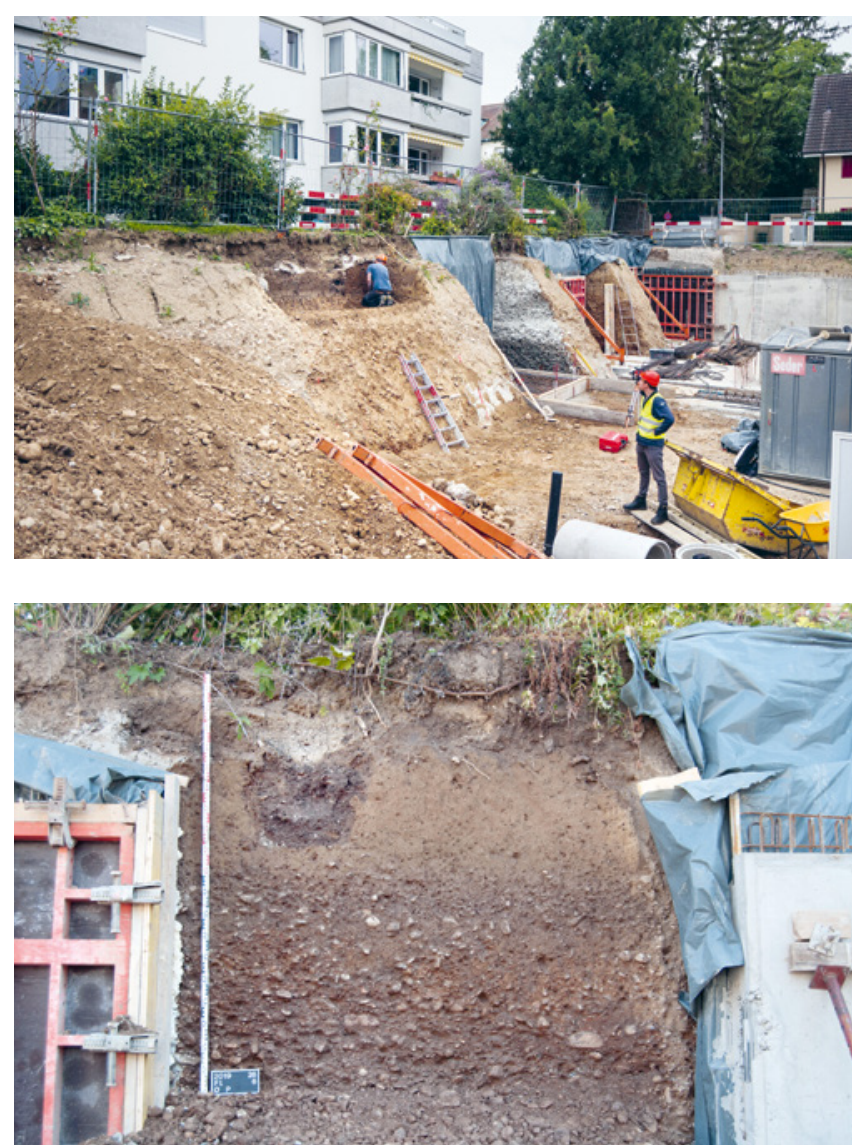

ABB. 32 Während des laufenden Baubetriebes putzt ein Mitarbeiter der Archäologischen Bodenforschung den oberen Bereich des Baugrubenprofils. Foto: Fabian Bubendorf.

ABB. 33 Die Fundschicht, die einige Kiesel und vereinzelt prähistorische Scherben enthielt, ist nur bei genauem Hinsehen erkennbar: sie hebt sich leicht dunkler von den natürlichen Schichten des Wiesenkieses und der eingeschwemmten Lösslehmabdeckung ab. Foto: Fabian Bubendorf.

\section{9/37}

\section{RIEHEN - HELLRING 41 (WENKENPARK)}

Anlass: Erdwärmenutzung mit Erdkörben

\section{Zeitstellung: Neuzeit}

Verantwortlich: Simon Graber, Michael Ketzler

Text: Simon Graber

Die historische Parkanlage des Wenkenhofs in Riehen ist archäologisch weitgehend unbekanntes Terrain. Umso wichtiger war es, die grossangelegten Bodeneingriffe für die Heizung der Reithalle zu begleiten. Im Rahmen des Bauprojektes wurden neun ca. $100 \mathrm{~m}$ lange Gräben mit einer Breite und Tiefe von einem Meter angelegt (ABB. 34), auf deren Sohle Löcher zur Versenkung von Erdkörben gebohrt wurden.

Seit man im Jahr 1913, ca. 200 m von den heutigen Eingriffen entfernt, ein mutmassliches Grubenhaus mit frühmittelalterlicher Keramik entdeckt hatte, ${ }^{66}$ wird auf dem Areal des Wenkenhofs jene frühmittelalterliche Siedlung postuliert, die im Jahr 751 als «Wahinkofen» erstmals eine schriftliche Erwähnung fand. Zudem sind immer wieder Einzelfunde aus neolithischer bis spätmittelalterlicher Zeit zum Vorschein gekommen. Die Ergebnisse der Baubegleitung waren allerdings ernüchternd. Es konnten lediglich vereinzelte neuzeitliche Funde geborgen werden, ansonsten stand Lösslehm an.

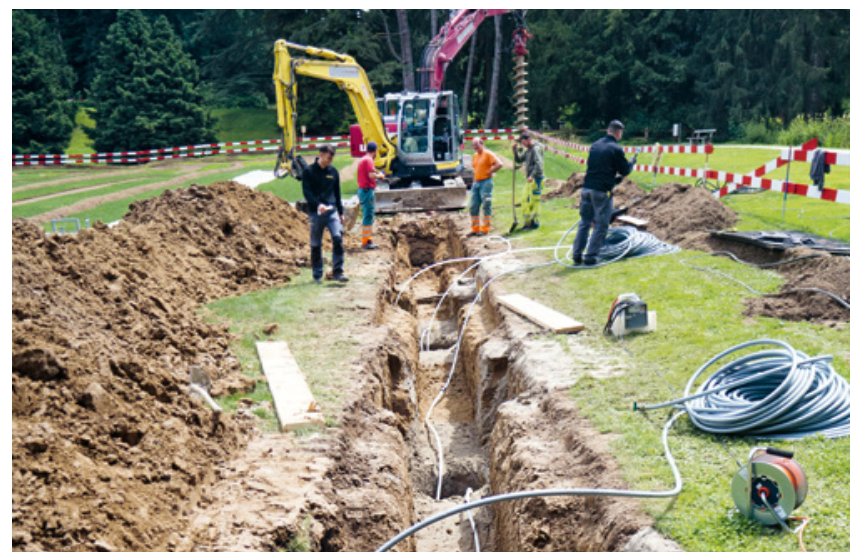

ABB. 34 Für die Erdwärmenutzung wurden im Wenkenpark insgesamt neun ca. 100 m lange Gräben mit Löchern zur Versenkung von Erdkörben angelegt. Foto: Michael Ketzler. 


\section{9/38}

\section{RIEHEN - OBERDORFSTRASSE 43}

Anlass: Abbruch und Neubau Wohnhaus

Zeitstellung: Geologie, Neuzeit

Untersuchungsdauer: Dezember 2019 bis Januar 2020

Verantwortlich: Susan Steiner, Michael Ketzler

Text: Susan Steiner

Die Oberdorfstrasse folgt dem ehemaligen Lauf des Aubachs, der in mehreren Quellen in und unterhalb von Inzlingen (D) entspringt. Durch das Aufbringen und Abtragen von Material hat er die Oberfläche und Form des Autals und auch der Oberdorfstrasse geprägt. Der Bach gehörte zum Riehener Strassenbild, bis er zwischen 1923 und 1932 nach und nach auf der ganzen Länge der Oberdorfstrasse eingedolt wurde. ${ }^{67}$

Auf der Baustelle an der Oberdorfstrasse 43 konnten an Baugrubenwänden die Ablagerungen älterer Verläufe des Aubachs beobachtet werden: Grobe Schotter wechseln mit feinkörnigen Überflutungssedimenten ab. Stellenweise ist Kalktuff und in einzelnen Schichten sind Holzkohlefragmente vorhanden. Diese ersten Beobachtungen zeigen eine hohe fluviale Dynamik und eine intensive Landnutzung im Einzugsgebiet des Aubachs (ABB. 35). ${ }^{68}$

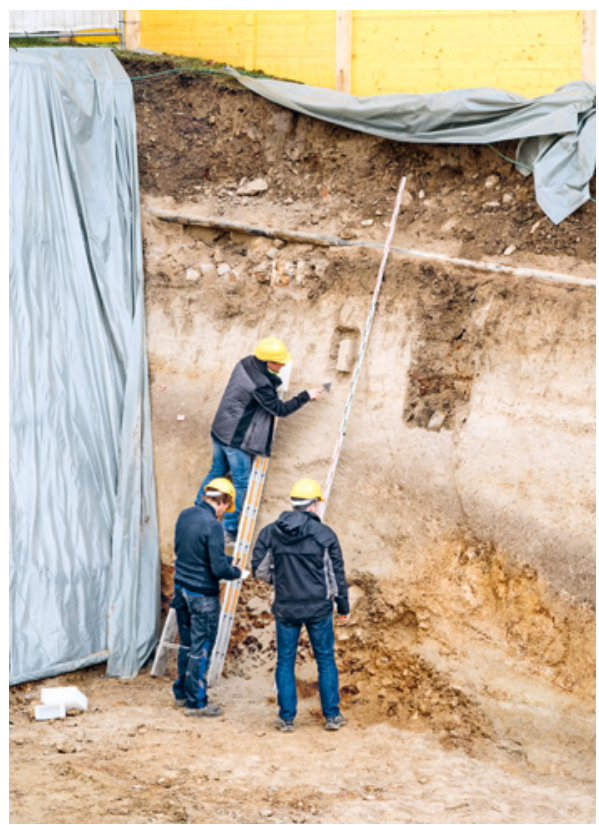

ABB. 35 Die kiesreichen, siltigen und stellenweise tuffartigen Ablagerungen des Aubaches werden dokumentiert und mikromorphologisch beprobt, um dessen Aktivitäten und Nutzungen über einen längeren Zeitraum zu verstehen. Foto: Michael Ketzler.
Spätestens im Mittelalter waren die Ortschaften Weil und Inzlingen (D) über die Oberdorfstrasse in Riehen miteinander verbunden. Eine wichtige Wegkreuzung befindet sich am westlichen Ende der Oberdorfstrasse: die Verbindung zwischen Basel und Lörrach, die weiter ins Wiesental führt. Mit diesem Verkehrsknotenpunkt wird ein alter Dorfkern von Riehen gefasst. ${ }^{69}$ Die Häuser an der Oberdorfstrasse lassen sich anhand der schriftlichen Quellen teilweise bis ins 16. Jahrhundert zurückverfolgen und einige der heute ersetzten Häuser dürften noch älter gewesen sein. ${ }^{70}$ Als das Haus an der Oberdorfstrasse 43 abgerissen wurde, fanden wir darunter keine älteren Fundamente, aber Scherben eines reduzierend gebrannten Gefässdeckels, der typologisch in die zweite Hälfte des 15. oder die erste Hälfte des 16. Jahrhunderts gehört. Der leicht gewölbte Deckel mit vollständig erhaltenem Knauf ist etwa zur Hälfte erhalten (ABB. 36). ${ }^{71}$

Da die Scherben zusammen mit einigen glasierten und damit jüngeren Keramikfragmenten in der Baugrubenverfüllung der nördlichen Kellerwand zum Vorschein kamen, stehen sie nicht in Zusammenhang mit dem nun abgerissenen Haus, sondern mit einem Vorgängerbau oder einem Nachbargebäude. Dabei könnte es sich um die erste an diesem Ort erwähnte Liegenschaft handeln, von der es in einer Quelle von 1569 heisst: «stosst vornen auff den bach». Diese «hoffstat» befand sich damals zusammen mit dem umgebenden Land im Besitz des Domstifts Basel. ${ }^{72}$

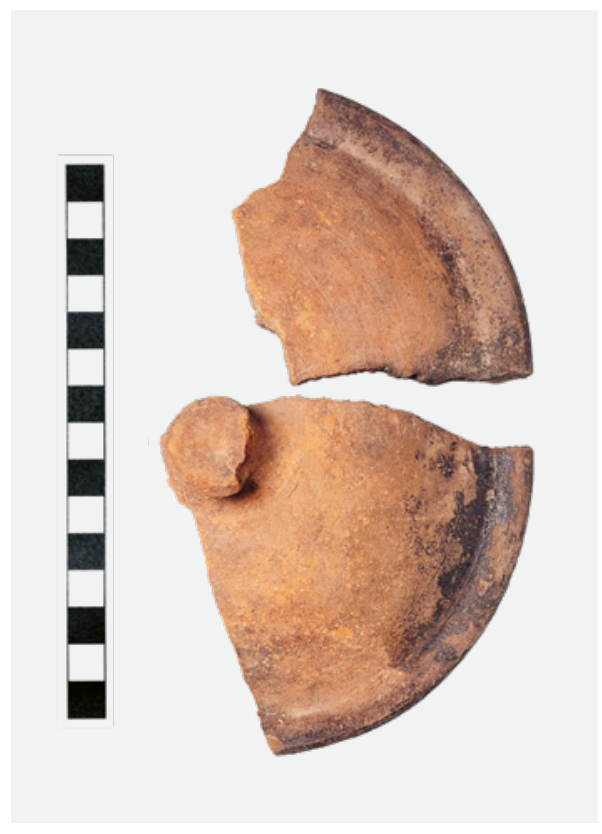

ABB. 36 Dieser Gefässdeckel aus dem 15./16. Jahrhundert wurde in der Hinterfüllung einer Kellerwand der ehemaligen Liegenschaft an der Oberdorfstrasse 43 in Riehen gefunden. Foto: Philippe Saurbeck. 


\section{0/1}

\section{RIEHEN - ARTELWEG}

Anlass: Oberflächenfunde vom frisch gepflügten Acker

\begin{tabular}{l} 
Zeitstellung: Römische Zeit, Mittelalter, Neuzeit \\
\hline Untersuchungsdauer: Herbst 2019 bis Februar 2020 \\
Verantwortlich: Ingmar M. Braun, Martin Allemann \\
\hline Text: Martin Allemann
\end{tabular}

Susanne Rudolf aus Riehen war bei Spaziergängen im Zeitraum zwischen Herbst 2019 und Februar 2020 eine Konzentration von Keramikfragmenten in der Flur Artelacker östlich des Riehener Dorfkerns aufgefallen. ${ }^{73}$ Sie wandte sich, da schweizweit herrenlose Bodenfunde dem Kanton gehören, an die Archäologische Bodenforschung, um ihre Funde abzugeben. ${ }^{74}$ Rasch wurde klar, dass es sich bei den Funden nicht nur um die «übliche» frühneuzeitliche glasierte Irdenware handelt, die flächig auf Riehener Äckern vorkommt, sondern dass im Umkreis von wenigen Metern Durchmesser, zusammen mit vielen Fragmenten römischer Leistenziegel, auch ein reichhaltiges Ensemble römischer Gefässkeramik vor allem des 2. bis 3. Jahrhunderts ${ }^{75}$ zum Vorschein gekommen war (ABB. 37). Das konzentrierte Vorkommen von Bau- und Gefässkeramik an der gleichen Stelle zeigt, dass es sich nicht bloss um verlagertes Fundmaterial, sondern um Reste einer antiken Siedlung handelt. Bereits 1970 fand der damalige Gymnasiast Guido Helmig im Artelacker römische Keramik, damals aber deutlich weiter hangaufwärts, östlich des Feldwegs. ${ }^{76}$ Die römische Ansiedlung dürfte also einst eine stattliche Ausdehnung gehabt haben und vielleicht doch besser erhalten sein, als die Flurnamen befürchten lassen: «Im Artelacker» (aus «Margelacker») und «In der Kalkdarre» legen nahe, dass hier im Mittelalter oder in der Neuzeit, an einem Ort, wo Kalkstein natürlich erst in grösserer Tiefe ansteht, eher die Bausteine einer römischen Villa zu «Margel» (Mergell gedarrt, d. h. verbrannt wurden. ${ }^{77}$

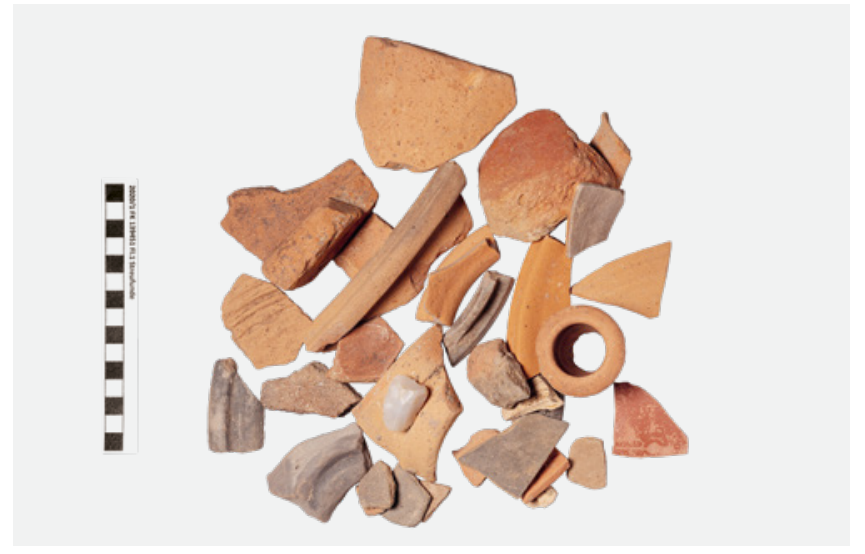

ABB. 37 Ensemble von römischen, mittelalterlichen und neuzeitlichen Lesefunden vom Artelacker. Foto: Philippe Saurbeck.

\section{$2020 / 2$}

\section{RIEHEN - HIRTENWEG 14, 22, 24, 28}

Anlass: Abbruch und Neubau von Mehrfamilienhäusern

Zeitstellung: Geologie

Untersuchungsdauer: Januar bis Juni 2020

Verantwortlich: Martin Allemann

Text: Martin Allemann

Seit langem ist die römische Ansiedlung - vermutlich eine sehr grosse villa rustica - beim ehemaligen Landauerhof bekannt. Beim Bau des Friedhofs Hörnli in den 1920/30er Jahren wurden grosse Teile davon ausgegraben und dokumentiert. Damals wurden die Befunde entfernt, und eine Baubegleitung im Jahr 2019 zeigte, dass sich unter der Hörnliallee keinerlei Überreste dieser einst bedeutenden Siedlung erhalten haben. ${ }^{78}$

2020 begleiteten wir am Hirtenweg den Ersatz von Wohnungen aus den 1950er Jahren, weil das Bauvorhaben eine Parzelle am Rand des Villenareals betraf, die von Geländekappungen beim Friedhofsbau weitgehend verschont geblieben war. Eine geomagnetische Prospektion, die die Bauherrschaft auf unsere Empfehlung hin veranlasste, ${ }^{79}$ zeigte lediglich flächige, unregelmässige Bodeneingriffe, jedoch keine Mauerbefunde. Der Aushub brachte denn auch ausser geologischen Schichtgrenzen und alten Eingriffen der bestehenden Bebauung nichts zu Tage, weshalb wir die Baubegleitung rasch einstellten. 


\section{$2020 / 4$}

\section{ST. ALBAN-ANLAGE 26-38}

Anlass: Abbruch und Neubau Helvetia-Campus

\section{Zeitstellung: Neuzeit}

Untersuchungsdauer: Februar bis März 2020

Verantwortlich: Sven Billo, Simon Graber

Text: Sven Billo

Beim Aushub der Baugrube für den Neubau des HelvetiaCampus an der St. Alban-Anlage kam unter dem Kellerfundament der Vorgängerbauten, rund $9 \mathrm{~m}$ unter dem heutigen Strassenniveau, der Rest eines Sodbrunnens zum Vorschein. ${ }^{80}$ Die Wände des Brunnens bestehen aus ca. $70 \mathrm{~cm}$ langen, bearbeiteten roten Sandsteinblöcken (AвB. 38). Der Brunnen wurde rund 4,30 m tief mit dem Bagger abgetragen. Damit war die Grubensohle für den Neubau, aber nicht das Ende des Sodbrunnens erreicht. Im feuchten Sediment erhaltene Funde, die es erlauben würden, die Datierung zu präzisieren, blieben daher aus. Einzig das verbogene und verrostete Blatt einer modernen Schaufel zeugt von der mühseligen Verfüllung des Brunnenschachts.

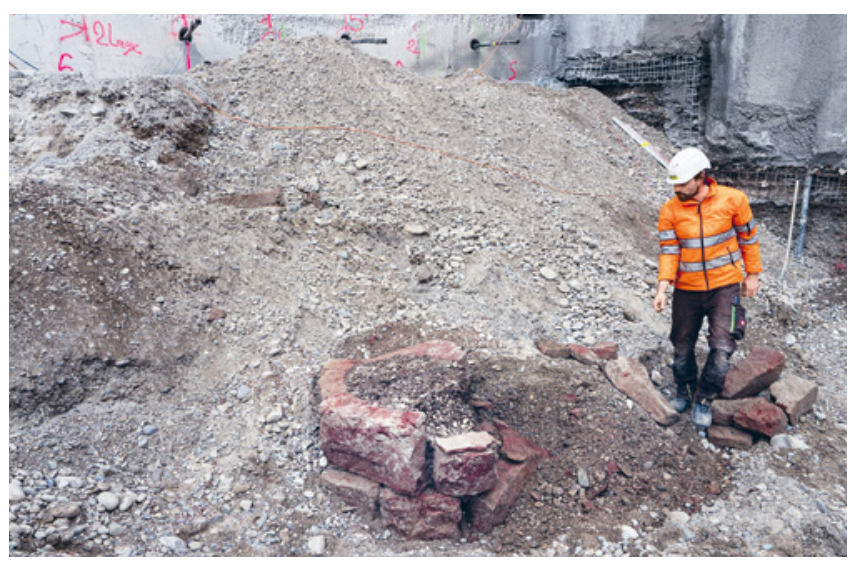

ABB. 38 Der in der Baugrube des Helvetia-Campus freigelegte Sodbrunnen, mit den länglichen roten Sandsteinblöcken. Foto: Sven Billo.

\section{0/5}

\section{BURGWEG - SCHAFFHAUSERRHEINWEG (A)}

Anlass: Grundwasserrückführungsleitung für Wärmepumpe

\begin{tabular}{l}
\hline Zeitstellung: Geologie \\
\hline Untersuchungsdauer: März 2020 \\
\hline Verantwortlich: Martin Allemann \\
\hline Text: Martin Allemann \\
\hline
\end{tabular}

Östlich des Burgwegs liegt eine wenig bekannte Fundstelle aus der Spätantike und dem Frühmittelalter. Als man im 19. Jahrhundert das rechte Ufer flussaufwärts des Rheinknies überbaute, stiess man auf «altes Gemäuer». ${ }^{81}$ Auch mittelalterliche Flurnamen deuten darauf hin, dass hier einst Gebäude standen. ${ }^{82}$ Dazu kamen später Grabfunde, grössere Erdbefestigungen und Informationen, die der Basler Jurist und Archäologe Karl Stehlin (1859-1934) im Gespräch mit Anwohnern zusammentrug. ${ }^{83}$ Es ist daher nicht auszuschliessen, dass hier einst - analog zum sogenannten Munimentum im Bereich Utengasse/Wettsteinplatz - ein spätantiker Wehrbau stand, um den herum man im Frühmittelalter die Toten bestattete. ${ }^{84}$

Geologische Profile und alte Landkarten deuten an, dass das Geviert Burgweg - Alemannengasse - Fischerweg einst ein östlich und westlich von buchtartigen Einschnitten begrenztes Plateau bildete. Um Aufschluss zu diesem Uferverlauf zu erhalten, begleiteten wir den Aushub einer Leitung zum Rhein, längs durch den weniger überbauten Abschnitt des Burgwegs. ${ }^{85}$ Wider Erwarten ergaben sich keine Einblicke in die Uferdynamik: Moderner schuttiger Kies lag direkt auf anstehendem Schotter, ohne dass etwa Verlandungssedimente, alte Bodenbildungen oder Gräben sichtbar gewesen wären. Auch Streufunde im Zusammenhang einer allfälligen antiken Bebauung oder frühmittelalterlicher Gräber blieben aus. 


\section{$2020 / 6$}

\section{RIEHEN - INZLINGERSTRASSE 51 / HASELRAIN / KETTENACKERWEG 5}

Anlass: Neubau Mehrfamilienhaus

Zeitstellung: Bronzezeit, Latènezeit, Römische Zeit, Neuzeit

Untersuchungsdauer: April bis Dezember 2020

Verantwortlich: Susan Steiner, Simon Graber, Corinne Hodel, Benedikt Wyss Text: Corinne Hodel

Auf dem rund $10000 \mathrm{~m}^{2}$ grossen Areal der ehemaligen Gehörlosen- und Sprachheilschule Riehen (GSR) erstellt die Raiffeisenbank eine Überbauung mit 101 neuen Wohneinheiten. Da bei der Ausgrabung in der benachbarten Parzelle Haselrain 20-24 im August 2018 Reste einer bronzezeitlichen Siedlung zu Tage kamen, ${ }^{86}$ waren auch hier bronzezeitliche Befunde zu erwarten. Die vorgängig durchgeführten Sondagen brachten denn auch entsprechende Hinweise. ${ }^{87}$

Die zahlreichen bei der aktuellen Ausgrabung zum Vorschein gekommenen bronzezeitlichen Funde und Befunde werden im wissenschaftlichen Bericht detaillierter vorgestellt (S. 119-151). Daher kommen im Folgenden nur die jünger datierenden Funde und Befunde zur Sprache.

Bei einem Maschinenabtrag im hellbraun-rötlichen Mineralboden zeichnete sich auffällig deutlich eine grosse Eintiefung $a b$, deren dunkelbraune Verfüllung sowie Tierknochen und einige Eisenfragmente dafür sprechen, dass es sich um einen nachbronzezeitlichen Befund handelt. ${ }^{88}$ Die Grube ist ungefähr rechteckig, hat abgerundete Ecken und misst bei einer Tiefe von knapp $60 \mathrm{~cm}$ ca. 3,5 × 2 m (ABB. 39, ABB. 41). Auf drei Seiten fallen die Grubenwände relativ steil $a b$, während sich im Nordwesten eine flache, rampenähnliche Zone abzeichnet (ABB. 41), die vielleicht als Abgang interpretiert werden kann. Ganz im Osten zeigt sich ein kleiner, in einem Winkel von $45^{\circ}$ ansteigender Fortsatz (АВB. 41, 13).

Solche grossen Gruben mit je einer Pfostenstellung an den Schmalseiten werden als «Grubenhäuser» angesprochen, wobei die beiden Pfosten als Teil einer Überdachung mit Firstpfosten interpretiert werden. ${ }^{89}$ Auf dem Grubenboden liessen sich auf der Achse der beiden Pfosten eine kleinere Grube unbekannter Funktion (ABB. 41,5) und eine kreisrunde, nur noch wenige Zentimeter tiefe Struktur fassen (авв. 41, 6). Ihre auffällige Verfüllung aus hellbraunem Lehm mit orangefarbenen Brandlehmbrocken und Grobkieseln, Holzkohle und Hammerschlag weist auf eine Schmiedegrube hin. Es handelt sich dabei möglicherweise um die letzten Reste einer Esse oder um deren Abraum. ${ }^{90}$ Die aufgrund der Pfostenstellungen zu postulierende Überdachung schützte vor dem Wetter und verdunkelte die Werkgrube. Dies erlaubte es dem Schmied, die Farbe des Werkstücks und damit die Farbe und den Härtegrad des Eisens besser beurteilen zu können.

Flecken von ebenfalls hellbraunem und grauem Lehm könnten letzte Reste von Böden sein. Die Untersuchung der entnommenen Mikromorphologie- und Sedimentproben wird dazu sicherlich weitere Hinweise zur Nutzung der Grube liefern können. Weitere kleinere Strukturen (ABB. 41, 8-12) dürften ebenfalls zum Befund rund um die grosse Grube gehören. Jedenfalls durchschlagen sie die bronzezeitlichen $\rightarrow$
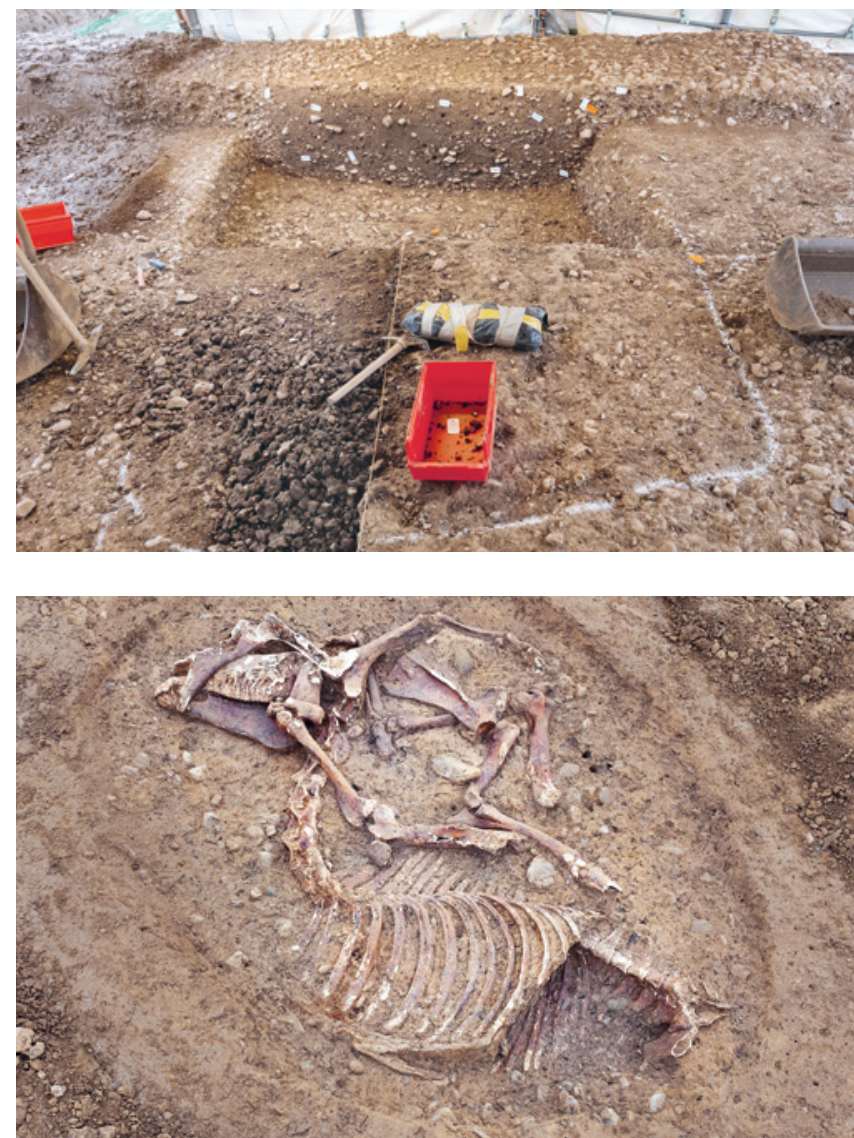

ABB. 39 Die eisenzeitliche Grube, die vermutlich als Schmiedegrube angesprochen werden kann, wird in mehreren Teilen sorgfältig von Hand abgebaut. Foto: Adrian Jost.

ABB. 40 Pferdeskelett mit abgetrennten und teilweise über dem Kadaver deponierten Extremitäten. Foto: Adrian Jost. 


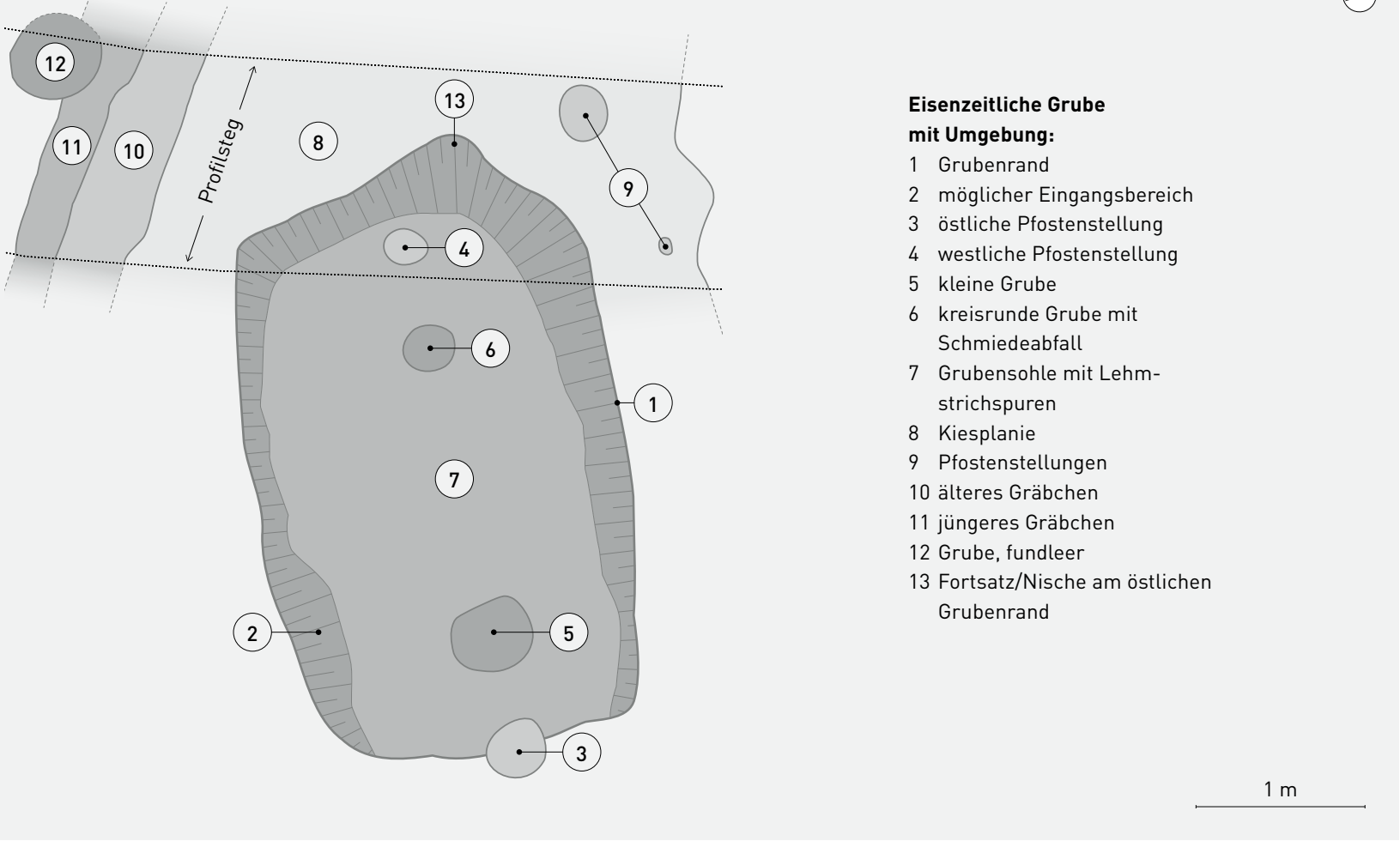

ABB. 41 Übersicht zu den Befunden des eisen-

zeitlichen «Grubenhauses». Plan: Corinne Hodel,

Peter von Holzen.

Schichten und werden von den römerzeitlichen Lössablagerungen überdeckt.

Ähnliche Befunde von grossen (Werk-) Gruben stammen vom Übergang von der älteren zur jüngeren Eisenzeit, $d . h$. aus der späten Hallstatt- bis in die frühe Latènezeit ${ }^{91}$ und aus der Spätlatènezeit. ${ }^{92}$ Während aus der Benutzungsschicht der Grube keine Keramik vorliegt, datieren die wenigen, stark fragmentierten Keramikscherben aus den Verfüllungsschichten grob in die Spätlatènezeit. ${ }^{93}$

Der eisenzeitliche Befund am Haselrain steht bisher isoliert da, wobei davon auszugehen ist, dass weitere entsprechende Strukturen der Erosion zum Opfer gefallen oder nicht als solche erkannt wurden. Hinweise darauf liefern eine mutmasslich latènezeitliche Bodenscherbe aus einem nur wenige Meter von der grossen Grube entfernten Pfostenloch und erste Analysen von Radiocarbondaten, die auf mindestens ein weiteres latènezeitliches Pfostengebäude hindeuten.

Aus dem bis zu 1,30 m mächtigen Hanglöss über der bronzezeitlichen Kulturschicht konnten einige stark verrollte römische Keramikscherben des 1. bis 3. Jahrhunderts n. Chr. und einige Fragmente von Ziegelschrotmörtel geborgen werden. Ganz im Süden der Grabungsfläche, wo die Lössschichten zu einem früheren Zeitpunkt abgetragen worden waren, wurde nur noch anstehender und umgelagerter Wiesenschotter angetroffen. Mittelalterliche Funde fehlen in den weitgehend sterilen Lössschichten. Etwas neuzeitliche grün glasierte Keramik und einige wenige Porzellanscherben dürften bei Grabarbeiten und durch Tiergänge in die Nähe der bronzezeitlichen Schichten gelangt sein.

Überraschend kam bei einem Baggerabtrag ein fast vollständig erhaltenes Pferdeskelett zum Vorschein. Beim Freilegen zeigte sich, dass die Beine und ein Schulterblatt des Tieres sauber ausgelöst neben und über dem Körper lagen - ein Hinweis auf eine sogenannte Wasengrube (АВв. 40). ${ }^{94}$ Da in christlicher Tradition der Verzehr von Pferdefleisch verboten war, mussten u. a. tote Pferde und Maultiere trotz wiederkehrender Hungersnöte «entsorgt» werden. Für die fachgerechte Behandlung und Entsorgung der Tierkadaver war 
der Abdecker oder Wasenmeister zuständig. Er entschied nach einer Schau von Leber und Herz über den Umgang mit dem toten Tier. Waren die inneren Organe infektiös, vergrub der Abdecker das Tier an einem abgelegenen Ort und bestreute es mit Asche und Kalk. Das Vergraben ausserhalb der Siedlung bot Schutz vor der Verunreinigung von Brunnen ein häufiges Problem, besonders bei infizierten Tieren. ${ }^{95} \mathrm{Ei}-$ nem aus Sicht des Wasenmeisters soweit «gesunden» Kadaver wurden erst die Haare abgeschnitten, dann wurde es abgeledert oder abgedeckt, d. h. enthäutet und das Fett entnommen. Mit einer speziellen Schnitttechnik trennte der Abdecker die Beine ab und zog die Sehnen heraus. Das tote Tier war nun einfacher zu bewegen und fand in einer kleineren Grube Platz als ein nicht zerlegtes Tier. ${ }^{96}$ Die nicht weiter verwertbaren Tierreste ${ }^{97}$ wurden schliesslich in einer grösseren Grube oder auf einem Wasenplatz mit vielen kleineren Gruben vergraben. Aus dem Verkauf der verwertbaren Kadaverteile bestritt der Abdecker einen Teil seines Unterhalts: Rosshaar, Horn, Fett und Sehnen waren vor der Entdeckung der Polymerkunststoffe begehrtes Material in verschiedenen Handwerkszweigen.

Der Acker am Haselrain, wo das Tier vergraben wurde, liegt auf dem ehemaligen Oberfeld. ${ }^{98}$ Das Gebiet um die Fundstelle lag ausserhalb des Dorfs und wurde erst im 20. Jahrhundert überbaut. ${ }^{99}$ Grube und Knochen geben bisher keine weiteren Hinweise auf die Umstände der Vergrabung: Das Pferdeskelett lag in sterilem Löss, vermischt mit etwas Kies vom direkt unter der Grube anstehenden Wiesenschotter der Niederflurterrasse. Warum das Pferdeskelett an dieser Stelle vergraben wurde, ist unklar. Zwei heute nicht mehr existierende Flurnamen weisen darauf hin, dass es in Riehen durchaus Wasenplätze gab: die Keybenegerten ${ }^{100}$ im Westen und der Keibenacker im Niederholz südlich des Dorfes. ${ }^{101} \mathrm{Al}-$ lerdings ging man mit der Zeit an einigen Orten auch dazu über, die Kadaver auf Geheiss des Abdeckers auf dem eigenen Grundstück an geeigneter Stelle - etwa auf einem «Wasen», einem meist feuchten und abgelegenen Stück Wiesland, das sich zur Entsorgung von Kadavern gut eignete - zu vergraben. ${ }^{102}$ So lautet die ursprüngliche Bezeichnung des 1694/95 erbauten Elb-Birrsch'en Guts, das sich in der Nähe der Fundstelle befindet, «Hofstatt am Wasen». ${ }^{103}$ Ob das damals am nördlichen Ortsrand stehende Anwesen Rössligasse 51-53 nur an einer ehemals abgelegenen Wiese gebaut wurde oder ob sich ein weiterer Wasenplatz in der Nähe befunden hat, bleibt unklar.

Für den Zeitpunkt der Vergrabung kommt zum jetzigen Zeitpunkt grob die Zeitspanne vom Spätmittelalter bis etwa Mitte des 19. Jahrhunderts in Frage.

\section{0/8}

\section{BIRSIGSTRASSE (A) 50}

Anlass: Bau einer Gasleitung

Zeitstellung: Mittelalter, Neuzeit

Untersuchungsdauer: März bis Juli 2020

Verantwortlich: Johann Savary, Fabian Bubendorf

Text: Johann Savary

Beim Ersatz einer Gasleitung an der Birsigstrasse kam ein Stück des Rümelinbachkanals zum Vorschein, der urkundlich bereits ab dem 13. Jahrhundert fassbar ist. Dabei liess sich eine zweiphasige Bauabfolge rekonstruieren: Nach dem Aushub einer Baugrube im anstehenden sandigen Kies wurde grauer Mörtel als Unterlage ausgegossen. Der Kanalboden bestand aus kleinen Blöcken feinkörnigen Buntsandsteins, während die Wände aus grösseren bis zu 1,60 m langen, $70 \mathrm{~cm}$ bis $1 \mathrm{~m}$ hohen und ca. $50 \mathrm{~cm}$ breiten Blöcken erstellt wurden. Am Boden und bis in die Höhe von ca. $10 \mathrm{~cm}$ wurde dann ein wasserdichter Verputz mit Ziegelschrot aufgetragen. Die äusseren Seiten des Kanals sind mit kleinformatigen Blöcken und Fragmenten grobkörnigen Buntsandsteins und weissem Mörtel verfüllt. Unklar bleibt, ob man diese Arbeiten bereits in der ersten Phase des Kanalbaus durchführt hatte oder erst in der zweiten, als die Kanalwände mit kleineren, ebenfalls feinkörnigen Buntsandsteinblöcken und Architekturspolien erhöht wurden. In der Hinterfüllung fanden sich Gefässkeramikfragmente, die es erlauben, diese zweite Phase in die frühe Neuzeit zu datieren.

An einer Stelle wurde die Oberkante der grossen Wandblöcke zum Kanal hin abgeschrägt und mit feinem Ziegelpulververputz versehen. Es muss sich um einen Zugang zum Kanal handeln, der wahrscheinlich für das gegenüberliegende Haus am Hasenberg 7 eingerichtet wurde. Teilweise war der Rümelinbach für eine Strassenüberquerung überdeckt, was sich am Löffelplan von 1862 auch feststellen lässt. Die Stahlträger, welche die grossen und langen Buntsandsteinblöcke stützen, lassen vermuten, dass man den Kanal an dieser Stelle im 19. Jahrhundert überdeckt hat. Die Verfüllung des Kanals zeigt, dass er zu Beginn des 20. Jahrhunderts aufgegeben wurde. 


\section{0/11}

\section{RIEHENRING (A) 63-75}

Anlass: Fernwärme-Hausanschluss für den Claraturm

\section{Zeitstellung: Mittelalter}

Untersuchungsdauer: März 2020

Verantwortlich: Martin Allemann

Text: Martin Allemann

Im Vorjahr hatte der Aushub für den neuen Claraturm lediglich einen Sodbrunnen und einen Aufschluss des «Krummen Dychs», eines mittelalterlichen Gewerbekanals, zum Vorschein gebracht. ${ }^{104}$ Im Berichtsjahr wurde der Kanal beim Aushub für den Fernwärme-Hausanschluss erneut angeschnitten und uns gemeldet. ${ }^{105} \mathrm{Im}$ neuen unter dem Strassenkoffer des Riehenrings gelegenen Aufschluss waren beide Seitenmauern des Kanals erhalten. Seine einstige Überwölbung ist hingegen schon vor langer Zeit gekappt worden.

Hier am Riehenring lag der Gewerbekanal lange noch ausserhalb der ummauerten Stadt und stand daher offen. Erst als sich im 19. Jahrhundert die Stadt ausbreitete, wurde er allmählich überwölbt. Spätestens in den 1860erJahren, als bei der Messe der erste Badische Bahnhof stand, war er zur Gänze überdeckt - führte aber nach wie vor Wasser. Die Gewerbekanäle waren bis zur kompletten Elektrifizierung wichtige Wasser- und Energielieferanten für das Kleinbasler Gewerbe. Angesichts dieser Bedeutung verwundert es nicht, dass an der einen Kanalmauer noch eine mit Zementmörtel ausgeführte Reparatur wohl aus dem 19. Jahrhundert zu sehen war.

\section{0/15}

\section{RIEHEN - BASELSTRASSE 30/34}

Anlass: Umbau und Sanierung Spielzeugmuseum, Dorfmuseum und Rebbaumuseum

Zeitstellung: Neuzeit

Untersuchungsdauer: Juli bis November 2020

Verantwortlich: Susan Steiner, Birgit Lißner

Text: Marco Bernasconi

Das Landgut des Riehener Landvogts und Basler Bürgermeisters Johann Rudolf Wettstein (1594-1666) an der Baselstrasse 30/34 beherbergt seit 1972 das Spielzeugmuseum Riehen. ${ }^{106}$ Der Umbau und die Sanierung des Museums erforderten mehrere Bodeneingriffe, die von der Archäologischen Bodenforschung begleitet wurden. Insbesondere die Einbringung einer neuen Bodenplatte im Anbau des auf das Jahr 1651 datierten hinteren Flügels des Wettsteinhauses machte eine Dokumentation notwendig.

Nach Entfernung der modernen Bodenplatte wurden Reste mehrerer Böden sowie Spuren von Einbauten aufgedeckt, darunter eine sandsteinerne Abflussrinne, an die ein Tonplattenboden anschloss (ABB. 42). Die Einbauten dürften in Zusammenhang mit der ehemaligen Nutzung als Waschhaus stehen.

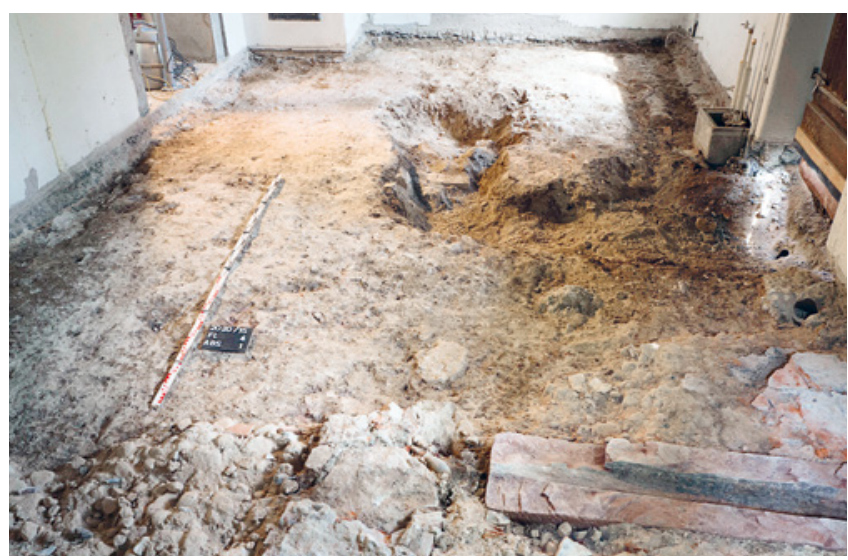

ABB. 42 Die sandsteinerne Abflussrinne mit wenigen Resten des Tonplattenbodens. Foto: Birgit Lißner. 


\section{0/16}

\section{ST. ALBAN-ANLAGE (A)}

Anlass: Koordinierte Werkleitungserneuerung

\begin{tabular}{l} 
Zeitstellung: Neuzeit \\
Untersuchungsdauer: Mai und September 2020 \\
\hline Verantwortlich: Martin Allemann \\
\hline Text: Martin Allemann
\end{tabular}

Eine koordinierte Werkleitungssanierung längs der St. AlbanAnlage begleiteten wir archäologisch, weil die heutige Strasse schräg entlang des Stadtgrabens der spätmittelalterlichen Äusseren Stadtmauer verläuft. Da die Leitungsgräben jedoch nicht sehr tief waren, tangierten sie die meist unterhalb der Gebäude liegenden Überreste der Stadtmauer nicht. Trotzdem wurde vor der Einfahrt zum Gebäude St. Alban-Anlage 62 unter dem Trottoir ein tiefes Mauergeviert angeschnitten und gemeldet. ${ }^{107}$ Die Mauerreste gehören zu einem Kanalisationsschacht des 19. Jahrhunderts, den wir mit Unterstützung der Bauequipe rasch dokumentieren konnten. Die aus grossen Sandsteinspolien nur innen bündig gefugten Kanäle vereinten sich in einem Schacht, der von zwei riesigen Platten aus gelblichem Kalkstein überdeckt war. Ein flacher Stichbogen aus Vollbacksteinen stützte die Platten offenbar bis heute verlässlich. Weiter stadtauswärts brachten die Bautätigkeiten später weitere Mauerreste zum Vorschein. Bei diesen handelte es sich um ältere, schon länger bekannte Mauerbefunde im Zusammenhang mit der St. Alban-Schanze. Diese mächtige Schanze wurde im 17. Jahrhundert als punktuelle Verstärkung der Stadtbefestigung vor dem St. Alban-Tor errichtet. ${ }^{108}$ Befunde zur mittelalterlichen Stadtmauer hingegen fehlen bis anhin - vielleicht bringt aber die geplante Umgestaltung des Parks und der Rabatten noch punktuelle Einblicke.

\section{0/19 \\ RIEHEN - BETTINGERSTRASSE (A), HELLRING (A) 5}

Anlass: Werkleitungen

\section{Zeitstellung: Neuzeit}

Untersuchungsdauer: Juli bis November 2020

Verantwortlich: Michael Ketzler, Birgit Lißner

Text: Marco Bernasconi

Im Gebiet rund um den Wenkenhof ist aufgrund des 751 urkundlich erwähnten Siedlungsnamens «Wahinkofen» sowie vereinzelt im Umfeld aufgedeckter Befunde aus karolingischer Zeit jederzeit mit weiteren Hinweisen auf die bisher nicht genau lokalisierte Siedlung zu rechnen. Dementsprechend wurden auch die Werkleitungsbauten rund um den Wenkenhof überwacht. In den massiven Lösssandschichten konnten jedoch weder frühmittelalterliche Befunde noch Funde festgestellt resp. geborgen werden.

Ein Fundstück ganz anderer Zeitstellung weckte aber unser Interesse. Ein tönernes, keilförmiges, kaum $15 \mathrm{~cm}$ langes Objekt kam unterhalb weniger in Linie gesetzter Kalkbruchsteine unter dem Strassenbelag zum Vorschein (ABB. 43). An der platten runden Oberseite prangte der in den weichen Ton gestempelte Basler Stab. Es handelt sich dabei um eine sogenannte Grenzlohe, einen Zeugen frühmoderner Landvermessungstechnik. Diese in vielfältiger Form und aus $\rightarrow$

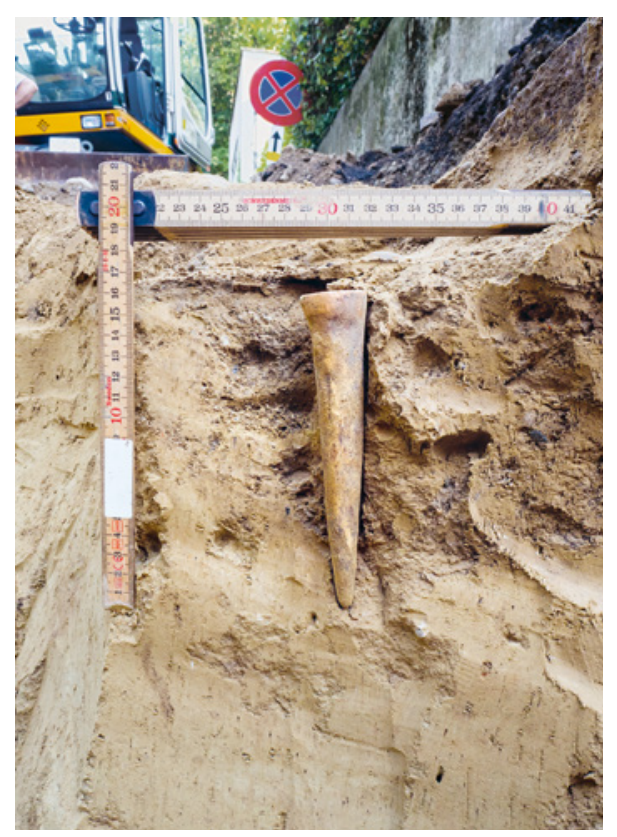

ABB. 43 Bei Verlust oder widerrechtlichem Versetzen des Grenzsteins konnte der Grenzverlauf dank der wenige Zentimeter unter der Oberfläche gesetzten sogenannten Grenzlohe festgestellt werden. Foto: Michael Ketzler. 
unterschiedlichen Materialien hergestellten Markierungen waren zwischen dem 18. und 20. Jahrhundert vielfach in Gebrauch, um einen Grenzverlauf festzuhalten. Sie waren oberirdisch nicht markiert und wurden durch die sogenannten «Gescheid-Leute» zweier Anrainerfraktionen unter Geheimhaltungspflicht gesetzt. ${ }^{109}$ So konnten Grenzverläufe auch im Falle des Verlusts oder einer widerrechtlichen nächtlichen Verschiebung von Grenzsteinen wiederhergestellt werden. Die Grenzlohe vom Hellring dürfte den Verlauf der ehemaligen Wenkengasse markieren, die als Teilstück der Vorgängerin der Bettingerstrasse bis ins 20. Jahrhundert nahe am Wenkenhof vorbeiführte. ${ }^{110}$

\section{0/21}

\section{SCHÜTZENMATTSTRASSE (A) 61}

Anlass: Leitungsanschluss

Zeitstellung: Mittelalter

Untersuchungsdauer: Juni 2020

Verantwortlich: Johann Savary

Text: Johann Savary

Beim Leitungsanschluss eines neu gebauten Hauses kamen in der Mitte der Schützenmattstrasse Mauerzüge zum Vorschein. ${ }^{111}$ Die Mauer war nur noch als maximal drei Lagen Steine erhalten. Daran stiessen Bodenplatten aus Buntsandstein in einem Lehmbett. Die Innenwand war weiss verputzt.

Aus dem Katasterplan von Falkner (um 1860) wird ersichtlich, dass sich in diesem Bereich eine neuzeitliche Gartenumgrenzung befand. Diese lag jedoch einige Meter weiter nördlich als die aufgedeckte Mauer. Von der Verortung her könnte es sich aber auch um einen mittelalterlichen Kanal handeln, der aus weiteren Grabungen zwischen dem Schützenmattweiher und der Spalenvorstadt in einzelnen Teilen bekannt ist. ${ }^{112}$ Dafür sprechen der mit Lehm abgedichtete Boden aus Buntsandsteinplatten, weniger Sinn macht allerdings der weisse, wohl nicht wasserdichte Verputz.

\section{0/24}

\section{BETTINGEN - AUF DEM BUECHHOLZ}

Anlass: Prospektionen (Feldbegehungen)

Zeitstellung: Paläolithikum, Neolithikum

Funddatum: Januar bis Dezember 2020

Verantwortlich: Ingmar M. Braun

Text: Ingmar M. Braun

Anlässlich von Feldbegehungen auf einem neu angelegten Acker im Bereich der Flur «Auf dem Buechholz» fand der Verfasser im Berichtsjahr erstmals steinzeitliche Artefakte. ${ }^{113}$ Aus der näheren Umgebung sind schon seit einigen Jahrzehnten zahlreiche steinzeitliche Fundstellen bekannt, aus denen u. a. ein Faustkeil aus Quarzit stammt. ${ }^{114}$

Das Silexensemble umfasst eine Pfeilspitze mit abgebrochenem Stiel aus Chalcedon, eine Dickenbännlispitze, das distale Fragment einer retuschierten breiten Klinge aus weissem ortsfremdem Silex (sehr wahrscheinlich von Kleinkems), einen retuschierten Abschlag, einen unretuschierten Kortexabschlag, 20 unretuschierte Abschläge, die mehrheitlich aus dem lokal anstehenden Chalcedon angefertigt sind, sowie ein proximal unretuschiertes Klingenfragment aus weiss patiniertem Silex. Hinzu kommt ein unretuschierter Abschlag aus weiss-rötlichem Quarzit. Von Bedeutung ist ein kleines, vollständiges spitznackiges Steinbeil aus Felsgestein, vermutlich Pelitquarz aus den Vogesen (ABв. 44).

Sämtliche Funde datieren wohl am ehesten ins Neolithikum. Der unretuschierte Quarzitabschlag könnte mit Vorbehalt im Zusammenhang mit der nahegelegenen Fundstelle des Faustkeils auch ins Paläolithikum datieren.

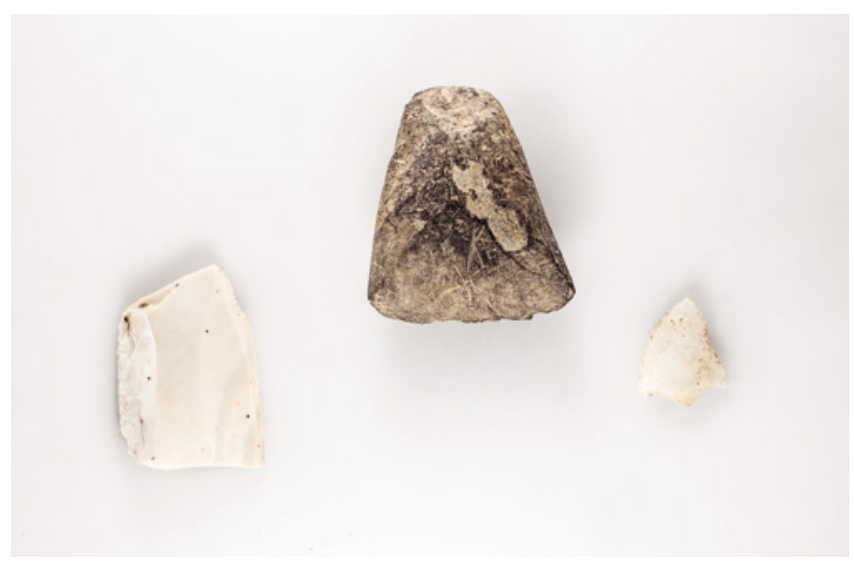

ABB. 44 Fragment einer breiten, retuschierten Klinge (links), Steinbeil aus Felsgestein (Mitte) und Pfeilspitze mit abgebrochenem Stiel aus Chalcedon (rechts). M 1:2. Foto: Philippe Saurbeck. 


\section{0/27}

\section{GUNDELDINGERSTRASSE 172}

Anlass: Sanierung Erdgeschoss «Vorderes Gundeldingen»

\begin{tabular}{l} 
Zeitstellung: Neuzeit \\
\hline Untersuchungsdauer: August bis September 2020 \\
\hline Verantwortlich: Marco Bernasconi, Margit Dauner \\
\hline Text: Marco Bernasconi
\end{tabular}

Ein unangemeldeter Bodeneingriff beim ehemaligen Landgut «Vorderes Gundeldingen» (ABB. 45) führte zu einer kurzen Baubegleitung. Das im 16. Jahrhundert erbaute Landgut gehört zur Reihe der vier «Schlösschen» am Fusse des Bruderholzes. Das Haupthaus steht nach wie vor, umgeben von einer im 20. Jahrhundert erstellten Wohnkolonie, zugunsten derer die Nebengebäude sowie die Einfriedung des Landguts weichen mussten.

An mehreren Stellen konnte das ehemalige Hofniveau mit der zeittypischen Rheinkieselpflasterung festgestellt und dokumentiert werden (АВB. 46).
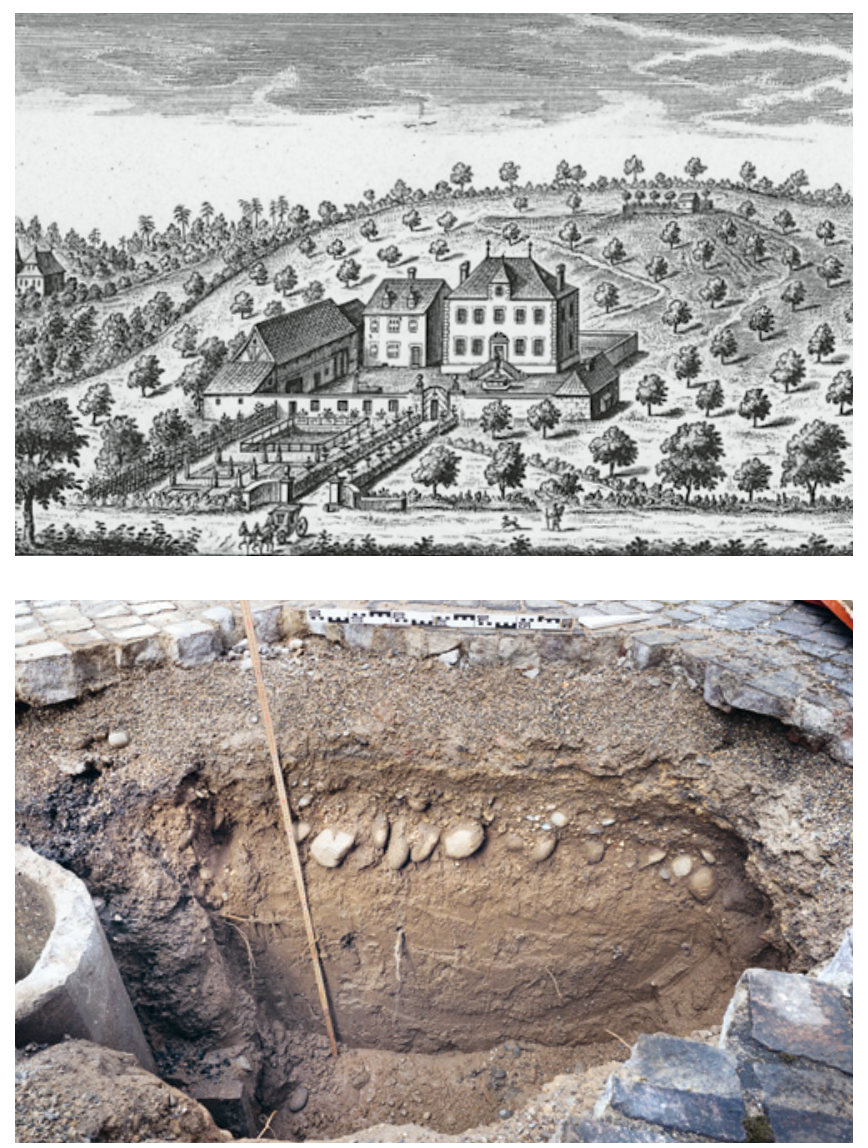

ABB. 45 Historische Ansicht des Landgutes «Vorderes Gundeldingen». Bild: Uni Bern Rhy-3221 21 B. https://biblio.unibe.ch/maps/ryh/ch/rec/ r0000500.htm.

ABB. 46 Die Rheinkieselpflasterung zeigt das ehemalige Hofniveau an, es liegt direkt auf dem Lösslehm. Foto: Margit Dauner.

\section{0/33}

\section{RIEHENSTRASSE 154}

Anlass: Leitungsbau im Garten

\section{Zeitstellung: Neuzeit}

Untersuchungsdauer: Oktober 2020

Verantwortlich: Martin Allemann

Text: Martin Allemann

Bei Grabarbeiten für eine Wasserleitung wurde im Garten des ehemaligen Landsitzes «zur Sandgrube» an der Riehenstrasse eine Bruchsteinmauer entdeckt und uns gemeldet. ${ }^{115}$ Die Mauer verlief in sehr kleinem Abstand parallel zur Südfassade des ehemaligen Landsitzes, des nachmaligen Sandgrubenschulhauses und Lehrerseminars. Ein Abgleich mit altem Karten- und Planmaterial zeigt, dass dieser Anbau nicht zum ursprünglichen Landsitz gehörte, sondern zwischen 1896 und 1905 an das ältere Gebäude angebaut wurde. Spätestens in den 1960er Jahren wurde der Anbau wieder abgebrochen, da er seitdem auf den Plänen fehlt. 


\section{0/42}

\section{BETTINGEN - IM JUNKHOLZ}

Anlass: Prospektionen (Feldbegehungen)

Zeitstellung: Neolithikum

Funddatum: Januar bis Dezember 2020

Verantwortlich: Ingmar M. Braun

Text: Ingmar M. Braun

Die Fundstelle im Bereich der Flur «Im Junkholz» ist seit 1990 bekannt. ${ }^{116}$ Anlässlich von wiederholten Feldbegehungen auch im Berichtsjahr fand der Verfasser weitere steinzeitliche Artefakte.

Das Silexensemble umfasst ein retuschiertes Klingenfragment, einen Kernstein, elf unretuschierte Abschläge und zwei Klopfsteine. Das Rohmaterial ist hauptsächlich der lokal anstehende Chalcedon und Trigonodus-Dolomit-Hornstein. Vereinzelte Objekte sind aus ortsfremdem Silex hergestellt.

Wie bereits bei früheren Begehungen wurden auch im Berichtsjahr Felsgesteinartefakte gefunden: ein längs gespaltenes proximales Steinbeilfragment aus Knotenschiefer, der aus den Vogesen stammt, ein Steinbeilrohling aus Grüngestein, ein Grüngesteinabschlag von der Steinbeilherstellung, ein grosser, nahezu vollständiger Mühlstein aus grobkörnigem Sandstein mit deutlich konkaver Arbeitsseite (ABB. 47), zwei Mühlsteinfragmente mit Arbeitsspuren auf einer Seite sowie zwei Fragmente von möglichen Schleifsteinen aus feinkörnigem Sandstein. Hinzu kommt - als drittes Exemplar von dieser Fundstelle - ein aus einem Quarzitgeröll angefertigter «Chopper» mit einem patinierten Abschlagsnegativ.

Die Funde stehen im Zusammenhang mit der dort schon bekannten grossen Anzahl von neolithischen Funden. Auch der «Chopper» datiert wohl daher am ehesten in das Neolithikum, auch wenn von dieser Fundstelle ein mittelpaläolithischer Levalloiskern aus rotem Radiolarit vorliegt. ${ }^{117}$

Von grosser Bedeutung ist der nahezu vollständige Mühlstein. Es ist der bisher am besten erhaltene neolithische Mühlstein von dieser Fundstelle und den anderen bisher bekannten neolithischen Fundstellen in Bettingen.

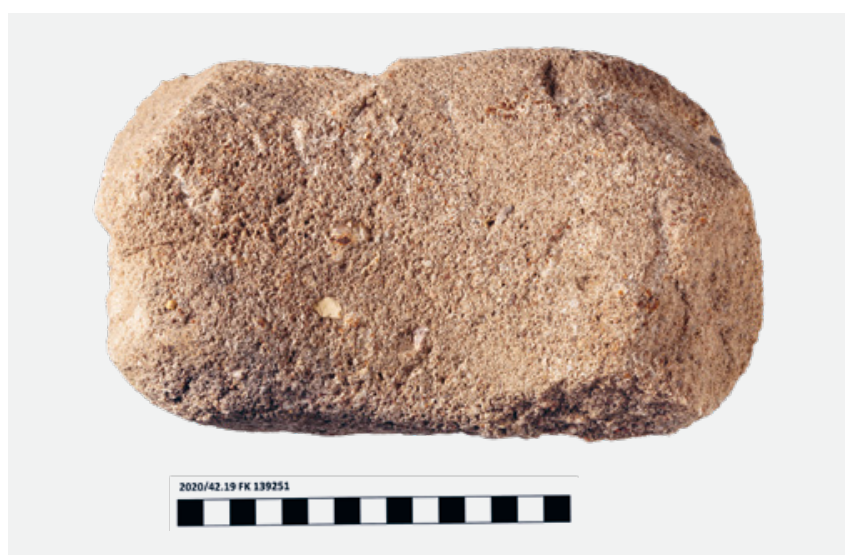

ABB. 47 Nahezu vollständiger Mühlstein aus grobkörnigem Sandstein. Foto: Philippe Saurbeck. 
ANMERKUNGEN

1 Vgl. Martin Allemann: 2019/6 Rittergasse 4, in: JbAB 2019, Basel 2020, 44-46.

2 Für die erneut sehr angenehme und konstruktive Zusammenarbeit danken wir herzlich Karine Grand und Steffen Keck (Grand Paysage), André Buess (Weberbuess Architekten), José Barreiro und seiner Equipe (StraumannHipp AG) sowie Samuel Töfferl und Jerôme Rigert und seiner Equipe (Jos. Schneider AG).

3 Wir danken den Architekten F. Schranz und D. Stauffer sowie M. Muster und den Mitarbeitern der FA Staumann-Hipp herzlich für die angenehme und konstruktive Zusammenarbeit.

4 Rudolf Moosbrugger: Martinskirchplatz 3 (1967/25), in: BZ 67 (1967), XVI-XXI, XXV; Marco Bernasconi, Sven Straumann: 2009/16 Martinsgasse (A), in: JbAB 2009, Basel 2010, 38-39; Markus Asal: Basilia - Das spätantike Basel. Untersuchungen zur spätrömischen und frühmittelalterlichen Siedlungsgeschichte. Die Grabung Martinsgasse 6+8 (2004/1) und weitere Grabungen im Nordteil des Münsterhügels, Materialhefte zur Archäologie in Basel 24A, Basel 2017, 223-234.

5 Martin Möhle: Martinskirchplatz 1, in: Anne Nagel, Martin Möhle, Brigitte Meles: Die Altstadt von Grossbasel I: Profanbauten, KDM VII, 326-327.

6 Die Entdeckung der Fundstelle ist Walter Schönholzer und Simon Graber zu verdanken. Für die Geduld und die angenehme Zusammenarbeit und Nachbarschaft danken wir herzlich Francisco Roda (Hochbauamt), Carlos Monteiro (Morath \& Crottaz AG) sowie dem Bau- und Gastgewerbeinspektorat und Britta Pollmann.

7 Sven Billo: 2017/1 Münsterplatz 10-12, in: JbAB 2017, Basel 2018, 43-44.

8 Yolanda Hecht: Die Ausgrabungen auf dem Basler Münsterhügel an der Rittergasse 4 , Materialhefte zur Archäologie in Basel 16, Basel 1998; Sven Straumann: Von Fechter und Werenfels bis Herzog \& de Meuron. Das Bachofensche Fabrikgebäude auf dem Basler Münsterhügel. Neuzeitliche Funde und Befunde der Ausgrabung 2008/3 «Museum der Kulturen», in: JbAB 2009, Basel 2010, 97-103.

9 Es handelt sich u. a. um eine Reibschüssel mit kantig abgeknicktem Rand und eine Wandscherbe wohl mit karbonatithaltiger Magerung. Vgl. Markus Asal: Basilia - Das spätantike Basel. Untersuchungen zur spätrömischen und frühmittelalterlichen Siedlungsgeschichte. Die Grabung Martinsgasse 6+8 (2004/1) und weitere Grabungen im Nordteil des Münsterhügels, Materialhefte zur Archäologie in Basel 24A, Basel 2017, 158-159.
10 Für diese erste provisorische Grobbestimmung danken wir Markus Peter herzlich.

11 Zur Baugeschichte und schriftlichen Überlieferung vgl. Brigitte Meles: Münsterplatz 12 (alte Nr. 1402) - Domhof, in: Anne Nagel, Martin Möhle, Brigitte Meles: Die Altstadt von Grossbasel I: Profanbauten, KDM VII, Bern 2006, 57-61.

12 Für den Hinweis und die angenehme Zusammenarbeit schulden wir dem Polier José Barreiro und seiner Equipe (Straumann-Hipp AG) grossen Dank.

13 Vgl. zuletzt Martin Allemann: 2017/5 Schlüsselberg (A), in: JbAB 2019, Basel 2020, 44.

14 Der Umbau des Universitätsgartens 2016 wurde baubegleitend untersucht. Siehe Norbert Spichtig: 2016/10 Rheinsprung 11, in: JbAB 2017, Basel 2018, 42-43.

15 Für die angenehme und konstruktive Zusammenarbeit danken wir herzlich Franz Bonetti (TBA), Jonas Lüscher (Stadtgärtnerei), Frank Löbbecke (Denkmalpflege) sowie Domenico Avati und seiner Equipe (Bertschmann AG).

16 Martin Möhle: Rheinsprung 9-11 (von 18611898 Nr. 7, alte Nr. 1508) - Unteres Kollegium der Universität, in: Anne Nagel, Martin Möhle, Brigitte Meles: Die Altstadt von Grossbasel I: Profanbauten, KDM VII, Bern 2006, 339 (StABS Ratsbücher A5, fol.47v).

17 Möhle 2006, 339 (BChr 1, S. 493-494).

18 https://www.stadtgaertnerei.bs.ch/stadtgruen/ park-gruenanlagen/garten-der-altenuniversitaet.html (24.5.2021).

19 Martin Möhle: Rheinsprung 16-18, in: Nagel, Möhle, Meles 2006, 354-369.

20 Johannes Stoffler: Der Garten der Alten Universität in Basel, in: k+a 3 (2016), 4-10.

21 Vgl. StABS PLA 61, 3-38.

22 Für die angenehme und konstruktive Zusammenarbeit und das grosse Interesse an unserer Arbeit danken wir Salvatore Achille (Trinkler Stula Achille Architekten), Philippe Merz (Merz Architekt) sowie Guillaume Waldy (Morath \& Crottaz AG) und seiner Equipe vor Ort.

23 Vgl. Martin Allemann: 2018/32 St.AlbanGraben (A) 5 / Luftgässlein (A), in: JbAb 2019 , Basel 2020, 49-51.

24 Für die konstruktive und angenehme Zusammenarbeit danken wir herzlich Beat Hofmann, Andreas Röthlisberger, Daniel Illerhaus, Severin Brosy, Pius Forster, André Martins und ihren Equipen (Implenia $A G$ ).

25 Für die Fundmeldung und die angenehme und konstruktive Zusammenarbeit danken wir herzlich Marianne Kistler (Hochbauamt), dem Baumpfleger Michael Weber und Ramazan und Manuel (Pensa AG).
26 Vgl. Cornelia Alder, Christoph Ph. Matt: Der mittelalterliche Friedhof der ersten jüdischen Gemeinde in Basel. Ausgrabungen im Kollegiengebäude der Universität. Mit einem numismatischen Beitrag von Beatrice Schärli und Michael Matzke, Materialhefte zur Archäologie in Basel 21, Basel 2010.

27 In den Merian-Ansichten des 17. Jahrhunderts ist der Graben noch quadratisch dargestellt, im Löffelplan aus der Mitte des 19. Jahrhunderts hingegen trapezförmig. Anhand der Baumaterialien und des Mörtels konnte klar festgestellt werden, dass die Mauer an diesem Ort jünger war als der Rest.

28 Vgl. Christoph Ph. Matt: 1999/51 Petersplatz 10 (Stachelschützenhaus), in: JbAB 1999, Basel 2000, 80; Peter Habicht, Christoph Matt: Das Spalentor und die Vorstadt. Die Geschichte des Basler Wahrzeichens, Basel 2015, 26.

29 Christoph Ph. Matt: unpublizierter Bericht zur Grabung 1999/51.

30 Zu Ausgrabungen im Spalenfriedhof vgl. etwa Bruno Kaufmann, Reto Marti: Schönbeinstrasse 6 (Botanisches Institut), 1987/4, in: BZ 88 (1988), 196-202; Martin Allemann: 2015/16 Spalengraben 8, in: JbAB 2015, Basel 2016, 57-58; Susan Steiner: 2017/50 Bernoullistrasse bis Petersgraben (A), in: JbAB 2018, Basel 2019, 57-58.

31 https://de.wikipedia.org/wiki/Steinholz (Belag) (11.3.2021); Roland Krippner: Untersuchungen zu Ersatzmöglichkeiten von Holzleichtbeton im Bereich von Gebäudefassaden. Dissertation Technische Universität München 2004. Online publiziert unter https://web.archive.org/ web/20131209102905/http://www.energieeffizientsanieren. org/data/Holzleichtbeton-Holzbeton.pdf (11.3.2021).

32 Für die angenehme und konstruktive Zusammenarbeit danken wir herzlich Franz Bonetti (TBA) und Roland Reich (Hans Reich AG).

33 StABS HGB $135 / 10$

34 Für die Zusammenarbeit und ihre Flexibilität danken wir dem Bauleiter Cédric Hausammann (Aegerten \& Bosshard) und der Firma Albin Borer AG.

35 Überschneidungen mit der Ausgrabungsfläche der Ausgrabungen 1975-1977 gab es lediglich in zwei Flächen (Fläche 44 und 45), wobei diese damals offenbar nicht bis in den Fundamentbereich der Kirche abgetieft worden sind Vgl. Dorothee Rippmann et al.: Basel Barfüsserkirche. Grabungen 1975-1977. Ein Beitrag zur Archäologie und Geschichte der mittelalterlichen Stadt, Schweizer Beiträge zur Kulturgeschichte und Archäologie des Mittelalters 13, Olten, Freiburg im Breisgau 1987, bes. Flächenplan S. 53. 
36 Grundsätzlich könnten die Fragmente von irgendeinem abgebrochenen Bau stammen. Die hohe Anzahl von hochqualitativen Architekturteilen und das Fragment einer Statue lassen es jedoch am wahrscheinlichsten erscheinen, dass die Spolien von der abgebrochenen ersten Barfüsserkirche stammen.

37 Die Farbproben wurden freundlicherweise von Bianca Burkhardt von der Münsterbauhütte untersucht.

38 Es kann aber auch nicht gänzlich ausgeschlossen werden, dass hier ein Patient des nahen Spitals (wieder-)bestattet wurde.

39 Für die angenehme und konstruktive Zusammenarbeit bedanken wir uns bei Polier Daniel Pazos (Albin Borer AG) und seiner Equipe.

40 Peter Roth: Das Almosen im Kreuzgang, in: Archäologische Bodenforschung des Kantons Basel-Stadt (Hg.): 1000 Jahre Basler Geschichte. Archäologie unter dem Musiksaal des Stadtcasino Basel, Basel 2020, 95-96.

41 Christoph Ph. Matt: Archäologische Aufschlüsse zum ehemaligen Spital an der Freien Strasse 68 (A), 1990/38, in: JbAB1990, Basel 1992, Abb. 8.

42 Guido Helmig, Udo Schön: 1999/13 Freie Strasse 89 (A), in: JbAB 1999, Basel 2000 , 66-67.

43 Für die angenehme und konstruktive Zusammenarbeit danken wir herzlich Stefan Wehner (TBA), Ivo Dändliker (GSI) sowie Ruben Vidal und seiner Equipe vor Ort (Bertschmann AG).

$44 \mathrm{Vgl}$. Coverstory im vorliegenden Jahresbericht (S. 77-117).

45 Für die wie gewohnt angenehme und konstruktive Zusammenarbeit vor Ort danken wir herzlich Franz Berchier (IWB) und der Equipe von Felipe (Tozzo AG)

46 Staatsarchiv Basel-Stadt: Historisches Grundbuch 1, 215/58 Steinenvorstadt 4 (Zum schwarzen Widder).

47 Vgl. Martin Allemann: 2018/32 St. AlbanGraben (A) 5 / Luftgässlein (A), in: JbAB 2019 Basel 2020, 49-51; Vgl. auch die Coverstory im vorliegenden Jahresbericht (S. 77-117). Für die unterirdischen Teile des Aushubs wurde aus organisatorischen Gründen eine neue Laufnummer vergeben.

48 Vgl. Allemann 2020, 51.

49 Vgl. Allemann 2020, 51; Coverstory im vorliegenden Jahresbericht (S. 77-117).

50 Geoarchäologische Begutachtung durch Christine Pümpin (IPNA), unpubl. Aktennotiz zu Ausgrabung 2018/32 St. Alban-Graben (A) 5 Luftgässlein (A), Feldbesuch vom 24.6.2019.
51 Erst ab dem 15. Jahrhundert, nachdem der Graben mit dem Bau der Äusseren Stadtmauer seine militärische Bedeutung verloren hatte, scheint die Stadt längerfristige private Nutzungen der Grabensohle geduldet zu haben. So erlaubte die Stadt am 6. November 1452 dem Anwohner Heinrich von Beinheim erstmals die dauerhaftere Nutzung des Grabens als Garten, allerdings unter der Bedingung, dass die Parzelle nach seinem Tode an die Stadt zurückfalle: StABS, HGB 1, 170/59.

52 Für die angenehme und konstruktive Zusammenarbeit danken wir herzlich Biagio Ferrara (GSI Ingenieure AG), Matthias Hell und Domenico Avati mit ihrer Equipe (Bertschmann AG)

53 Vgl. Martin Allemann, Johann Savary: 2018/6 Totentanz (A), in: JbAB 2018, Basel 2019 61-62.

54 Susan Steiner: 2018/23 Riehen - Haselrain 20 24, in: JbAB 2018, Basel 2019, 72-73.

55 Wir danken B. Mäusli von der Raiffeisen Pensionskasse sowie M. Morath und R. Kaspar (Losinger-Marazzi AG) für diesen frühen und intensiven Austausch.

56 Für die gute Zusammenarbeit danken wir A. Felde und seiner Equipe der StraumannHipp AG.

57 Urs Leuzinger entdeckte einen Silexkern mit Schlagspuren, der keine Hinweise auf Verlagerung zeigte. Vgl. Rolf d'Aujourd'hui: 1988/32: Riehen, Inzlingerstrasse 51, in: JbAB 1988 Basel 1990, 12.

58 Für die frühe Einbindung und die angenehme und konstruktive Zusammenarbeit danken wir herzlich Salome Hug und Hendrik Schikarski (Rapp Architekten AG), Roberto Peresani und Harald Steck (CSG Baumanagement AG), Marcel Jeker, Felix Thüring, Jean-Luc und Pascal Saner (Jeker Aushub AG) sowie Dominik Jörger und Benjamin Sauser (PNP Geologie und Geotechnik AG)

59 Zu den Gräbern aus der frühen Latènezeit im Roche-Areal (1943/1), an der Bergalingerstrasse (0/27) und in der Nähe des Rankhofs (1907/1) zusammenfassend und mit Literatur Eckhard Deschler-Erb, Toni Rey, Norbert Spichtig: Eisenzeit. 800-52 v. Chr., in: Unter Uns, Archäologie in Basel, Basel 2007. 117-147.

60 Vgl. Stefan Lehmann: Das frühmittelalterliche Gräberfeld Basel-Gotterbarmweg, Basel 2014; Martin Allemann, Kati Bott: 2015/36 Schwarzwaldallee (A), in: JbAB 2016, Basel 2017, 51-53.

61 Für die grosse Hilfe bei Bestimmung und Recherchen danken wir Johannes Wimmer herzlich.

62 Aktenmappe der ABBS zu 1907/8; Dieter Holstein: Die bronzezeitlichen Funde aus dem Kanton Basel-Stadt, Materialhefte zur Archäologie in Basel 7, Basel 1991, 51.
63 Guido Lassau: Bronzezeit 2200-800, in: Unter uns - Archäologie in Basel, Basel 2008, 101.

64 Für die gute Zusammenarbeit danken wir dem Architekten und örtlichen Bauleiter C. Löliger sowie dem Polier B. Abilio und seinem Team (R. Soder AG).

65 Susan Steiner: 2018/23 Riehen - Haselrain 2024, in: JbAB 2018, Basel 2019, 72-73.

66 Rudolf Moosbrugger-Leu: Die Ur- und Frühgeschichte, in: Albert Bruckner (Red.): Riehen. Die Geschichte eines Dorfes, Riehen 1972, 58 (ABBS-interne Laufnummer: 1913/13).

67 Sibylle Meyrat: Der Aubach, ein Wasser mit vielen Gesichtern, in: Riehener Zeitung vom Freitag, 22.10.2004, 83. Jg. (43), 1.

68 Wir danken dem Geoarchäologen Philippe Rentzel und seinem Team vom IPNA (Universität Basel) für die wertvolle Unterstützung. Die Fragen der Archäologen an die Geoarchäologen betreffen meist die Lokalisierung und Beschreibung von Strukturen, die durch menschliche Aktivitäten entstanden sind. Im Gegensatz dazu geht es bei der Baustelle an der Oberdorfstrasse in erster Linie um Landschafts- und Umweltrekonstruktion.

69 Moosbrugger 1972, 59

70 Michael Raith: Gemeindekunde Riehen Riehen ${ }^{2} 1988,154-155$

71 Vgl. Christine Keller: Gefässkeramik aus Basel, Materialhefte zur Archäologie in Basel 15B, Basel 1999, Nadelberg 20, 1985/31. Taf. 87,192 (zweite Hälfte des 15. Jahrhunderts) oder Spalenberg 40, 1979/15, Taf. 97,203 (erste Hälfte des 16. Jahrhunderts).

72 StABS Klosterarchiv: Domstift DD 2 p. 223.

73 Für das Vermitteln des Kontakts, den Augenschein des Materials, den sehr bereichernden Austausch und für ihre ausdauernde Begleitung beim Ortstermin, den Sturmfront «Sabine» meteorologisch recht unangenehm gestaltete, danke ich herzlich Susanne Rudolf, Ingmar M. Braun und Jürg Christ.

74 Artikel 724 ZGB

75 Die Typen entsprechen den in Augst geläufigen. Vgl. Caty Schucany, Tamara Mattmann: Die Keramik von Augusta Raurica. Typologie und Chronologie, Forschungen in Augst 52 Augst 2019.

76 Rudolf Moosbrugger: Riehen-Artelacker (1970/32), in: BZ 1971,2 (1971), 177.

77 Jürgen Mischke, Inga Siegfried: Die Ortsnamen von Riehen und Bettingen. Namenbuch Basel-Stadt 1, Basel 2013

78 Die Baubegleitung unter der Laufnummer 2019/18 er brachte keine Befunde oder Funde. 
79 Für die angenehme und konstruktive Zusammenarbeit danken wir herzlich Harald Schmidt (Harry Gugger Studio), Marcel Gasser und seiner Equipe (Erne Holzbau) und vor allem Erdmann Jacobeit (Terra Vermessungen).

80 Herzlichen Dank an A. Malstedt, M. KerkerSteg und M. Brunner (Rapp Architekten AG) für die Meldung des Funds sowie an die Equipe der Aregger AG für die unkomplizierte Zusammenarbeit.

81 Vgl. Rolf d'Aujourd'hui (mit Beiträgen von Guido Helmig, Max Martin und Werner Meyer): Archäologische Untersuchungen im Kleinbasel. Ein Beitrag zur Geschichte der Stadt Kleinbasel, in: BZ 81 (1981), 220-319.

82 Jürgen Mischke, Inga Siegfried (Hg.): Die Ortsnamen von Basel. Namenbuch Basel-Stadt 2, Basel 2016, 173-175.

83 d'Aujourd'hui 1981, 294-297.

84 Vgl. dazu Michael Baumann, Markus Asal, Martin Allemann: Die spätantike Gräbergruppe Basel-Waisenhaus. Anthropologische und archäologische Ergebnisse der Ausgrabung 2020/11 - Theodorskirchplatz 7 (Bürgerliches Waisenhaus), in: JbAB 2017, Basel 2018, 118-139.

85 Für die angenehme und konstruktive Zusammenarbeit danken wir herzlich Nathalie Herzog und Sandra Rudolf (Gruner Böhringer $A G)$ sowie Matthias Hell und Angelo Schilirò (Bertschmann AG).

86 Vgl. Susan Steiner: 2018/23 Riehen - Haselrain 20-24, in: JbAB 2018, Basel 2019, 72-73.

87 Vgl. Susan Steiner: 2019/14 Riehen - Inzlingerstrasse 51 / Haselrain / Kettenackerweg 5 im vorliegenden Jahresbericht (S. 58-59).

88 Die bronzezeitlichen Schichten sind aufgrund des Entkalkungsprozesses stark sauer, so dass sich unverbrannte Knochen kaum erhalten haben.

89 Felix Müller, Gilbert Kaenel, Geneviève Lüscher (Hg.): Die Schweiz vom Paläolithikum bis zum Frühen Mittelalter, Eisenzeit - Age du Fer Età del Ferro, Basel 1999, 142-144.

90 Eine mit Holzkohle befeuerte Esse kann ebenerdig gebaut sein. Die nötige Luft muss ihr von der Seite zugeführt werden, damit die Blasebalgdüsen nicht verstopfen. Hammerschlag fällt in Schmiedegruben in grosser Menge an. Vgl. Michel Mauvilly et al.: Sévaz Tudinges: Chronique d'un atelier de métallurgistes du début de la Tène dans la Broye, in: Archéologie Suisse 21 (1998), 144-154, bes. 148.

91 Müller et al. 1999, 143, Abb. 65,1.2.

92 Tours FR, Hôpital - Clocheville, INRAP: spätlatènezeitliches Grubenhaus mit Schmiedeabfall. https://multimedia.inrap.fr/atlas/tours/ syntheses/themes/voirie-amenagement\#.YFtela9Ki70 (23.3.2021).
93 Für einige Scherben ist eine mittellatènezeitliche Datierung nicht auszuschliessen. Erhaltungszustand und Menge erlauben zum aktuellen Zeitpunkt keine präzisere Datierung. Besten Dank an Norbert Spichtig und Johnny Wimmer (ABBS).

94 Besten Dank an Hubi Blättler (Team Inzlingerstrasse) für den Hinweis.

95 Jürg Manser et al.: Richtstätte und Wasenplatz in Emmenbrücke (16.-19. Jh.), Basel 1992, 157-159.

96 Manser et al. 1992, 63-64.

97 Knochen in grösseren Mengen wurden erst nach Aufgabe der Dreifelderwirtschaft zum Düngen der Felder gebraucht, in Riehen im Verlauf des 19. Jahrhunderts. Vgl. Michael Raith: Gemeindekunde Riehen, Riehen ${ }^{2} 1988,66$

98 Vgl. Raith 1988, 66.

99 Raith 1988, 119, 121.

100 Schwzdt. Ägerte(n) f. geht zurück auf mhd. egerde, egerte swf. «Brachland, unfruchtbares Land». «Ägerte» steht auch allgemein für minderwertigen Acker- oder Wiesenboden oder für unfruchtbares und unbebautes Land, in der Regel weit entfernt von bewohntem Gebiet und ausserhalb des Kulturlands der Dreizelgenwirtschaft. Vgl. www.ortsnamen.ch, Das Portal der schweizerischen Ortsnamenforschung (10.3.2021).

$101 \mathrm{Zu}$ den in den Quellen zwischen 1503 und 1797 fassbaren Bezeichungen Keybenägerten resp. Keibenacker vgl. Ludwig E. Iselin: Geschichte des Dorfes Riehen: Festschrift zur Jubiläumsfeier der 400jährigen Zugehörigkeit Riehens zu Basel, 1522-1922, Basel 1923, $30 *-31 *$ (Anhang). Ein «Cheib» ist ein erkranktes oder krepiertes Tier, Kadaver. Vgl. Schweizer Idiotikon, Band III, 99-100 (www.digital. idiotikon.ch, 10.2.2021)

102 Manser et al. 1992, 206.

103 Iselin 1923, 30*-31*; Raith 1988, 145

104 Vgl. dazu Norbert Spichtig: 2019/5 Riehenring 63-75 (Claraturm), in: JbAB 2019, Basel 2020, 67.

105 Für die prompte Fundmeldung und die angenehme und konstruktive Zusammenarbeit danken wir herzlich Martin Becker (GSI Bauund Wirtschaftsingenieure AG) und Domenico Avati und seiner Equipe (Bertschmann AG).

$106 \mathrm{https} / / / \mathrm{hls}-$ dhs-dss.ch/de/articles/ 019086/2015-01-11 (18.3.2021).

107 Für die Fundmeldung und die angenehme und konstruktive Zusammenarbeit danken wir herzlich Frau Marti (Gruner AG); grosser Dank auch für die engagierte Unterstützung vor Ort an Angelo Schilirò und seiner Equipe (Bertschmann AG) und für die Hilfe bei der Einmessung an Raphaela Schilliger (TBA).
108 Die Kontermauer der St. Alban-Schanze wurde hier schon oft dokumentiert, vgl. zuletzt Martin Allemann: 2015/44 Zürcherstrasse / St. Alban-Talstrasse (A), in: JbAB 2015, Basel 2016, 75; vgl. auch Christoph Ph. Matt: 2006/39 St. Alban-Talstrasse (A) 19, in: JbAB 2006, Basel 2008, 45-46 und Christoph Matt: 1986/27 St. Alban-Talstrasse 19 (A), in: BZ 86 (1986), 222.

109 Hans Stohler: Die Basler Grenze. Von römischer Vermessungskunst, alten Grenzzeichen und geheimen Grenzbräuchen. 142. Neujahrsblatt, hg. von der Gesellschaft zur Beförderung des Guten und Gemeinnützigen, Basel 1964.

110 Für die Abgleichung der Koordinaten und weitere Hinweise zu den Basler Grenzlohen gebührt Andreas Kettner (BVD) besonderer Dank.

111 Für die rechtzeitige Fundmeldung bedanken wir uns bei der Firma Reich AG und deren Mitarbeitern ganz herzlich

112 Vor allem Grabung 1972/16: Teuchelweiher, Schützenmattstrasse (A) 69, in: BZ 73 (1973), 231. Siehe auch Eduard Golder: Der Teuchelweiher (Schützenmattweiher) und der Herrengraben, in: Der Birsig und seine Nebengewässer, Basel 1995, 163-172.

113 Der genaue Fundort ist der ABBS bekannt.

114 Ingmar M. Braun (mit einem Beitrag von Reto Jagher): Zur Entdeckung eines Faustkeiles und anderen paläolithischen Funden aus Bettingen, in: JbAB 1998, Basel 1999, 75-81.

115 Für die Fundmeldung danken wir herzlich Colin Beyeler (Beyeler \& Trueb Landschaftsarchitektur) und Stefan Blöchlinger (Wenger Gartenbau), für die angenehme und konstruktive Zusammenarbeit vor Ort der Equipe von Wenger Gartenbau.

116 Vgl. Urs Leuzinger: 1990/53 Bettingen, Wyhlenweg (Im Junkholz), in: JbAB 1991, Basel 1994, 20; Ingmar M. Braun: 1990/53 Bettingen, Im Junkholz (A), in: JbAB 1998, Basel 1999, 39-41; ders.: 1999/53 Bettingen, Im Junkholz (A), in: JbAB 1999, Basel 2000, 80; ders.: 2011/27 Bettingen, in: JbAB 2011, Basel 2012, 78-79; ders.: 2016/39 Im Junkholz, in: JbAB 2016, Basel 2017, 62; ders.: 2019/40 Bettingen Im Junkholz, in: JbAB 2019, Basel 2020, 72. Die Koordinaten der Fundstelle sind der ABBS bekannt.

117 Ingmar M. Braun (mit einem Beitrag von Reto Jagher): Zur Entdeckung eines Faustkeiles und anderen paläolithischen Funden aus Bettingen, in: JbAB 1998, Basel 1999, 75-81. 